\title{
On the Trichoptera of China with relatives of adjacent territories $I$.
}

\author{
J. OLÁH ${ }^{1}$, J. OLÁH JR ${ }^{2} \&$ W.-H. LI \\ ${ }^{1}$ János Oláh, Residence postal address: Tarján u. 28, H-4032 Debrecen, Hungary, profolah@gmail.com \\ ${ }^{2}$ János Oláh Jr, Residence postal address: Tarján u. 6, H-4032 Debrecen, Hungary, sakertour@gmail.com \\ ${ }^{3}$ Weihai Li, Department of Plant Protection, Henan Institute of Science and Technology, Xinxiang 453003, \\ China,lwh7969@163.com
}

\begin{abstract}
In our first paper on Chinese Trichoptera we have reinstated the species status of Polymorphanisus hainanensis Martynov, 1930 stat. restit. and furthermore described 44 species new to science: Chimarra fureses sp. nov., Stenopsyche levelaga sp. nov., S. tulipanos sp. nov., Dipseudopsis kulonc sp. nov., Nyctiophylax (Paranyctiophylax) bubos sp. nov., Diplectrona dedomba sp. nov., D. kinulta sp. nov., Polymorphanisus liorum Oláh, sp. nov., P. totaorum sp. nov., Hydromanicus heges sp. nov., H. mintas sp. nov., H. ritkas sp. nov., Hydropsyche cernaka sp. nov., H. keses sp. nov., $H$. nagpupos sp. nov., H. vaza sp. nov., H. keska sp. nov., H. tagra sp. nov., H. laposhat sp. nov., H. picibunk sp. nov., H. lelapa sp. nov., H. nulanka sp. nov., H. kispupos sp. nov., H. lehajla sp. nov., Cheumatopsyche bujkala sp. nov., C. domborula sp. nov., C. forrta sp. nov., C. kiugra sp. nov., C. lepa sp. nov., C. magaska sp. nov., C. perem sp. nov., C. rovides sp. nov., $C$. sikoska sp. nov., C. bunkos sp. nov., C. kurtula sp. nov., C. sara sp. nov., C. harma sp. nov., C. lekera sp. nov., Rhyacophila simpla sp. nov., R. taraja sp. nov., Oecetis girba sp. nov., Asynarchus delies sp. nov. and Pseudostenophylax haromsog sp. nov.
\end{abstract}

Keywords. Trichoptera, biodiversity, caddisfly, China, new species.

\section{INTRODUCTION}

$\mathrm{C}$ hinese research on Chinese Trichoptera has a solid basement rooted in the very first study of the Chinese caddisfly founder Hwang Chi-ling (1957) and produced significant progress reaching 1267 described species (Yang et al. 2016), out of the estimated potential of 5000 species (Yang et al. 2005). This is a rather conservative estimation of the real caddisfly biodiversity detectable by fine phenomics or genetics. During our present study we were highly impressed by the exceptional diversity of Chinese Trichoptera. Here we report on 93 species including 44 species new to science.

\section{MATERIAL AND METHODS}

With this paper we intend to lunch some research on Chinese Trichoptera collected mostly by local Chinese scientists as well as by the junior author, J. Oláh jr. In our srtudies on caddisflies we apply the the principles, methods and procedures of fine phenomics in order to delineate incipient sibling species forming well-defined species complexes. In traditional routine taxonomy of gross phenomics these species are treated by lumpers as single species frequently qualified as "widely distributed and highly varying". Most of the types are deposited in Chinese institutions.

Depositories

British Museum (Natural History), London (BMNH)

Department of Plant Protection, Henan Institute of Science and Technology (DPP-HIST)

Entomological Museum of China Agricultural University, Beijing (CAU)

National Museum of Natural History, Smithsonian Institution, Washington, D.C. (NMNH)

Oláh Private Collection, Debrecen, Hungary, under national protection by the Hungarian Natural History Museum, Budapest (OPC). 


\section{TAXONOMY}

\section{Annulipalpia}

Philopotamoidea

Philopotamidae

Chimarrinae

Chimarra cachina Mosely, 1942

Material examined. China, Guangxi, Jinxiu County, Yinshan Wild Station, 17.VIII.2016, light trap (1 male, OPC).

\section{Chimarra fureses sp. nov.}

(Figures 1-4)

Material examined. Holotype: China, Shaanxi Province, Foping, Yueba, 1099.8 m, 25.VIII. 2014, leg. Lu Xiumei (1 male, CAU). Paratypes: same as Holotype (1 male, OPC). China, Shaanxi Province, Foping, Daguping, 1269.7 m, 23.VIII. 2014, leg. Lu Xiumei (1 male, OPC). China, Hubei, Yingshan, Taohuachong, 600m, 15.VI. 2018, leg. Jiang Yunlan (1 male, DPP-HIST)

Diagnosis. Having digitiform paraproct, digitiform gonopod and short segment IX this new species is most close to Chimarra quadridigitata Yang, Sun \& Yang, 2001 described from China (Zhejiang) and to C. talos Malicky, 2007 described from Bhutan. Chimarra fureses sp. nov. has an almost completely fused dorsal arm of paraproct and the cerci forming together a serrated structure. The new species has a pair of very long and parallel-sided endothecal spines accompanied by two rows of small spine clusters.

Description. Male (in alcohol). Male genitalia. Segment IX very short forming an almost regular parallel-sided band-like ring with unsclerotized dorsum. Segment X long, membranous, hardly indiscernible. The paraproct composed of a pair of digitate ventral arm; its basal part turning mesad encircling ventrally the phallic organ; the dorsal arm of paraproct is fused to the cerci forming together a heavily sclerotized bilobed structure serrated on the ventral margin; apical lobes represent the dorsal arm of the paraproct with sensory pits; the basal more rounded lobes represent the fused cerci with sensory setae. Phallic organ with two long and strong spines seems somehow fixed parallel-sided; there is a pair of small spine row located apicad, at the terminal ending of the two long spines.

Etymology. fureses from "fürészes" serrated in Hungarian, refers to the fused dorsal arm of paraproct and cerci with serrated ventral margin in lateral view.

\section{Stenopsychidae}

\section{Stenopsyche angustata Martynov, 1930}

Material examined. China, Henan Province, Xinxian County, Mt. Liankangshan, 22.IX.2014, (1 male, DPP-HIST; 1 male, OPC). China, Shaanxi, Hanzhong, Yang County, Huayang Town, Banqiao Village, N33.6155 ${ }^{\circ}$ E107.5079, $1154 \mathrm{~m}$, 4.V.2017, (2 males, DPP-HIST, 2 males, OPC). China, Shaanxi, Yang County, Huayang Town, Zhoujiayu Village, N3360'10", E107 47'42.82", 1362m, 12.V.2017, (1 male, DPPHIST; 1 male, OPC). China, Shaanxi, Hanzhong, Yang County, Huayang Town, Banqiao Village, $\mathrm{N} 33.6155^{\circ}$ E107.5079 ${ }^{\circ}, 1154 \mathrm{~m}, 4 . V .2017$, light traps (4 males, DPP-HIST).

\section{Stenopsyche tienmushanensis Hwang, 1957}

Material examined. China, Shaanxi Province, Zhashui, Guanghuojie, N33.4548 E108.4615, 1172m, 26.VII.2014, leg. Tang Chufei (1 male, DPP-HIST; 1 male, 1 female; OPC).

\section{Stenopsyche levelaga sp. nov.}

(Figures 5-7)

Material examined. Holotype: China, Shaanxi Province, Zhouzhi, Houzhenzi, 1278m, 16.VIII. 2014, leg. Lu Xiumei (1 male, CAU). 

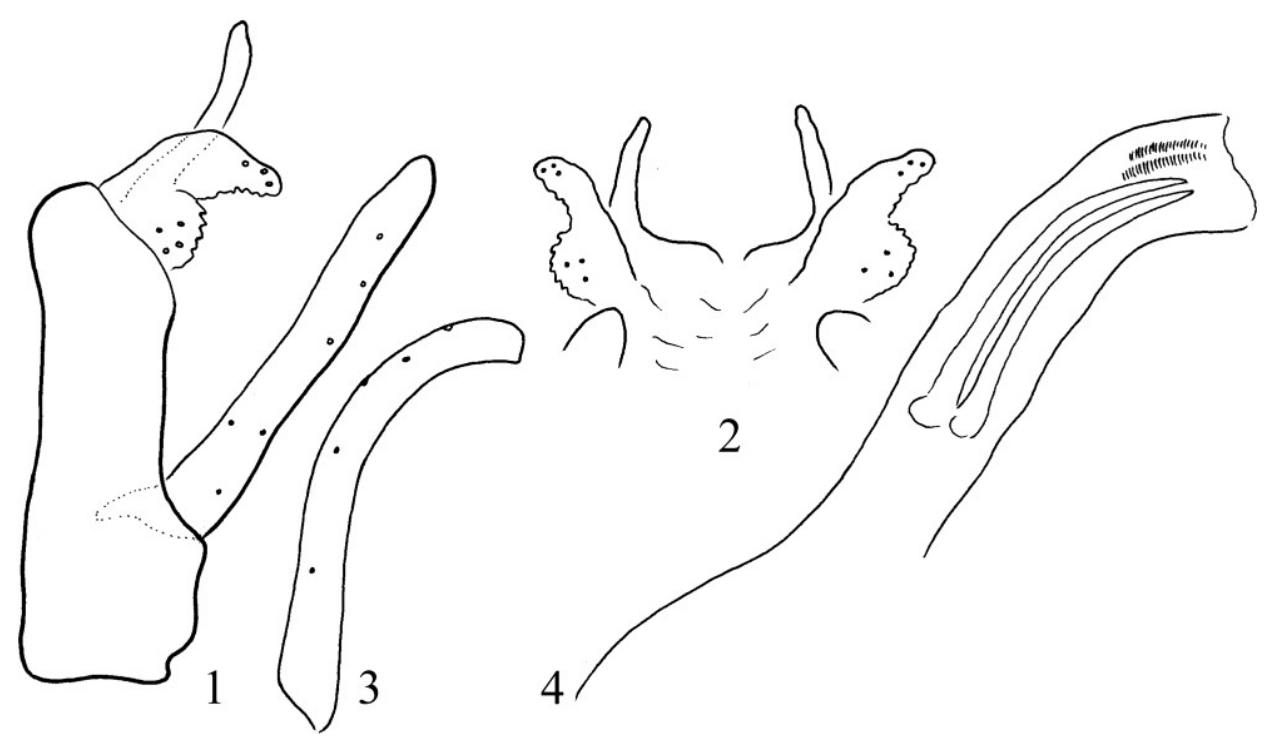

Figures 1-4. Chimarra fureses sp. nov. Holotype. 1 = male genitalia in left lateral view, $2=$ male genitalia in dorsal view, $3=$ left gonopod in ventral view, 4 = phallic organ in left lateral view.
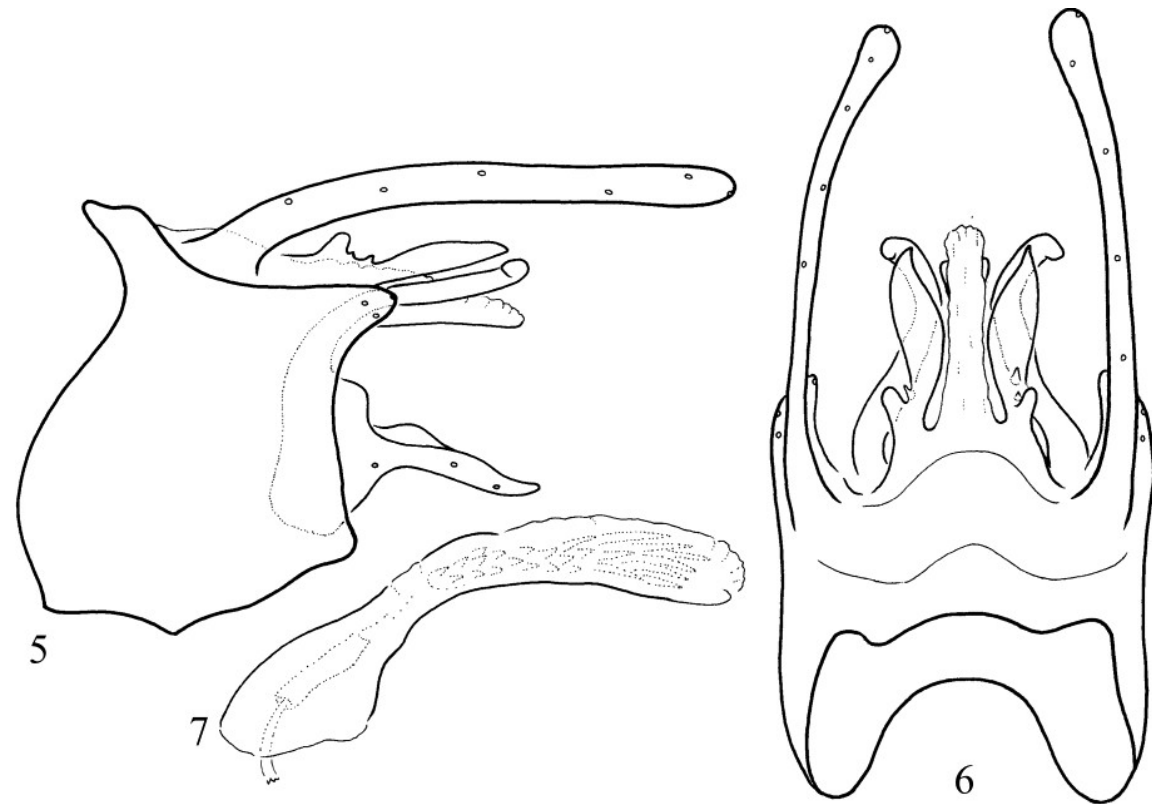

Figures 5-7. Stenopsyche levelaga sp. nov. Holotype. 5 = male genitalia in left lateral view, $6=$ male genitalia in dorsal view, $7=$ phallic organ in left lateral view.

Diagnosis. Having segment X large, partially sclerotized and paraproct long heavily sclerotized this new species belongs to the $S$. simplex species group and to subgroup with straight directed paraproct. Although the endothecal armature comprised of many spines, but the spies are not fine, there are short, but stout and even these short strong spines are elongating apicad. Most close to Stenopsyche ningshanensis $\mathrm{Xu}$, Wang \& Sun, 2014, but differs by having larger size, differently shaped paraproct and dorsal arms of gonopods. The endothecal spine armature different. 
Description. Male (in alcohol). Medium-sized, reticulate-patterned brown animal with broad lighter pattern along the margin on the forewing anal region. Forewing length $26 \mathrm{~mm}$.

Male genitalia. Segment IX subquadrangular and with blunt triangular pointed apical lobe on its posterolateral margin. Segment X long, its dorsum membranous, ventrum sclerotized. Paraproct foliform with small dorsobasal twig. The heavily sclerotized dorsal arms of gonopods slightly Sshaped with laterad turning apices. Endotheca with short stout spines gradually elongating apicad at least in inverted state.

Etymology. levelaga from "levélága" "leaf and twig" in Hungarian, refers to the broadened foliform parameres armed with basad located small branch.

\section{Stenopsyche tapaishana Schmid, 1959}

Material examined. China, Shaanxi Province, Zhouzhi, Houzhenzi, 1278m, 16.VIII.2014, leg. $\mathrm{Lu}$ Xiumei (1 male, OPC). China, Shaanxi Province, Zhashui, Guanghuojie, N33.4548 E108.4615, 1172m, 26.VII.2014, leg. Tang Chufei $(1$ male, 1 female, DPP-HIST; 1 male, 1 female, OPC).

\section{Remarks. New species record for China!}

\section{Stenopsyche tulipanos sp. nov.}

(Figures 8-10)

Material examined. Holotype: China, Heibei Province, Xionglong, Dagoucun, 589m, 11.VI. 2014, leg. Tang Chufei, (1 male, OPC).

Diagnosis. This new species belongs to the $S$. marmorata species group, having segment $\mathrm{X}$ elongate, partially sclerotized, semimembranous, paraproct small lobiform, laterad directed endothecal armature composed of short numerous spines dispersed along its entire length. Most close to Stenopsyche uniformis Schmid, 1965, but differs by having segment $X$ quatrilobed apex, not bilobed, paraproct without lateral twig and reaching almost to the tip of segment $X$, not only to the middle, curvature of the dorsal arm of gonopods different both in dorsal and lateral view.

Description. Male (in alcohol). Medium-sized, reticulate, marbled light fleck patterned faded brown forewing. Forewing length $24 \mathrm{~mm}$.

Male genitalia. Segment IX short dorsad and long almost subcircular ventrad in lateral view; apical lobe on its posterolateral margin long slender and pointed. Segment $X$ with quadrilobed apex, mesal lobes membranous, lateral lobes sclerotized. Paraproct lobiform, long arching mesad. The heavily sclerotized dorsal arms of gonopods strongly S-shaped with laterad turning club shaped apices with needle pointed tip. Endotheca with short thin spines gradually elongating and apicad in inverted state.

Etymology. tulipanos from "tulipános" tulip shaped in Hungarian, refers to the tulip outline shape of the dorsal arm of gonopods in dorsal view.

\section{Dipseudopsidae}

\section{Dipseudopsis kulonc sp. nov.}

(Figures 11-15)

Material examined. Holotype: Malaysia, Sabah, Mt.Trus Madi, The Borneo jungle girl camp, 2016.II.19, leg. Liu Xingyue (1 male, CAU).

Diagnosis. Dipseudopsis kulonc sp. nov. is an unusual species with several unique character states. All the known member of the Dipseudopsis genus is characterized by the almost vestigial pleural sclerite XI, it is reduced to a very indistinct structure; poorly discernible as a very short, band or strip like vertical structure partially or entirely hidden or obscured by cerci. The pleural sclerite IX is present and very much produced, strong, heavily sclerotized, almost as long as the cerci. The other unusual character state is the sternal sclerite producing a dorsoapical extension as much enlarged as the entire sternite itself. These two unique character states distinguish this new species from all the known species of the genus. 


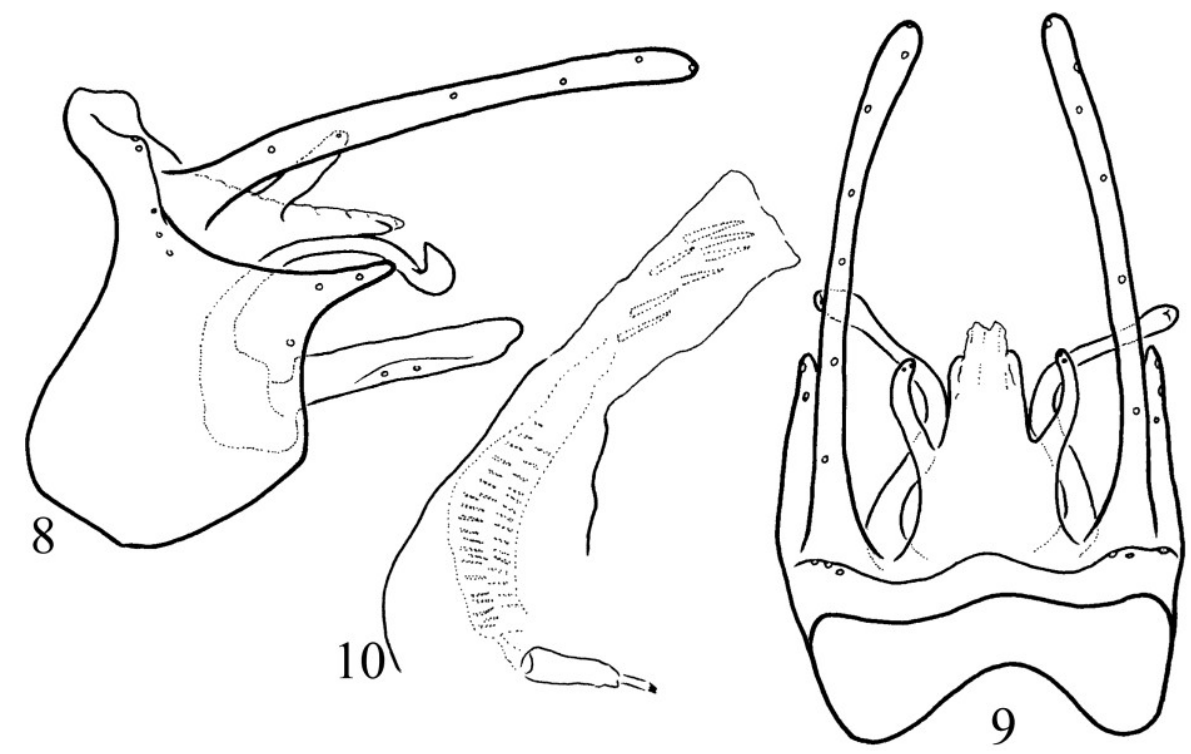

Figures 8-10. Stenopsyche tulipanos sp. nov. Holotype. $8=$ male genitalia in left lateral view, $9=$ male genitalia in dorsal view, $10=$ phallic organ in left lateral view.
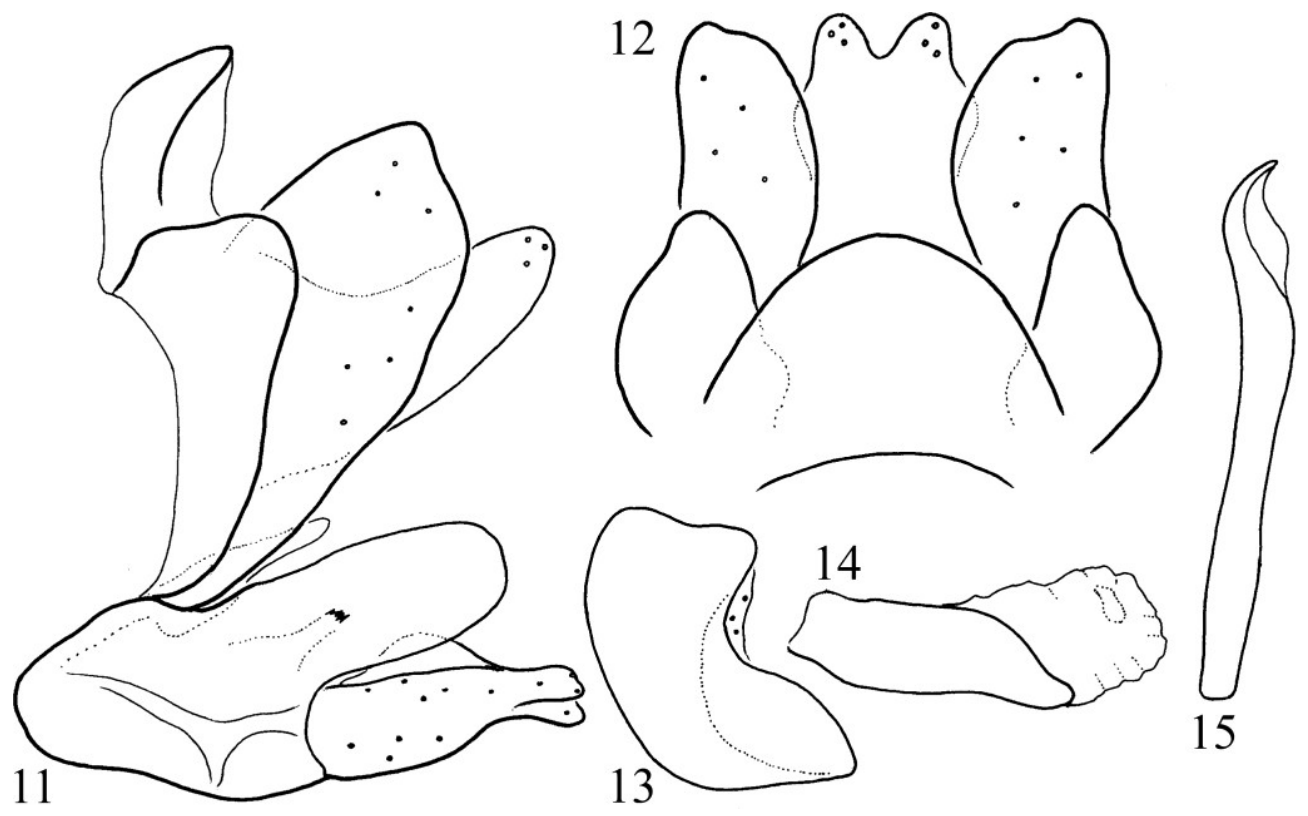

Figures 11-15. Dipseudopsis kulonc sp. nov. Holotype. 11 = male genitalia in left lateral view, 12 = male genitalia in dorsal view, 13 = left gonopod in ventral view, 14 = phallic organ in left lateral view, 15 = modified left hind leg mesoapical spur in ventral view.

Description. Male (in alcohol). Medium-sized brown species with banded forewing pattern, light banded longitudinal cell delineated by dark brown are along veins. Hind leg modified spur slightly twisted spatulate. Forewing length is $12 \mathrm{~mm}$.
Male genitalia. Segment IX with small tergite, well-produced pleural sclerite and larger sternite; tergite IX rounded in dorsal view; pleurite IX is almost as long and high as the cerci; sternite IX articulating to pleurite IX and cerci uniquely 
developed; its dorsoapical region extremely produced into a long rounded lobe, longer and bigger than the sternite itself. Segment $\mathrm{X}$ as long as sternite IX, slightly overlapping with tergite IX, forming heavily pigmented hood with several sensory pits on bilobed apex; thumb-shaped, slightly concave dorsally in lateral view; with excised apex in dorsal view. Intersegmental depression between segment IX and segment $\mathrm{X}$ forming high vertical concavity in lateral view by slightly overhanging tergite IX. Cerci large, auriform, narrowing dorsoapicad. Gonopods each without harpago, as long as the dorsoapical extension of sternite IX; very broad in ventral view. Phallic apparatus small, consisting of phallotheca, endotheca and aedeagus; phallotheca forming heavily sclerotized, broad, basal tube and slightly narrowing ventroapical lobe; no minute alveoli or small setae visible basal part. Delineation of membranous dorsal part, apical endotheca, and aedeagus obscured; weakly chitinized sclerite complex discernible.

Etymology. kulonc from "különc" deviating, unique in Hungarian, refers to the plesiomorphic presence of the pleural sclerite IX and the extremely elongated apomorphic apicodorsal rounded lobe-like extension of sternite IX.

\section{Psychomyioidea \\ Polycentropodidae}

\section{Nyctiophylax (Paranyctiophylax) bubos sp. nov.}

(Figures 16-17)

Material examined. Holotype: China, Guangxi, Jinxiu County, Dayaoshan, Yinshan Wild Station, 2016.VIII.17, light traps (1 male, CAU). Paratype same as Holotype (1 male, DPP-HIST; 1 male, OPC).

Diagnosis. This new Nyctiophylax species is close to species of $N$. (Paranyctiophylax) archemoros Malicky, 1999 described from Thailand, $N$. (Paranyctiophylax) antenor Malicky, 1997 described from Nepal, N. (Nyctiophylax) catunujah Oláh \& Johanson, 2010 described from Myanmar and N. (Nyctiophylax) gracilis Morse, Zhong \& Yang,. 2012 described from China (Jiangxi). It differs from all by having large rectangular cerci and straight not curving ventral paraproctal processes with slightly hooked or knotted apex. All species are members of the Paranyctiophylax subgenus with looped anal veins in the forewing. $N$. (Nyctiophylax) catunuyah having the same type of genital structure, but has normal pattern of anal veins without any loop.

Description. Male (in alcohol). The entire body is uniformly brown coloured. Spur formula 344. Maxillary palp formula is (I,II)-IV-III-V, third segment inserted mesosubapicad. Forewing length is $6 \mathrm{~mm}$. Discoidal cells both on forewing and hindwing are closed; median cells on forewing open. Forewing with apical forks 2, 3, 4, 5, hindwing with apical forks 2,5 present. In forewing A1, A2 and A3 anal veins with loop.

Male genitalia. The IXth abdominal segment is composed of the robust sclerotized sternite, rounded quadrangular in lateral view; there is sclerotized tergite discernible as fused to cerci and paraproct. Segment X semisclerotized, deeply excised in dorsal view producing a bilobed process in dorsal view scarcely setose. Cerci large, qudrangular and setose in lateral view; arising from the fused complex of IXth tergite and paraproct. Paraproctal complex consists of the basal body and a pairs of ventral paraproctal processes; as usual it is unsetosed, heavily sclerotized and straight slightly downward curving supplied withdorsosubapical hump. Gonopods are robust, basal elbow well-developed representing a ventral lobe-like branch; dorsal branch of the gonopod straight both in lateral and ventral view. The phallic apparatus located dorsad, fixed and guided by the spine-like ventral paraproctal straight processes; the phallic apparatus characterised by a tube-like faintly sclerotized phallotheca armed with a pair of lateral knob-like sclerotized structure, continuing into a membranous endotheca or aedeagus with a pair of long arching spines arising from the phallobase.

Etymology. bubos from "búbos" cristate in Hungarian, refers to the dorsosubapical hump-like process on the ventral arm of the paraproct. 


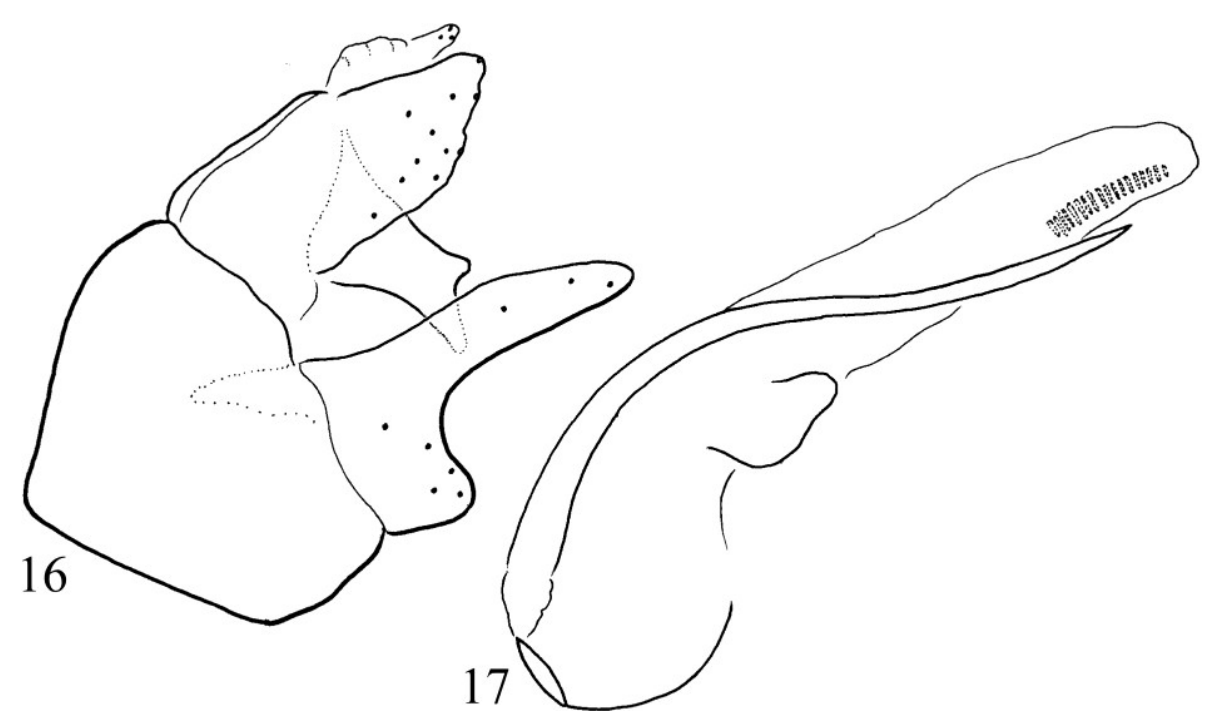

Figures 16-17. Nyctiophylax (Paranyctiophylax) bubos sp. nov. Holotype. 16 = male genitalia in left lateral view, $17=$ phallic organ in left lateral view.

\section{Psychomyiidae}

\section{Psychomyia extensa Li, 1999}

Material examined. China, Hubei, Yingshan, Taohuachong, 600m, 15.VI.2018, leg. Jiang Yunlan (1 male, DPP-HIST).

\section{Hydropsychidae}

\section{Diplectroninae}

\section{Diplectrona dedomba sp. nov.}

(Figures 18-22)

Material examined. Holotype: China, Guangxi Zhuang Autonomous Region, Shangsi County, Shiwandashan Natural Forest Park, small forest brook and the surrounding mountain forest, $\mathrm{N} 21^{\circ} 50.574$ '，E10751.802'，365m，28.III.2015 (/20), leg. J. Kontschán, W. H. Li, D. Murányi \& G. Q. Wang (1 male, CAU). Paratypes: same as Holotype (2 males, DPP-HIST; 2 males, OPC).

Diagnosis. This new species with fused dorsoapical setose lobes and the setaless paraproct is similar to D. wangyipingi Sun, 2017 described from China (Zhejiang Province), but differs by the differently shaped fused segment X; by the fine structure of the endothecal processes as well as by the lateral and ventral profiles of the phallotheca.

Description. Male (in alcohol). Dark brown animal. Forewings without pattern. Forewing length $7 \mathrm{~mm}$, apical fork I present on hindwing. Eyes setaless, not enlarged. Maxillary palp formula I-IV-III-II-V. Anterodorsal filament on sternite $\mathrm{V} 2 \mathrm{X}$ as long as the sternite, there are no anx internal large sacs present in segment VIII.

Male genitalia. Segment IX convex anterad, dorsum long and flat with a middle depression line. Segment X fused to the tergum IX. The dorsoapical setose lobes (inner lobes) and the unsetose paraproct (outer lobes or lateral plates of segment X) fused together into a pair of subtriangular plate. Cerci form setose area in lateral view, visible both in lateral and dorsal view. Gonopods are robust, almost straight with dilated apical half; the broad harpago mesad turning. Phallic apparatus with slightly downward curving and broadening basal and tube-forming apical sections; its ventrum elongated; two pairs plus a single of endothecal processes visible, both with pointed apices; phallotremal sclerite less distinct.

Etymology. dedomba euphonic coined from "domb, dedombos" hill in Hungarian, refers to the basal part of segment $\mathrm{X}$ with a pronounced hump in lateral view. 


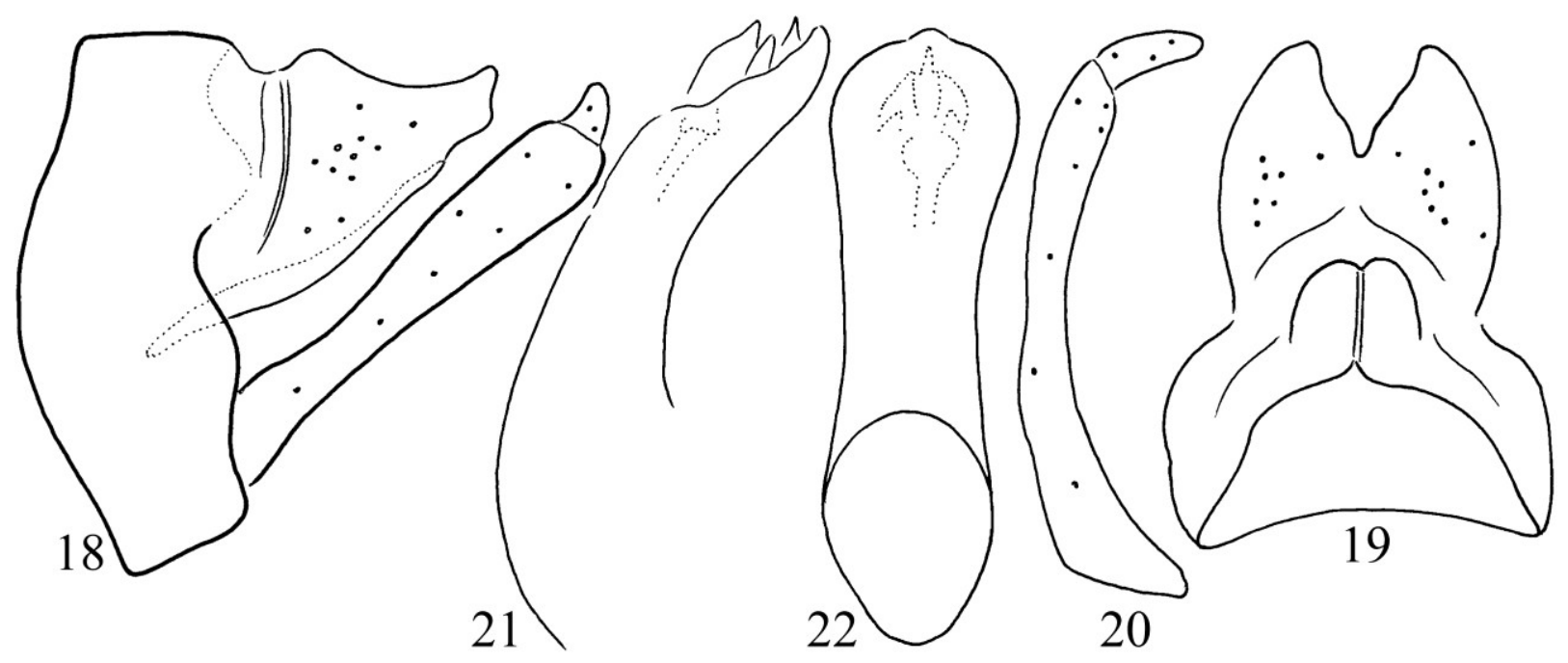

Figures 18-22. Diplectrona dedomba sp. nov. Holotype. $18=$ male genitalia in left lateral view, $19=$ male genitalia in dorsal view, 20 = left gonopod in ventral view, 21 = phallic organ in left lateral view, 22 = phallic organ in ventral view.

\section{Diplectrona keto Malicky, 2002}

Material examined. China, Taiwan, Province Taitung, $4 \mathrm{~km} \mathrm{~N}$ of Tupan, $390 \mathrm{~m}, 12 . X I .1996$, leg. T. Csőváry \& Cs. Szabóky (1 male, HNHM).

\section{Diplectrona kinulta sp. nov.}

(Figures 23-27)

Material examined. Holotype: China, Tibet, Muotuo, 80K 1000m, 24.VII.2012, leg. Li Wenliang (1 male, CAU). Paratypes: same as Holotype (8 males, DPP-HIST; 5 males, OPC).

Diagnosis. This species belongs to the species, like D. burha characterized by subquadrangular, plate-like paraproct with variously diverged apical pattern. It differs from each by the character combination of small setaless eyes; a pair of large internal sacs in segment VIII; long anterodorsal filament on sternite $\mathrm{V}$, presence of fork I on hindwing; elongated lobes of segment $\mathrm{X}$; delta-shaped head of the phallic organ.

Description. Male (in alcohol). Light brown animal. Forewings light spotted brown. Forewing length $8 \mathrm{~mm}$, apical fork I present on hindwing. Eyes setaless, not enlarged. Maxillary palp formula I-IV-III-II-V. Cephalic setose warts on head dorsum represented by two pairs (1) large eggshaped compact occipital setose warts, (2) vertexal ocellar compact setose warts, as well as a single vertexal medioantennal compact setose wart; epicranial suture abbreviated; curves of lateral vertexal grooves rounded subtriangular; ending posterad far from epicranial groove. Anterodorsal filament on sternite V $2.24 \mathrm{X}$ as long as the sternite, there are two internal large sacs present in segment VIII.

Male genitalia. Segment IX convex anterad, dorsum long and flat with a middle depression line. Segment $X$ fused to the tergum IX. The dorsoapical setose lobes (inner lobes) of segment $\mathrm{X}$ well-developed, extremely elongated rounded broad, protruded; seems bilobed, but tightly adhered; the ventroapical setose area distinct. Cerci setose, high and short in lateral view, semicircular in dorsal view. Unsetose paraproct (outer lobes or lateral plates of segment X) subquadrangular flat plate in lateral view with upward directed pointed dorsal process and a laterad directed smaller ventral process. Gonopods robust straight and its harpago mesad turning. Phallic apparatus with down curving and broadening basal section and with a longer tube-forming horizontal two thirds with rounded obliquely cut apex in lateral view; two pairs of endothecal processes visible, both with blunt apices in lateral and pointed triangular in ventral view; dorsal 


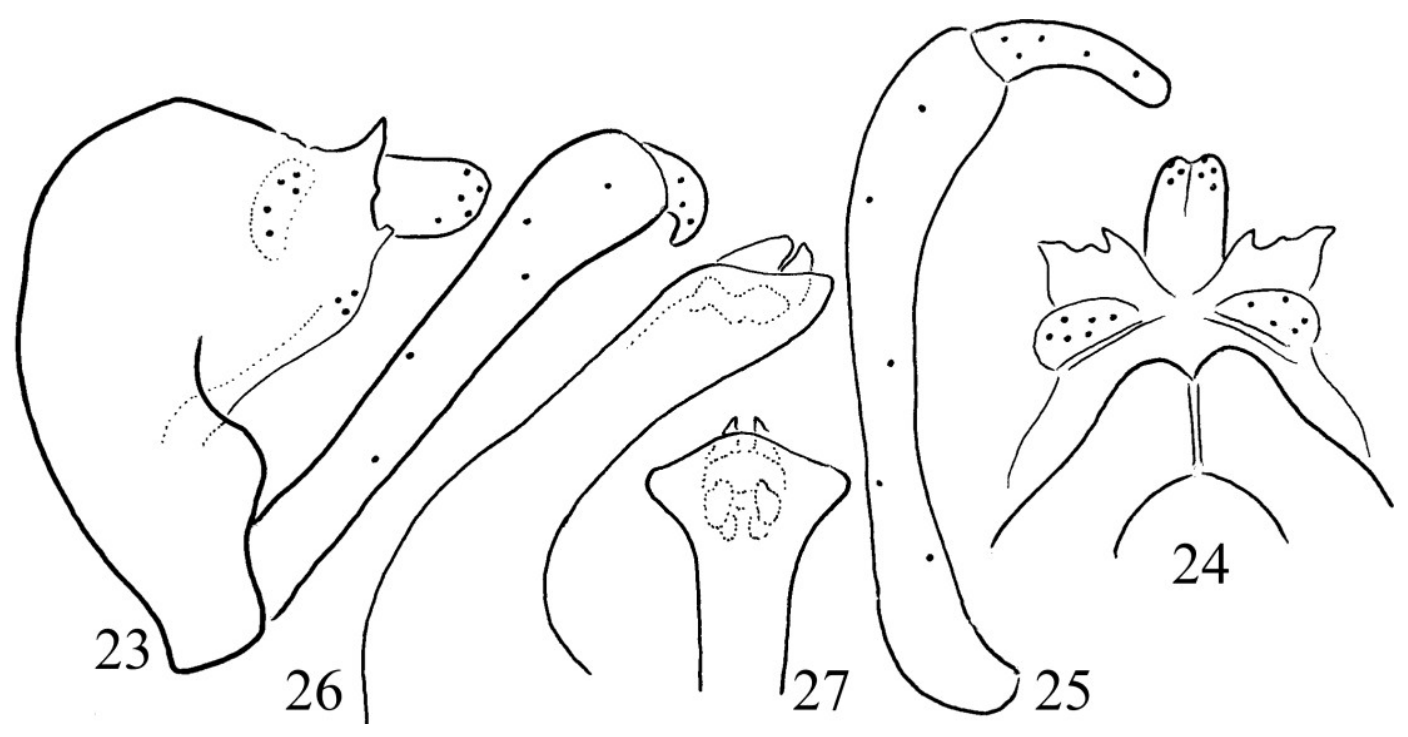

Figures 23-27. Diplectrona kinulta sp. nov. Holotype. 23 = male genitalia in left lateral view, $24=$ male genitalia in dorsal view, $25=$ left gonopod in ventral view, 26 = phallic organ in left lateral view, 27 = phallic organ in ventral view.

endothecal process larger and more pigmented; phallotremal sclerite less distinct. The phallic organ with much produced wing-like triangular delta-shaped head in ventral view.

Etymology. kinulta coined from "kinyúlt" stretched in Hungarian, refers to elongated lobes of segment $X$ compared to the paraproct.

\section{Diplectrona sanguana Kimmins, 1964}

Material examined. China, Tibet, Muotuo, 80K 1000m, 24.VII.2012, leg. Li Wenliang (2 males, DPP-HIST; 1 male, OPC).

Remarks. New species record for China! Malicky (2002) has redrawn a specimen from Dakhi Khola, Nepal, fitting well to the original drawings of the Holotype. However, emphasising the extremely varying nature of the lateral plate of segment $\mathrm{X}$, that is the paraproct, he has drawn specimens from several regions under the name of D. sanguana with completely different paraproct profiles. The drawn specimens under the name of $D$. sanguana represent probably three different siblings of incipient species. Paraproct has been found as an extremely stable and not varying organ (Oláh et al. 2017). In the same paper
Malicky (2002) has listed similarly probable siblings of incipient species under the name of $D$. dilutensis, D. fama, D. aurovittata and D. burha differing by the subtle, but stable divergences in paraproct shape. Paraproct as a titillating or stimulating organ of the genitalia is usually formed by adaptive mechanism and are the most stable genetic component compared to the neutral organs under the influence of stochastic events. It seems that the Diplectrona genus is very diverse in the Oriental region and there are diverse species complexes existing under a single a name. This hidden diversity is explorable only by fine phenomics that is by examining population samples and applying higher resolution and more care with research focus on the adaptive speciation traits.

\section{Diplectrona tamdaophila Mey, 1998}

Material examined. China, Guangxi Zhuang Autonomous Region, Shangsi County, Shiwandashan Natural Forest Park, Pearl River above tourist route bridge, $\mathrm{N} 21^{\circ} 53.913^{\prime} \mathrm{E} 107^{\circ} 54.283^{\prime}$, 375m, 27.III.2015 (/15), leg. J. Kontschán, J. N. Li, S. Li, W. H. Li, D. Murányi \& G. Q. Wang (1 male, DPP-HIST).

Remarks. New species record for China! 


\section{Macronematinae subfamily}

Macronematini tribe

\section{Amphispyche gratiosa Navas, 1922}

Material examined. Laos, Xainabouli, near Hatdai, 250m, 26.III.2016, leg. Liu Xingyue (5 males, OPC).

\section{Macrostemum fastosum (Walker, 1852)}

Material examined. China, Guangxi Zhuang Autonomous Region, Shangsi County, Shiwandashan Natural Forest Park, light trap above the confluence of Pinglong River and Minan River, $\mathrm{N} 21^{\circ} 51.929^{\prime}, \mathrm{E} 107^{\circ} 50.675^{\prime}, 315 \mathrm{~m}, 28 . \mathrm{III} .2015$ (/21), leg. J. Kontschán, J. N. Li, S. Li, W. H. Li, D. Murányi \& G.Q. Wang (1 female, DPP-HIST). China, Guangxi Zhuang Autonomous Region Wuming County, Liangjiand town, Neichao Ming Hotel, terrace above Neichao River, N23⒉ $29.547^{\prime}$ E108 ${ }^{\circ} 21.507 ', 195 \mathrm{~m}, 23-24$. III.2015(/07), leg. J. Kontschán, J.N. Li, W.H. Li, D. Murányi \& G.Q. Wang (1 male, OPC).

\section{Macrostemum punctatum (Betten, 1909)}

Material examined. China, Guangxi Zhuang Autonomous Region, Shangsi County, Shiwandashan Natural Forest Park, light trap above the confluence of Pinglong River and Minan River, N21 ${ }^{\circ} 51.929^{\prime} \quad$ E107 $50.675 ', 315 \mathrm{~m}, 28$. III.2015 (/21), leg. J. Kontschán, J.N. Li, S. Li, W.H. Li, D. Murányi \& G. Q. Wang (1 male, OPC).

Remarks. New species record for China!

\section{Polymorphanisini tribe}

Polymorphanisi is a distinct tribe in the Macronematinae subfamily having the mouthparts lost; wings are without the taxonomic character of the pronounced Macronematini type of wing pattern.

\section{Polymorphanisus genus}

The male genitalia were considered not yielding useful characters for the determination of species in the Polymorphanisus genus (Barnard 1980). Species delineation was and is still based mainly on wing venation, coloration, thoracic marking and on locality character state of distribution. Applying the speciation trait principle of fine phenomics we have discovered subtle, but stable adaptive trait divergences in the phallic head proved to be sensitive enough to separate species within the Aethaloptera genus of the Polymorphanisini tribe (Oláh 2018a, b). Examining a few available males of the Oriental Polymorphanisus species we have found the phallic profiles as a similar potential to delineate siblings of incipient species. The phallic head of the Polymorphanisus genus represents an advanced apomorphic character state in the Hydropsycindae family along the transformation series of simplification from the plesiomorphic state of the phallic head with abbreviated, but free structures present in the ancestral Arctopsychinae, Diplectroninae and Smicrideinae subfamilies, in most genera of Hydropsychinae subfamily and in the ancestral genera of Macronematinae, to the much specialised apomorphic state of abbreviated plus retracted terminal structures in a few species groups in the Hydropsche genus of the Hydropsychinae subfamily and in most genera of the Macronematinae subfamily (Oláh \& deVries 2019).

Further studies are required to confirm the stability of this trait in order to apply the lateral and ventral phallic profiles reliably to separate the poorly known species of this difficult genus. The difficulty to collect population samples of Polymorphanisus males makes the stability test not easy. We have large series of Polymorphanisus species from the Afrotropical region, mostly females. The collection of Polymorphanisus nigricornis species in India, Orissa State, Bhubaneshwar, Dhauli marshy area, during four trips between 1985 and 1987 has resulted only female specimens. Similarly, during our five Vietnamese trips we have collected only females. It is understandable that several described species are based only on female Holotypes. We have 2 males from Vietnam and 1 male from China with the character combination of the Polymorphanisus 
astictus species, but found very significant adaptive divergences in the morphology of the phallic organ accompanied by divergences in the nonadaptive neutral periphallic organs of the segment $\mathrm{X}$ and paraproct.

\section{Polymorphanisus astictus new species complex}

This new species complex belongs to the Polymorphanisus nigricornis species group: (1) males no enlarged eyes, well separated ventrally; (2) gonopod segmented; (3) wings long and narrow; (4) there are no dark spots on forewing; (5) in forewing $\mathrm{M}_{1}$ is closely associated at base with $\mathrm{R}_{5}$; (6) $\mathrm{M}_{2}$ is a direct continuation of $\mathrm{M}_{1+2}$; (7) discoidal cell much shorter than median cell; in hind wing $\mathrm{R}_{1}$ terminates on wing margin. In this species group the Polymorphanisus astictus new species complex has diverged and easily distinguished by having no dark thoracic marking present in all the other member of the species group.

There are two species known in this species complex, the nominate species of $P$. astictus and the doubtful species of $P$. umbripes. The later species was described from a large series of female specimens identified by Banks (1939) erroneously as $P$. nigricornis. The dark antennae, tibiae and femora without thoracic marking inspired the new species status with the possibility of simple colour variation (Barnard 1980). The character state of colour at $P$. astictus does not seem to be stable (Malicky 1998).

Actually the species status of the $P$. astictus females and males is based on character combination of the $P$. nigricornis species group without any dark marking present on the thorax. However, the fine phenomics of our two males from Vietnam and one male from China having this character combination revealed significant divergences in the fine structure of the phallic organ as well as in the shape of segment $X$ and the paraproct. Here we compare these structures with the lectotype of $P$. astictus and describe two new species and reinstate the species status of Polymorphanisus hainanensis Martynov. We keep the species status of $P$. umbripes with dark antennae, tibiae and femora until its male be- comes known. All the females with light antennae, tibiae and femora can be classified as $P$. astictus until males from the same populations confirm their real species status. The lateral and ventral profiles of the phallic organ, and especially of the phallic head like in the Aethaloptera genus (Oláh 2018a, b), can be applied to distinguish easily any species divergences. Here we present a brief survey on this new species complex having five members: the nominate species Polymorphanisus astictus, $P$. hainanensis, $P$. liorum sp. nov., $P$. totaorum sp. nov., $P$. umbripes. However, much more taxa are hidden behind the females collected from various remote Oriental regions with the character combination of Polymorphanisus nigricornis species group accompanied with thorax without any dark marking pattern. We need males to discover them by the speciation trait of the phallic profiles.

\section{Polymorphanisus astictus Navás, 1923}

(Figures 28-31)

Material examined. Vietnam, Bac Kan Province, $13 \mathrm{~km}$ SW from Bac Kan City, $90 \mathrm{~m}$, 19.V.2012, leg. W.H. Li (1 female, DPP-HIST). Malysia, Perak, Temegor lake, 11.IX.1993, light leg. G.S. Robinson (1 female, OPC).

Remarks. The male lectotype of Navas's species was collected in Kweichow (Guizhou Province) and was examined, drawn and designated by Barnard (1980). According to his detailed drawings tergite IX is clearly capitate in dorsal view. Segment $X$ is less discernible mesal lobes. Phallic organ with rounded apical margin in lateral view and the phallic head with elongated ovoid ventral profile.

All the females with character combination of the $P$. nigricornis species group without thoracic marking and with light antennae, tibiae and femora will be classified as $P$. astictus until males will be associated and determined to species. If population samples of sufficient number of specimens will be available there could be a possibility to distinguish species by the ventral profile of the sclerotized and sensory setosed apical margin of sternite VIII. 


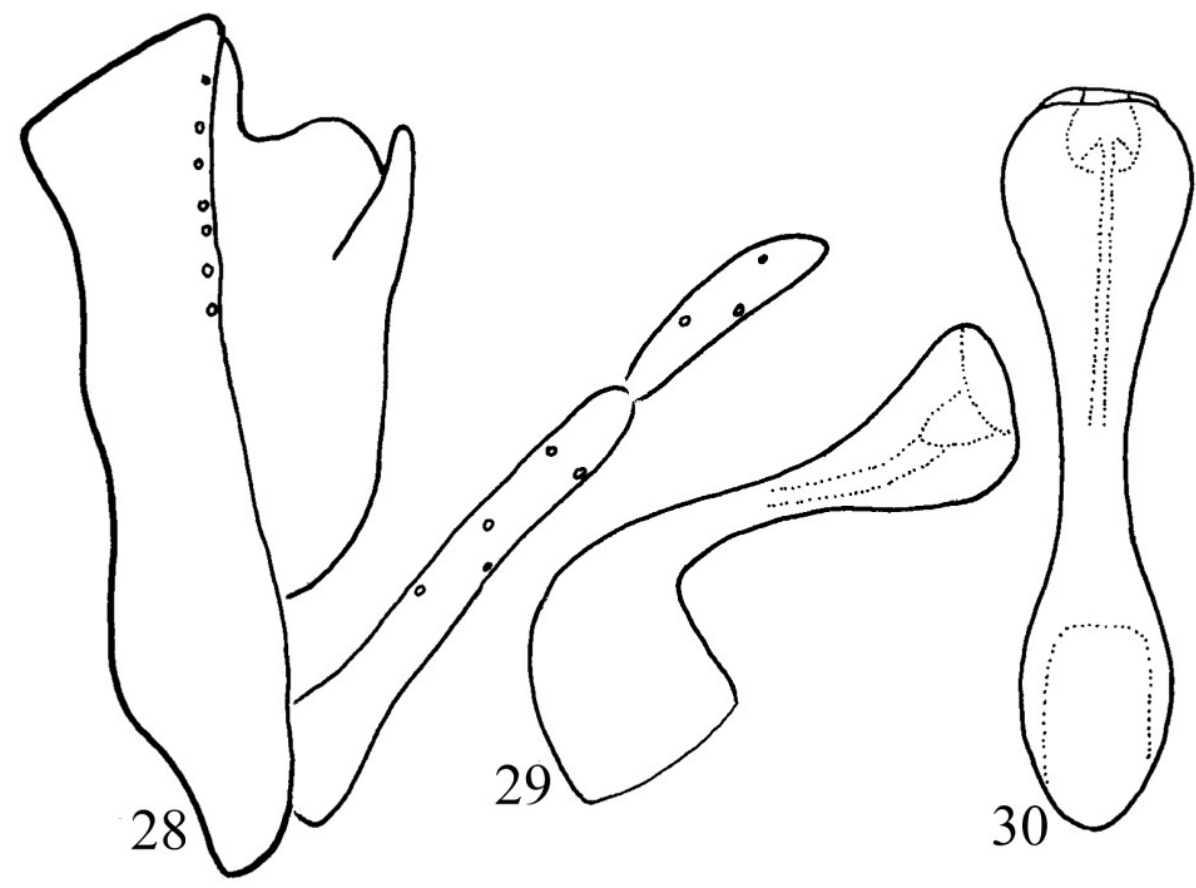

Figures 28-30. Polymorphanisus astictus Navás 1923. Lectotype: $28=$ male genitalia in left lateral view, $29=$ phallic organ in left lateral view, $30=$ phallic organ in ventral view.

Polymorphanisus hainanensis Martynov, 1930 stat. restit.

(Figure 32)

Polymorphanisus hainanensis Martynov, 1930: 82. Holotype male, China: Hinan Tao I., Mt. Wuchih Shan, 20.V.1903 deposited in BMNH.

Polymorphanisus hainanensis Martynov, 1930. Barnard 1980:79. Synonymised with Polymorphanisus astictus Navás, 1923.

Remarks. Based on the excellent original drawings of the species description, the lateral lobes of segment $X$ housing the vestigial cerci of the setose slightly elevated flat area and the laterad produced apical termination of the vestigial paraproct are more produced posterad and parallel-sided forming a deep mesal excision compared to the completely differently structured shape of the same complex at $P$. astictus. P. hainanensis has resemblance to $P$. liorum $\mathrm{sp}$. nov., but the complex of lateral lobes longer and posterad directed, not short and laterad directed.
Polymorphanisus liorum J. Oláh, sp. nov.

(Figures 33, 35-38)

Material examined. Holotype: Vietnam, Quang Tri Province, Da Krong Nature Reserve, 2 km SE of HQ, light trap at small forest stream, 16.V. 2007, leg. G. Csorba (male, HNHM). Paratype: same as Holotype (1 male, DPP-HIST).

Diagnosis. According to the dorsal view of the segment $\mathrm{X}$ complex this large species with extremely long brown-ringed antennae is most close to $P$. hainanensis. Both species have bifid dorsal profile of segment $X$, but the new species has the lateral lobes shorter and directed laterad, not long digitate and not directed posterad. Ninth tergite rounded in dorsal view at the new species but rectangular at $P$. hainanensis. Unfortunately Martynov has not cleared his specimens, his drawings were drawn from intact genitalia. The phallic organ was almost invisible in the intact genitalia of his species. Its unique spur number of 2.3.3 differs from all the species in the complex. 

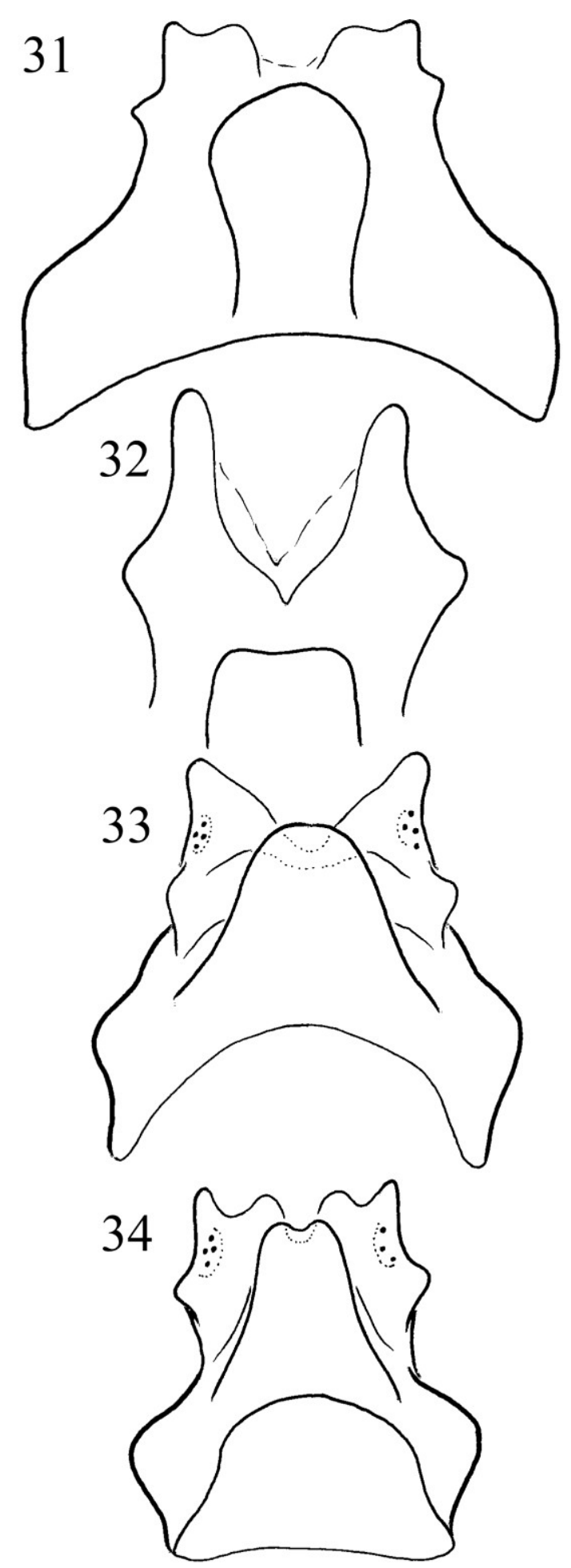

Figures 31-34. Dorsal view of the male genitalia. $31=$ Polymorphanisus astictus Navás, 1923, lectotype, 32 = Polymorphanisus hainanensis Martynov, 1930 stat. restit.

$33=$ Polymorphanisus liorum Oláh sp. nov. $34=$ Polymorphanisus totaorum sp. nov.
Description. This large new species is characterised with light brown body, darker brown banded abdominal tergite and light brownish wings. It has small eyes, well separated ventrally; extremely long dark ringed antennae with $70 \mathrm{~mm}$ length; no dark spots on forewing; forewing 28 $\mathrm{mm}$ long and narrow; in forewing $\mathrm{M}_{1}$ is closely associated at base with $\mathrm{R}_{5} ; \mathrm{M}_{2}$ is a direct continuation of $\mathrm{M}_{1+2}$; discoidal cell twice smaller than median cell; in hind wing $\mathrm{R}_{1}$ terminates on wing margin and has no dark thoracic marking. Spur number: 2.3.3.

Male genitalia. Segment IX short, its tergite longer; tergite IX broad slightly narrowing apicad with rounded apical ending. The complex of segment $\mathrm{X}$ broad-based subtriangular in lateral view; bilobed and divorcing laterad in dorsal view with clearly visible setose area of the vestigial cerci; the other vestigial component of segment $X$ is the paraproct discernible as a long sclerotized straps ventrolaterad, terminating posterad in a lateral hump visible both in lateral and especially in dorsal view; this vestigial paraproct functions as the phallic guides forming dorsolateral sheath of the phallocrypt or fused membranously to the basis or dorsum of the phallotheca serving in the intromitting movements of the phallic apparatus. Gonopods segmented. Phallic organ in lateral view with right angled high and long basal third of the phallotheca, low horizontal middle region funnel-like terminal and straight-cut truncate; in ventral view the phallic head is rather tunnel-like, but with a middle constriction.

Etymology. liorum, this wonderful large green animal with $7 \mathrm{~cm}$ long antennae is dedicated to the family of the second author, Weihai $\mathrm{Li}$, who has realised an intensive collection of caddisfly adults in China and in adjacent territories, including Vietnam.

\section{Polymorphanisus totaorum sp. nov.}

(Figures 34, 39-42)

Material examined. Holotype: Laos, Xainabouli, near Hatdai, 250m, 26.III.2016, leg. Liu Xingyue (1 male, CAU). Paratype: same as Holotype (1 male, DPP-HIST). 


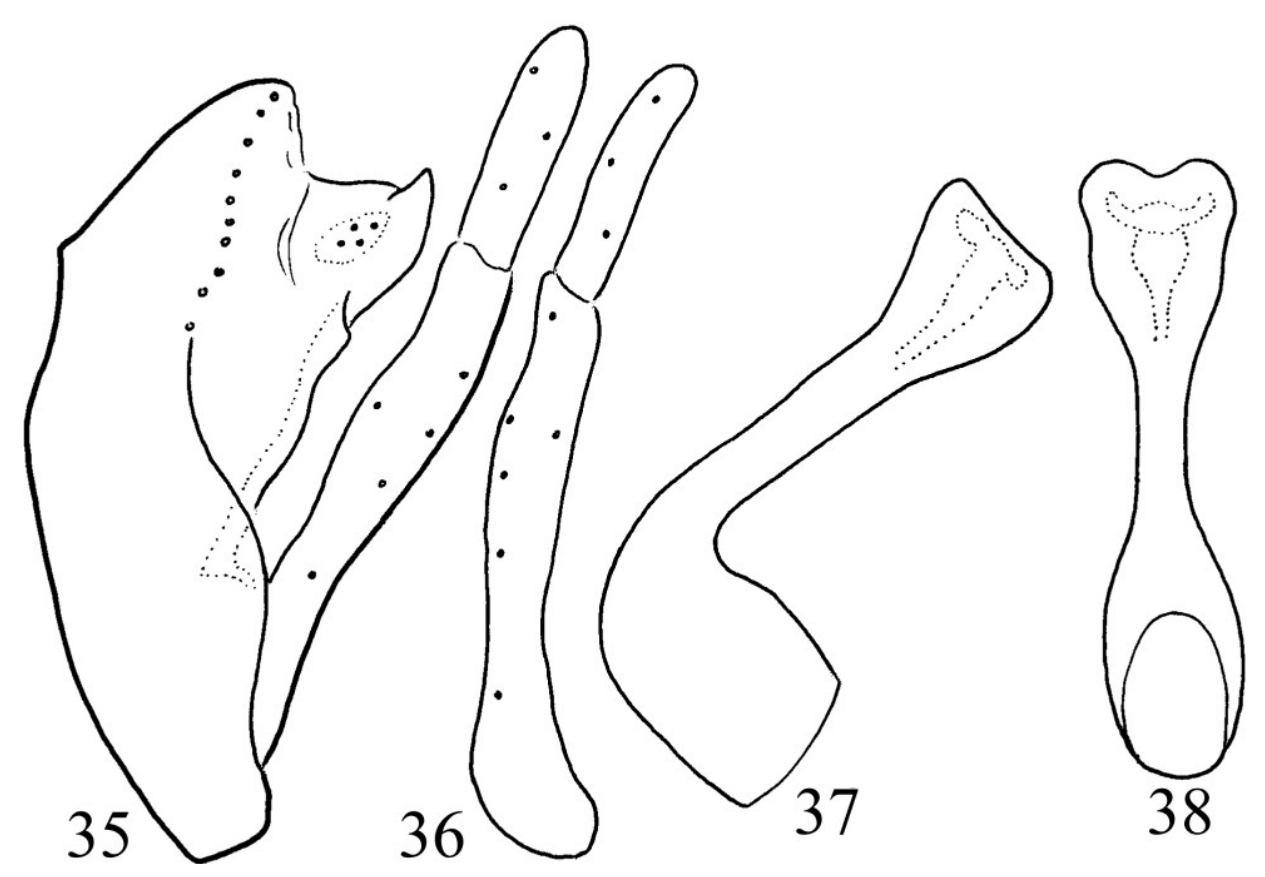

Figures 35-38. Polymorphanisus liorum J. Oláh, sp. nov. Holotype. $35=$ male genitalia in left lateral view, $36=$ left gonopod in ventral view, 37 = phallic organ in left lateral view, $38=$ phallic organ in ventral view.

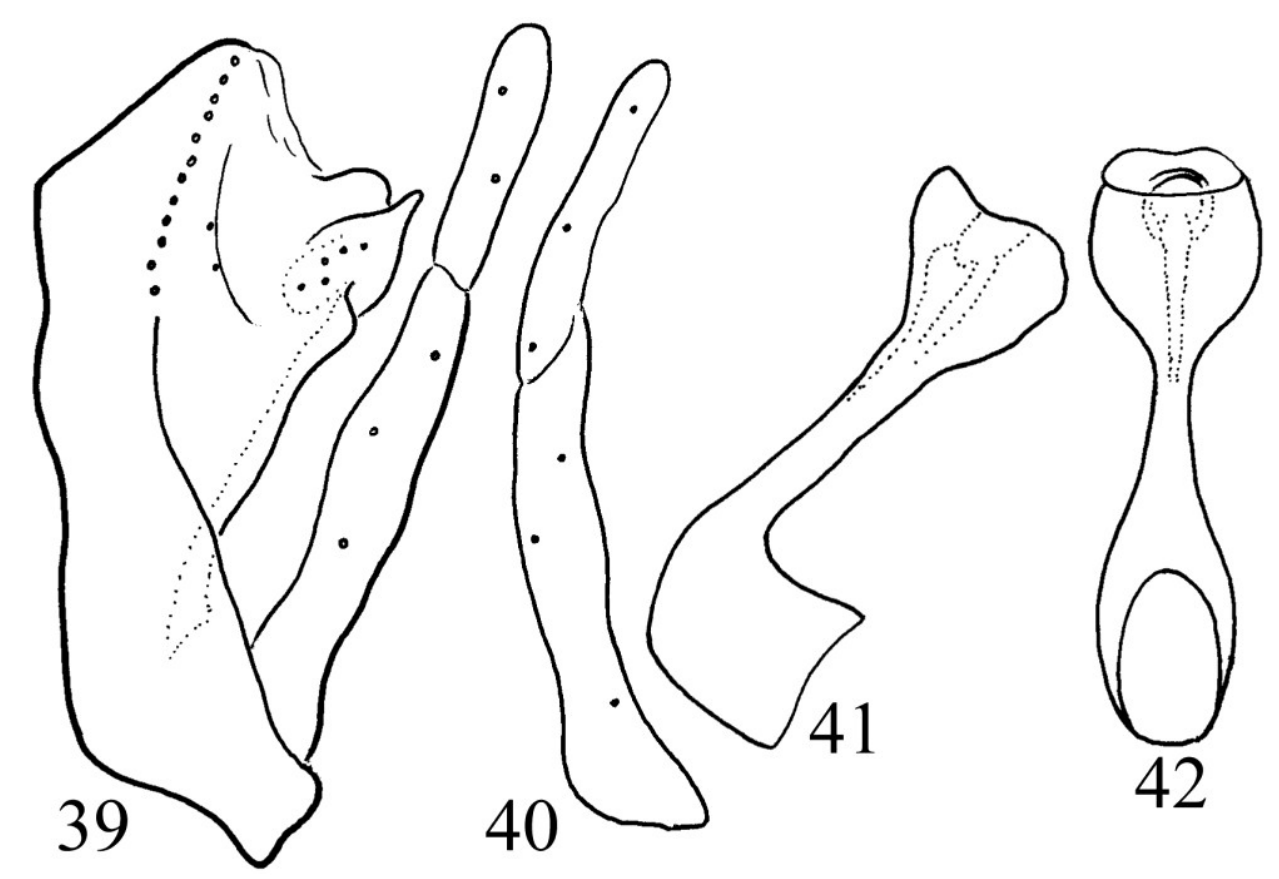

Figures 39-42. Polymorphanisus totaorum sp. nov. Holotype. $39=$ male genitalia in left lateral view, $40=$ left gonopod in ventral view, 41 = phallic organ in left lateral view, $42=$ phallic organ in ventral view. 
Diagnosis. According to the dorsal view of the segment $\mathrm{X}$ complex this large species with long brown-ringed antennae is most close to the nominal species of $P$. astictus. Both species have quadrifid dorsal profile of segment $X$, but the new species has deeper excision and the mesal lobes are more produced. In dorsal view the ninth tergite narrow and narrowing and ending in bifid apex, not capitate. The phallic head is circular in ventral view, not elongated ovoid. Moreover the spur number is 1.3.2, not 13.3.

Description. This new species is characterised with light brown body, darker brown banded abdominal tergite and light greenish-yellowish wings. It has small eyes, well separated ventrally; long dark ringed antennae; no dark spots on forewing; forewing $23 \mathrm{~mm}$ long and narrow; in forewing $\mathrm{M}_{1}$ is closely associated at base with $\mathrm{R}_{5}$; $\mathrm{M}_{2}$ is a direct continuation of $\mathrm{M}_{1+2}$; discoidal cell twice smaller than median cell; in hind wing $\mathrm{R}_{1}$ terminates on wing margin and has no dark thoracic marking. Spur number 1.3.2.

Male genitalia. Segment IX short, its tergite longer; tergite IX narrow and narrowing apicad with slightly excised apical ending. The complex of segment X broad-based subtriangular in lateral view; quadrilobed and parallel-sided in dorsal view with clearly visible setose area of the vestigial cerci; the other vestigial component of segment $\mathrm{X}$ is the paraproct discernible as a long sclerotized straps ventrolaterad, terminating posterad in a pronounced lateral hump visible both in lateral and especially in dorsal view; this vestigial paraproct functions as the phallic guides forming dorsolateral sheath of the phallocrypt or fused membranously to the basis or dorsum of the phallotheca serving in the intromitting movements of the phallic apparatus. Gonopods segmented. Phallic organ in lateral view with right angled low and long basal part of the phallotheca, low horizontal middle region, funnel-like terminal region with patterned-cut truncate head; in ventral view the phallic head is rather circled, without any middle constriction.

Etymology. totaorum epithet comes from coining "Toth" and "Tao", to remind the magnificent
Holon of human nature, the integrated cooperation of the "whole" as it is expressed in every myths of the prehistoric human populations in each corner of Eurasia, until negated by Western modernism manifested in the new myths of imbalanced competion and natural selection. This Holon is epithetised by combining Toth and Tao. Toth, symbolising the Occident, is the creator of universal analogy in the tabula smaragdina (superior is like to inferior, all have been and arose from one), the Egyptian god of knowledge, later the Greek named Hermes Trismegistos (thrice great). Tao, symbolising the Orient, is the central concept of Chinese Laoce, the principle of $W u$ $W e i$ (action of non-action, going with the unified flow of nature) and adopted also by Buddhism (non-clinging to individual ego).

\section{Polymorphanisus umbripes Barnard, 1980}

Polymorphanisus umbripes Barnard, 1980:95-96. Holotype 9 , India: Mysore, Shimoga, R. Tunga, $1865^{\prime}(560 \mathrm{~m})$, at light, 18.VI.(?year) (Nathan) (type no. 32396, MCZ, Harvard). Paratypes. India: 29 \% , data as Holotype, various dates (26 in MCZ, Harvard; 2 in USNM, Washington; 1 in BMNH; 4 , Mysore, Bhadravati (Nathan) (MCZ, Harvard).

Remarks. Distinguished from $P$. astictus by the dark antennae, tibiae and femora. In spite of colour variability detected in various remote populations of $P$. astictus the species status of $P$. umbripes is retained until male will be available to compare its segment $\mathrm{X}$ and phallic profiles with the other males of the species complex.

\section{Hydropsychinae}

\section{Hydromanicus deceptus (Banks, 1939)}

Material examined. China, Guangxi Zhuang Autonomous Region, Tianlin County, Cenwangloashan Mt., Dalongping station, 24.V.2013 (1 male, DPP-HIST).

\section{Hydromanicus eleasar Malicky, 1993}

Material examined. China, Tibet, Muotuo, $80 \mathrm{~K} 1000 \mathrm{~m}$, 24.VII.2012, leg. Li Wenliang (3 males, DPP-HIST; 2 males, OPC). 
Remarks. New species record for China! It was described from Nepal and recorded later from Myanmar (Oláh \& Johanson 2008).

\section{Hydromanicus heges sp. nov.}

(Figures 43-47)

Material examined. Holotype: China, Tibet, Muotuo, 80K 1000m, 24.VII.2012, leg. Li Wenliang (1 male, CAU). Paratype: same as Holotype (1 male, DPP-HIST).

Diagnosis. This new species belongs to the Hydromanicus luctuosus species group, established as $H$. truncatus species group by Oláh \& Johanson (2008). Very specialised by the head of the phallic organ, the ventral keel is modified and combined with apicolateral dorsal wings (widened head in dorsal or ventral view). Has resemblance to $H$. falax, but differs by the mesad turning pointed tip of the harpago and by the modified phallic head.

Description. A brown coloured animal with light spotted forewing, forewing length is $12 \mathrm{~mm}$.

Male genitalia. Abdominal segment IX divided by suture into a smaller dorsal and a larger ventral part; its median keel short and narrow; anterior margin arciform, resulted in a very short ventrum and short dorsum; apical lobe on posterolateral margin robust semicircular, comprising the bulk of the segment; intersegmental depression between the ninth and tenth segments low in lateral view. Body of segment X broad-based less sclerotized; setose cerci elongated foliform; dorsoapical setose lobes form the bilobed apex of segment $X$. The basal segment of the gonopods almost parallel-sided slightly sinuous; terminal segment, the harpago parallel-sided with sharp mesad turning pointed tip. Phallic apparatus robust, subapical ventral keel small and shallow, endothecal sclerites downward curving, phallic apex dilated forming a dorsolateral wing visible in dorsal and lateral view.

Etymology. heges, coined from "hegyes" pointed, acute in Hungarian, refers to very tip of the harpago with mesad directed very sharp, pointed structure.

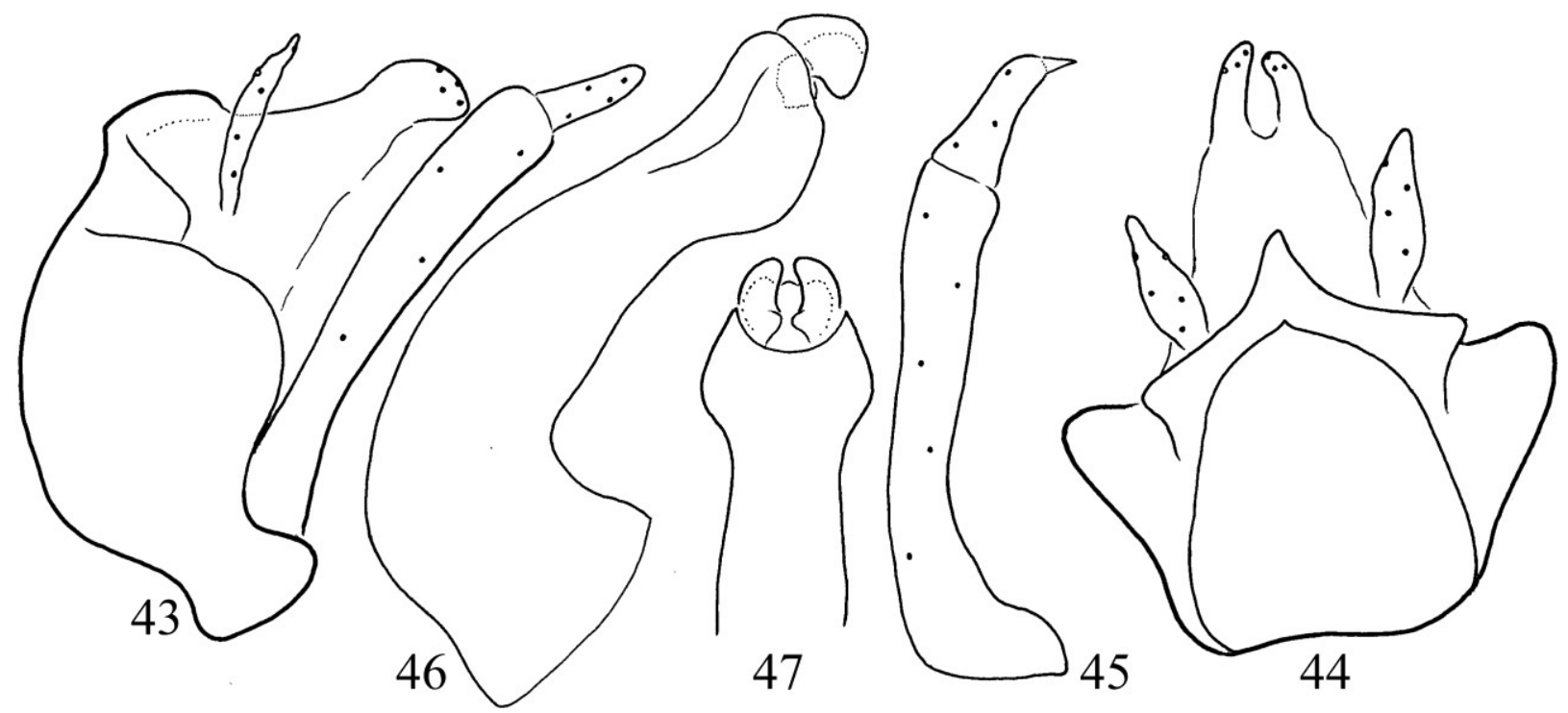

Figures 43-47. Hydromanicus heges sp. nov. Holotype. $43=$ male genitalia in left lateral view, $44=$ male genitalia in dorsal view, 45 = left gonopod in ventral view, 46 = phallic organ in left lateral view, 47 = phallic organ in ventral view. 


\section{Hydromanicus luctuosus Ulmer, 1905}

Material examined. China, Tibet, Beibengxiang, $700 \mathrm{~m}$, 30.VII.2012, leg. W. Li (1 male, DPP-HIST). China, Tibet, Muotuo, 1100 m, 26. VII.1912, leg. Li Wenliang (1 male, DPP-HIST). China, Tibet, Muotuo, 80K 1000m, 24.VII.2012, leg. Li Wenliang (1 male, OPC).

\section{Hydromanicus melli species complex}

These medium-sized species with variously brown patterned forewing have rather complicated phallic head: the phallotheca produced ventroapicad into specific ventral profile and the phallotremal sclerites are surrounded by complex system of endothecal processes: (1) dorsally a heavily sclerotized pair of downward curving elongated plates with inner concavity is accompanied by a pair of upward or downward curving strong spines; ventrally two pairs of variously developed and curved spines. The complex of segment X with a dorsal anterad directed pointed hook before the fused dorsoapical setose lobes. The periphallic organs of cerci and gonopods are less diverged. The specification is realised mostly by the shape divergences of the endothecal processes in sexual adaptation of the integrative organisation. The following species belong to this complex: $H$. huapingensis, $H$. melli, $H$. mintas sp. nov., $H$. respersarius, $H$. ritkas sp. nov.

\section{Hydromanicus melli (Ulmer, 1925)}

Material examined. China, Zhejiang, Jingning, Wangdongyang N.N.R, 2017.7 Zhang Tingting (1 male, DPP-HIST; 1 male, OPC). China, Fujian Province, Huankeng, Aotou village, 2.V.2004, leg. Liu Xing-Yue (1 male, OPC). China, Fujian Province, Wuyishan, Sangang, 740 m, 9.V.2004, leg. Liu Xingyue (1 male, DPP-HIST).

\section{Hydromanicus mintas sp. nov.}

(Figures 48-49)

Material examined. Holotype: China, Guangxi Zhuang Autonomous Region,, Shangsi County, Shiwandashan Natural Forest Park, light trap above the confluence of Pinglong River and Minan River, N21 ${ }^{\circ} 51.9^{\prime} 9^{\prime}$ E107 $50.675^{\prime}, 315$ m, 28.III.2015(/21), leg. J. Kontschán, J. N. Li, S. Li, W. H. Li, D. Murányi \& G. Q. Wang (1 male, OPC).

Diagnosis. This new species belongs to the Hydromanicus melli species complex, and differs from the siblings of the complex by the rather flat and more anterad directed dorsal hook and by the specialised pattern of endothecal processes and spines.

Description. A brown coloured animal with strongly contrasted darker brown forewing pattern with forewing length $12 \mathrm{~mm}$.

Male genitalia. Abdominal segment IX short; anterior margin arciform, resulted in a very short dorsum and longer ventrum; posterior margin almost straight vertical, delineated by vertical row of strong spines; intersegmental depression between the ninth and tenth segments low and obtuse angled in lateral view. Body of segment $X$ complex with a dorsal anterad directed pointed hook before the fused dorsoapical setose lobes; setose cerci elongated filiform with more setose basal lobe; dorsoapical setose lobes fused and upward directed in lateral view. The basal segment of the gonopods almost parallel-sided; terminal segment, the harpago parallel-sided long and upward arching. Phallic apparatus robust, phallobase low oblique; phallic head with the pair of down curving dorsal plates, upward curving pair of strong dorsal spines; ventral spines composed of short dorsal and long ventral pairs of spines; the produced ventral lip of the phallotheca broad apicad.

Etymology. mintas, coined from "mintás" patterned in Hungarian, refers to strongly patterned forewing.

\section{Hydromanicus ritkas sp. nov.}

(Figures 50-51)

Material examined. Holotype: China, Guangxi Zhuang Autonomous Region,, Shangsi County, Shiwandashan Natural Forest Park, light trap a- 


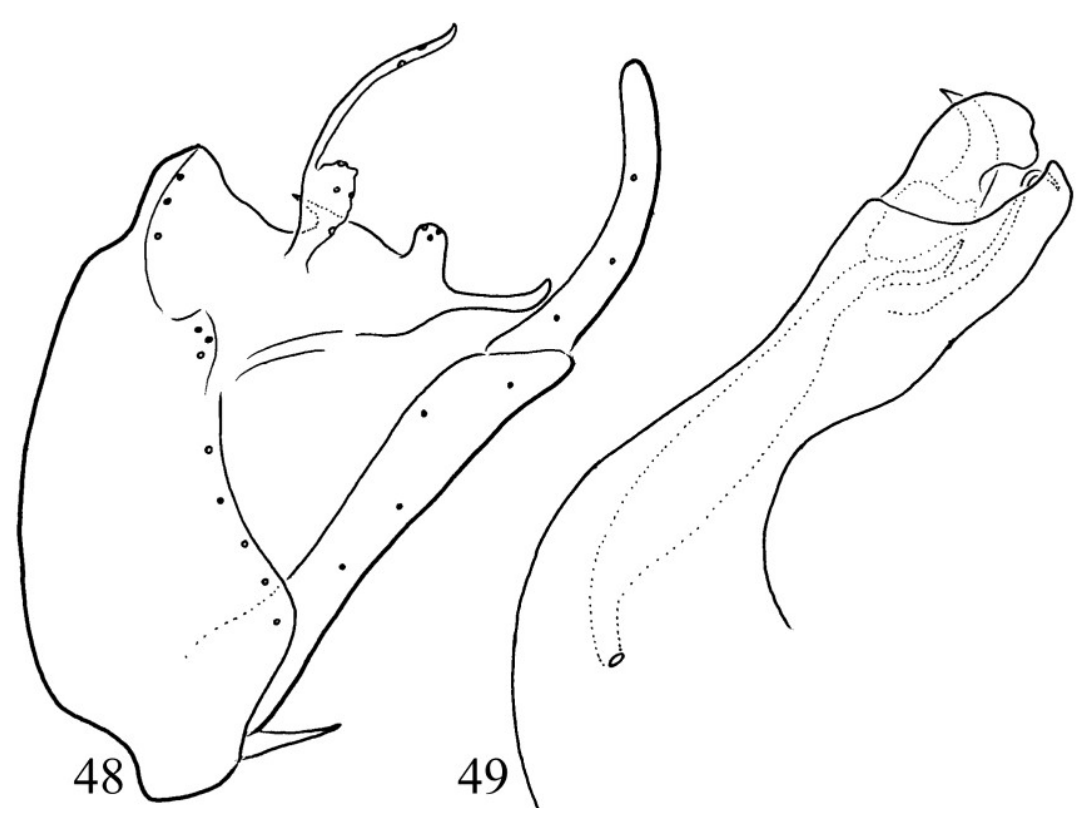

Figures 48-49. Hydromanicus mintas sp. nov. Holotype. $48=$ male genitalia in left lateral view, $49=$ phallic organ in left lateral view.

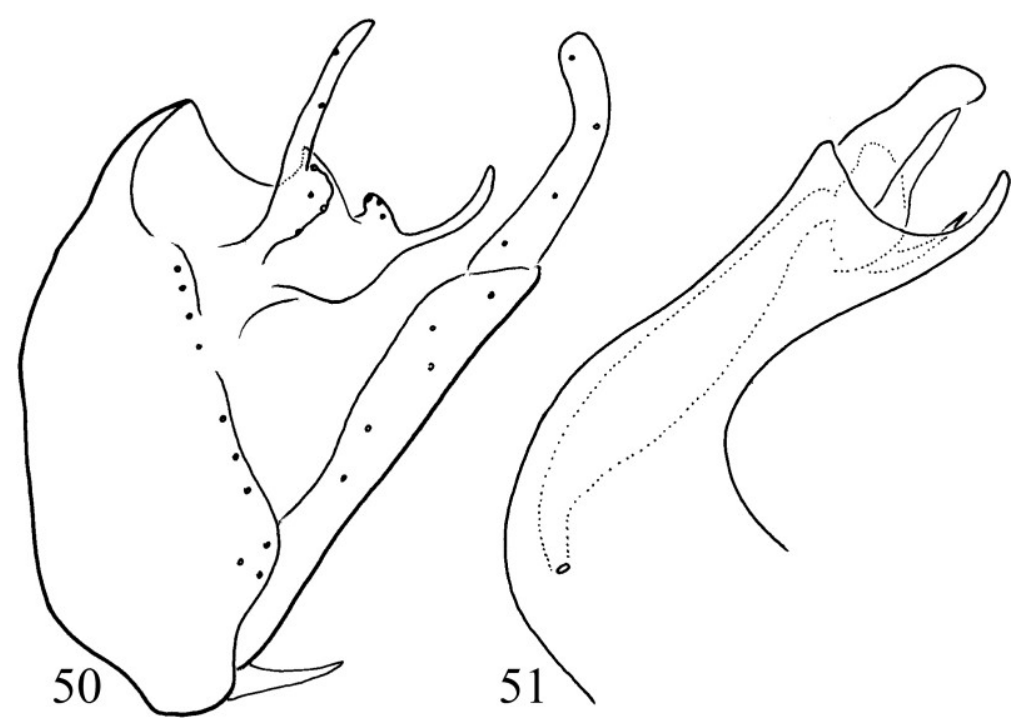

Figures 50-51. Hydromanicus ritkas sp. nov. Holotype. 50 = male genitalia in left lateral view, $51=$ phallic organ in left lateral view.

bove the confluence of Pinglong River and Minan River, N2151.929' E10750.675', $315 \mathrm{~m}$, 28.III.2015(/21), leg. J. Kontschán, J. N. Li, S. Li, W. H. Li, D. Murányi \& G. Q. Wang (1 male, OPC). Paratype: China, Shangsi County, Shiwandashan Natural Forest Park, light trap on Yunwu Hotel balcony above Pearl River, N21 $1^{\circ} 54.316^{\prime}$ E107 54.203', $295 \mathrm{~m}, \quad 26-$ 29.III.2015(/14), leg. J. Kontschán, J. N. Li, S. Li,
W. H. Li, D. Murányi \& G. Q. Wang (1 male, CAU).

Diagnosis. This new species belongs to the Hydromanicus melli species complex, and differs from the siblings of the complex by the upward produced and more upward directed dorsal hook and by the specialised pattern of endothecal processes and spines. 
Description. A brown coloured animal with faintly developed, almost indiscernible darker brown forewing pattern, forewing length is 11 $\mathrm{mm}$.

Male genitalia. Abdominal segment IX short; anterior margin arciform, resulted in a very short dorsum and longer ventrum; posterior margin almost straight vertical, delineated by vertical row of strong spines; intersegmental depression between the ninth and tenth segments deep and obtuse angled in lateral view. Body of segment $X$ complex with a dorsal upward directed pointed hook before the fused dorsoapical setose lobes; setose cerci elongated filiform with more setose basal lobe; dorsoapical setose lobes fused and upward and anterad directed, slightly tapering in lateral view. The basal segment of the gonopods almost parallel-sided; terminal segment, the harpago parallel-sided long and upward arching. Phallic apparatus robust, phallobase high rightangled; phallic head with the pair of down curving dorsal plates, a pair of strong and straight dorsal spines; ventral spines vestigial, reduced to a pair of small spines; the produced ventral lip of the phallotheca narrowing apicad.

Etymology. ritkas, coined from "ritkás" sparse in Hungarian, refers to faintly, sparsely patterned forewing.

\section{Hydropsyche genus}

In the present survey on the Hydropsyche taxa we follow our "diagnostic" classification system of species groups and clusters (or clades?) elaborated around ten years ago (Oláh \& Johanson 2008). At that time the "modern" distinction between diagnostic (cluster) and phylogenetic (clade) systems of classification was still dominating as a valid epistemic scenario. Today such a hubristic epistemic distinction is losing theoretical ground.

Theoretical limits of classification. The growing conundrum between gross and molecular morphology, superimposed by fine phenomics and supported by ontic and epistemic structural realities, by space-time ontology and by Hei- degger's philosophy of Dasein's being in the world, makes it more and more evident that the reality is reticulated, not cladded and resulted in contextual individuality of taxa as a more realistic search fundament for taxonomy. Individuals have only a heuristic role. Structures of entanglement with nodes of structures dominate rather than the objects with an intrinsic identity. Modality of causal structures with causal properties dominates over categorical properties of objects. Therefore every classification must be diagnostic that is necessarily artificial. It's getting more and more evident that similarly to the quantum universe the classical world is also entangled into networks both in the compositional scalar and in the vectorial specification hierarchies. In the vectorial battle field between divergence (dark inflation energy) and integration (negentropy) reticulation organises and maintains the network of living universe as intact as possible against the stochastic effects of divergence.

The terms of cluster and clade are sometimes used interchangeably, but in the naive belief of molecular taxonomy they were considered not synonymous, at least according to the wishful dreams of phylogenetics to distinguish between artificial and natural systems of classification. Following their reductionist distinction a cluster is a group of organisms placed together in a classification system on the basis of their resemblance and practiced in phenetics by cluster analysis (identical by state) without special care to their evolutionary relationship. At the same time the clade is a group of organisms defined by their common biological ancestor, without particular care to their resemblance (identical by descent). In molecular genealogy, such clades are defined usually by single nucleotide polymorphism or by short tandem repeat of microsatellites, determined by polarity of ancestral or descendant character states and arranged in hierarchical branching of cladograms by cladistics.

This reductionist procedure was faced and questioned by the reality of incongruent convergences and parallelisms in the chimeric world of integrative organisation (Oláh et al. 2019). 
Contrary to the Darwinian "descent with modification" on the tree of life, taxa are descendants of the multitude of ancestors forced by causal essence of power and realised by external and internal random effects in stochastic mechanisms. Branching of phylogeny is only the apparent surface of the reality recognised, understood and interpreted by low resolution power of human senses. Instead of this superficial simplification the reality of organisation of living or any entities is reticulated netlike in the deep. In reality, stochastic networking of scalar-dependent hologeny on universal scale and retigeny on partial scales are acting behind any speciation processes: Holon (the Whole) and Rete (the Network) dictate the universal reality. Taxonomist's trials to classify this network of reality into distinct hierarchy of taxa are fundamentally and theoretically artificial. We try to classify natural network into artificial classwork of objects for human practice according to our growing, but still limited human epistemic capacity.

Based on this theoretical consideration here we prefer to use the term cluster instead of clades due to the taxonomic incongruences and discordances getting theoretical support and practical importance and proving to be rather a rule, than an exception; branching is the surface and reticulation is the deep (Oláh \& deVries 2019). Besides the species groups and clusters here we delineate species complexes, if relevant, as detected by the presence of incipient phylogenetic species of siblings.

\section{Hydropsyche vasoumittra species group}

\section{Hydropsyche cernaka sp. nov.}

(Figures 52-55)

Material examined. Holotype: China, Yunnan Province, Gongshan, Dulongjiangi, 1542 m, 1. VII.2013, leg. Zhang Wei (1 male, CAU). Paratypes: same as Holotype (20 males, DPP-HIST; 15 males, OPC).

Diagnosis. This new species belongs to the Hydropsyche vasoumittra species group having several pairs of spine sclerites as endothecal processes as well as some types of sclerous structure at the terminal opening of the endophallus, as the reduced phallotremal sclerites. Differs by all the described species by the very slender and elongated ventroapical setose lobes and to the very thin, almost vestigial thread-like harpago.

Description. A medium sized species with forewing length of $11 \mathrm{~mm}$. Body and wing colour brown, forewing with light spotted pattern.

Male genitalia. Abdominal segment IX fused annular, short; its median keel short with granulose dorsal surface; anterior margin arciform, resulted in a very short ventrum and dorsum; apical lobe on posterolateral margin robust triangular. Intersegmental depression between the ninth and tenth segments deep right-angled in lateral view. Body of segment $\mathrm{X}$ short; lateral setose area (cerci) in middle position; apicoventral setose lobe slender elongated and downward curving from middle; dorsoapical setose lobe shifted back to basal region forming a fused pair of elongated setose area; a setaless winglet attached to the fused dorsoapical setose lobes very produced; the unsetose cavity on the anterolateral area of the segment just discernible. The basal segment of the gonopod sinuous with dilated apical half; the terminal segment, the harpago is broad based and very slim. Phallic apparatus having large and low phallobase; horizontal shaft of the phallotheca broad and bellied tube, the phallic head is composed of specific pattern of six pairs of variously sized spines based by membranous endothecal lobes.

Etymology. cernaka euphemic coining from "cérna, cérnácska" diminutive form of thread in Hungarian, refers to the slender and elongated ventroapical setose lobes and to the very thin, almost disappeared thread-like harpago.

\section{Hydropsyche dhusaravarna Schmid, 1975}

Material examined. China, Tibet, Muotuo, 80K 1000m, 24.VII.2012, leg. Li Wenliang (10 males, DPP-HIST, 12 males, OPC).

Remarks. It belongs to the Hydropsyche vasoumittra species group (Oláh \& Johanson 2008). 


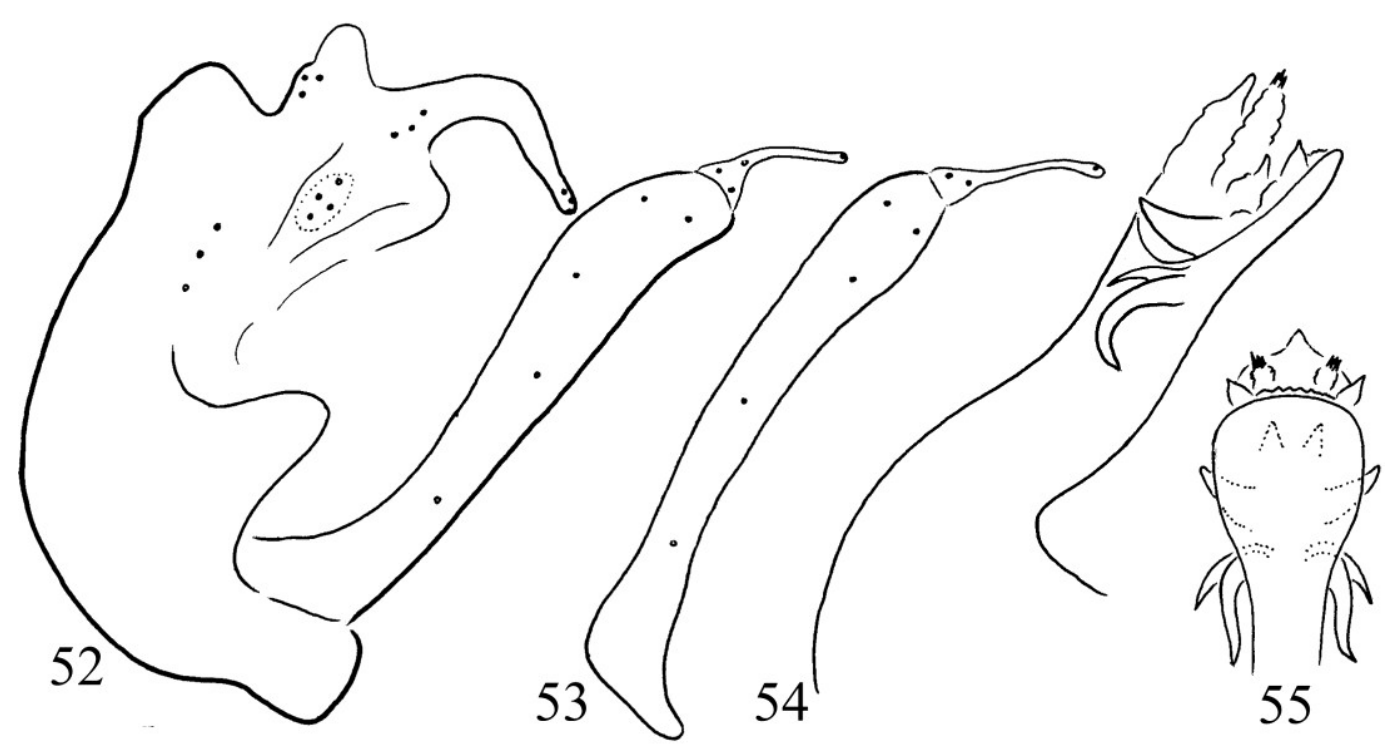

Figures 52-55. Hydropsyche cernaka sp. nov. Holotype. 52 = male genitalia in left lateral view, $53=$ left gonopod in ventral view, 54 = phallic organ in left lateral view, $55=$ phallic organ in ventral view.

\section{Hydropsyche nevae species group}

\section{Hydropsyche nevae species cluster}

\section{Hydropsyche cerva Li \& Tian, 1990}

Material examined. China, Yunnan Province, Ruili, Nanjingli, 18.IV.2014, leg. Lu Xiumei (2 males, DPP-HIST, 2 males, OPC).

\section{Hydropsyche keses sp. nov.}

(Figures 56-60)

Material examined. Holotype: China, Shaanxi Province, Zhouzhi, Houzhenzi, 1278 m, 16.VIII. 2014, leg. Lu Xiumei (1 male, CAU). Paratypes: China, Sichuan Province, Jiuzhaigou County, Jiuzhaigou, $2300 \mathrm{~m}$, 1.VIII.2011, (1 male, DPPHIST; 1 male, OPC)

Diagnosis. This new species belongs to the Hydropsyche newae cluster of the $H$. newae species group and similar to various species having only a pair of extrusible endothecal dorsal membrane with a single spine anterad of the phallotremal sclerites and a fused endothecal apical membranes, when fully expanded their apex tipped by a pair of few spicules, in reverted po- sition the small clump of spicules hardly discernible. The unique very high phallobase with produced dorsal hump has resemblance to $H$. nagpupos sp. nov. but differs by having blade-like harpago, more robust and patterned ventroapical setose lobes on segment X complex, broad and bellied apical half of the phallotheca and the phallic head not bilobed in ventral view.

Description. A medium sized species with forewing length of $11 \mathrm{~mm}$. Body and wing colour brown, forewing without any pattern.

Male genitalia. Abdominal segment IX fused annular, short; its median keel short and broad with granulose dorsal surface; anterior margin arciform, resulted in a very short ventrum and dorsum; apical lobe on posterolateral margin robust semicircular. Intersegmental depression between the ninth and tenth segments small rightangled in lateral view. Body of segment $\mathrm{X}$ broad rounded and short; lateral setose area (cerci) in deep ventroapical position; apicoventral setose lobe digitiform; dorsoapical setose lobe shifted back to basal region forming a fused pair of elongated setose area; the unsetose cavity on the anterolateral area of the segment discernible. The basal segment of the gonopod slightly sinuous, with dilated apical half; the terminal segment 


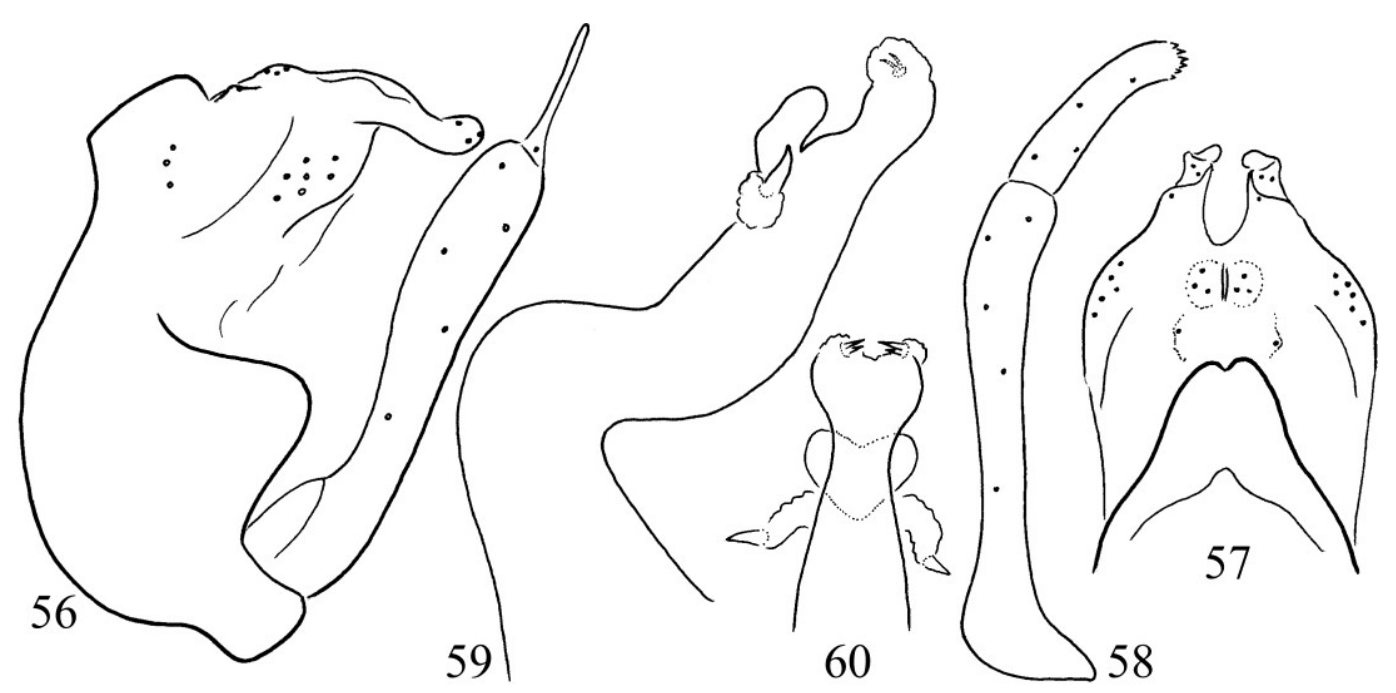

Figures 56-60. Hydropsyche keses sp. nov. Holotype. 56 = male genitalia in left lateral view, $57=$ male genitalia in dorsal view, $58=$ left gonopod in ventral view, $59=$ phallic organ in left lateral view, $60=$ phallic organ in ventral view.

blade-like, narrow in lateral and broad in ventral view. Phallic apparatus having large and high phallobase with produced dorsum; horizontal shaft of the phallotheca broad and bellied tube, the pair of the endothecal dorsal membrane anterad of the phallotremal sclerites armed with a single spine; the endothecal apical membranes fused; the phallotremal sclerite regular heartshaped in ventral view.

Etymology. keses from "késes" bearing knife blade in Hungarian, refers to the lateral profile of the harpago, narrow in lateral, but broad in ventral view due to the blade shape of the terminal gonopod segment.

\section{Hydropsyche nagpupos sp. nov.}

(Figures 61-65)

Material examined. Holotype: China, Taiwan, Hualien, Pi-lu, Sacred tree, 6.VI.2013, leg. Li Wenliang (1 male, CAU). Paratypes: same as Holotype (7 males, DPP-HIST; 6 males, OPC).

Diagnosis. This new species belongs to the Hydropsyche newae cluster of the $H$. newae species group and similar to various species having only a pair of extrusible endothecal dorsal membrane with a single spine anterad of the phallotremal sclerites and a pair of endothecal apical membranes, when fully expanded their apex tipped by a few spicules, in reverted position the small clump of spicules hardly discernible. The new species differs from all the known species by having unique phallobase with much produced dorsal hump.

Description. A medium sized species with forewing length of $11 \mathrm{~mm}$. Body and wing colour brown, forewing faintly dotted with light spots.

Male genitalia. Abdominal segment IX fused annular, short; its median keel short and broad with granulose dorsal surface; anterior margin arciform, resulted in a very short ventrum and dorsum; apical lobe on posterolateral margin robust semicircular. intersegmental depression between the ninth and tenth segments small rightangled in lateral view. Body of segment X broad rounded and short; lateral setose area (cerci) in deep ventroapical position; apicoventral setose lobe digitiform; dorsoapical setose lobe shifted back to basal region forming a fused pair of elongated setose area; the unsetose cavity on the anterolateral area of the segment discernible. The basal segment of the gonopod slightly sinuous, with dilated apical half; the terminal segment with abruptly narrowing apex. Phallic apparatus having large phallobase with uniquely produced dorsum; 


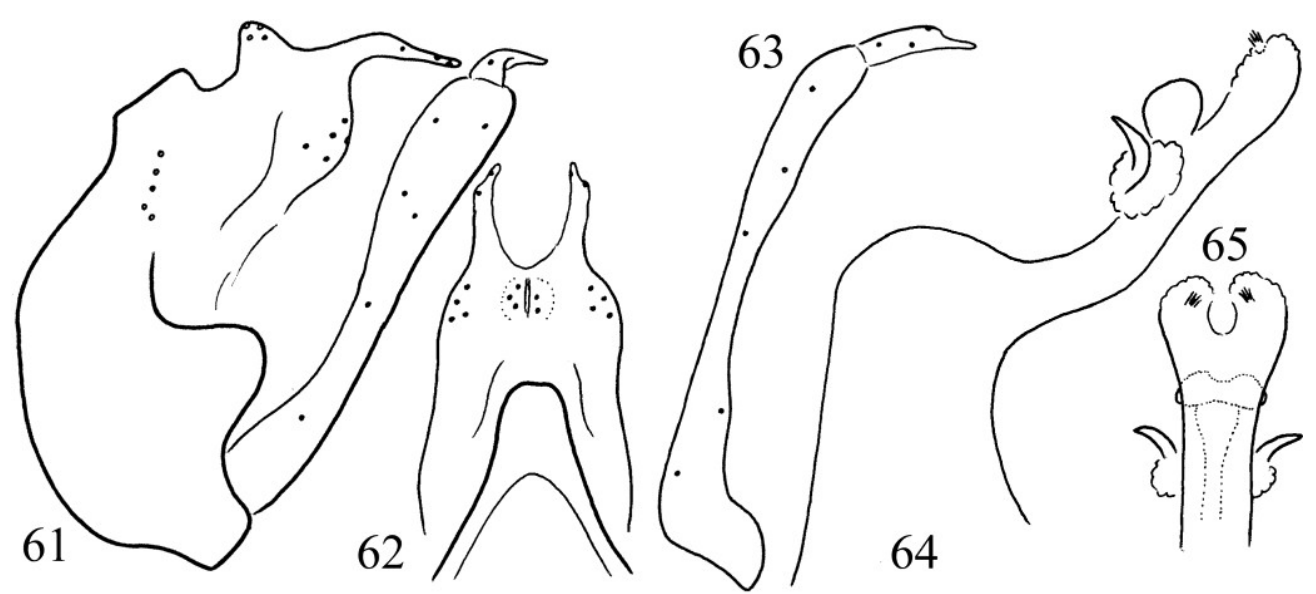

Figures 61-65. Hydropsyche nagpupos sp. nov. Holotype. $61=$ male genitalia in left lateral view, $62=$ male genitalia in dorsal view, 63 = left gonopod in ventral view, 64 = phallic organ in left lateral view, $65=$ phallic organ in ventral view.

horizontal shaft of the phallotheca narrow tube, the pair of the endothecal dorsal membrane anterad of the phallotremal sclerites armed with a single spine; the a pair of endothecal apical membranes with a group of 3-4 small spicules.

Etymology. nagpupos from "nagy púpos" large hump in Hungarian, refers to the lateral profile of the phallotheca having uniquely produced large hump on the dorsum of the phallobase.

\section{Hydropsyche nevoides Malicky \& Chantaramongkol, 2000}

Material examined. China, Henan Province, Song County, Mt. Funiu, Muzhaling, 19.VIII. 2012 (1 male, OPC). China, Henan Province, Xinxiang, Hui County, Guangshan, 800 m, 16.VII. 2008 (1 male, DPP-HIST).

\section{Hydropsyche newae Kolenati, 1858}

Material examined. China, Xinjiang Province, Buerjin, Hema Town, 10.VII.2016 leg. Tiang Yunlan (1 male, DPP-HIST).

\section{Hydropsyche vaza sp. nov.}

(Figures 66-70)

Material examined. Holotype: China, Guangxi Zhuang Autonomous Region, Shangsi County,
Shiwandashan Natural Forest Park, light trap on Yunwu Hotel balcony above Pearl River, N21 ${ }^{\circ}$ 54.316' E10754.203'， 295m, 26-29.III.2015 (/14), leg. J. Kontschán, J. N. Li, S. Li, W. H. Li, D. Murányi \& G. Q. Wang (1 male, OPC). Paratypes: same as Holotype (1 male, DPP-HIST).

Diagnosis. This new species belongs to the Hydropsyche newae cluster of the H. newae species group and similar to various species having only a pair of extrusible endothecal dorsal membrane with a single spine anterad of the phallotremal sclerites and a pair of endothecal apical membranes, when fully expanded their apex tipped by a few spines or spicules, in reverted position the spines discernible inside. The new species is most close to $H$. nevoides having almost identical periphallic organs, but differ by almost every structural units of the diverged phallic organ and easily delineated by the vaseshaped ventral profile of the apical half of the phallotheca.

Description. A medium sized species with forewing length of $10 \mathrm{~mm}$. Body and wing colour brown, forewing without any pattern of light spots.

Male genitalia. Abdominal segment IX fused annular, short; its median keel short and broad with granulose dorsal surface; anterior margin arciform, resulted in a very short ventrum and dorsum; apical lobe on posterolateral margin ro 


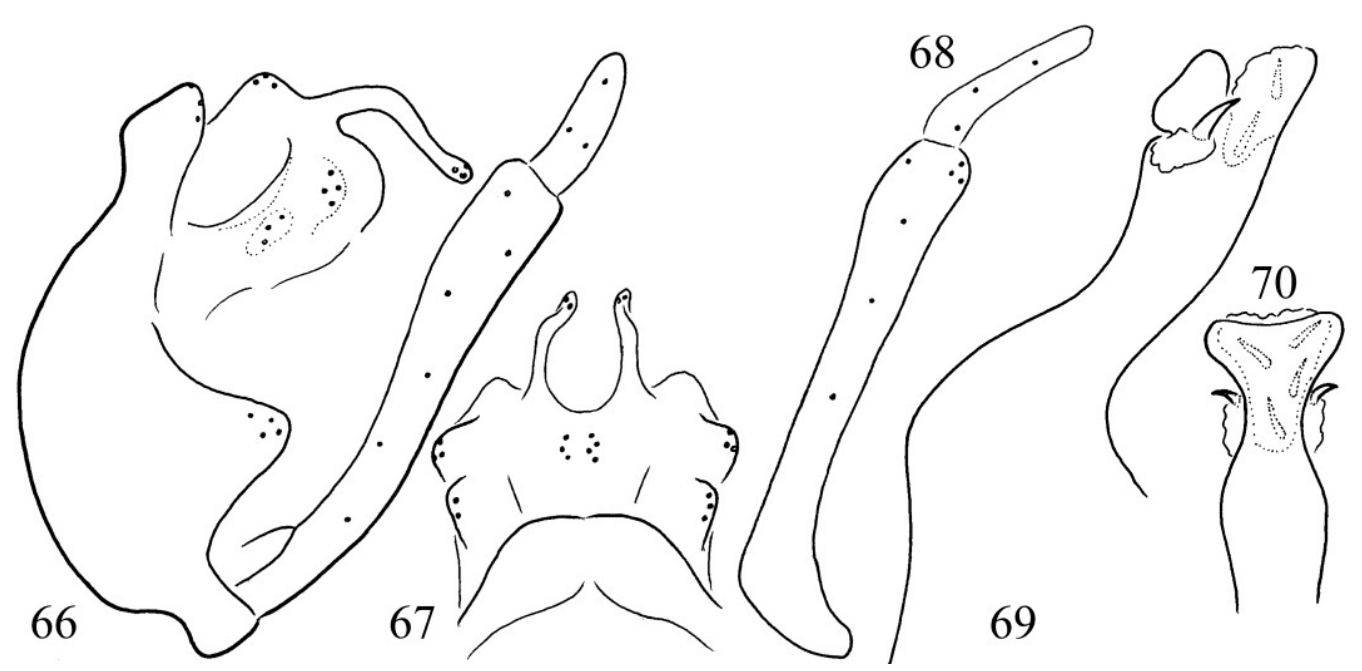

Figures 66-70. Hydropsyche vaza sp. nov. Holotype. $66=$ male genitalia in left lateral view, $67=$ male genitalia in dorsal view, $68=$ left gonopod in ventral view, $69=$ phallic organ in left lateral view, $70=$ phallic organ in ventral view.

bust triangular; intersegmental depression between the ninth and tenth segments sharp-angled in lateral view. Body of segment X broad and short, subquadrangular in dorsal view; lateral setose area (cerci) in deep ventral position; apicoventral setose lobe digitiform, downward turning; dorsoapical setose lobe shifted back to basal region forming a fused pair of triangular setose area; the unsetose cavity on the anterolateral area of the segment discernible. The basal segment of the gonopod slightly sinuous, with dilated apical half; the terminal segment almost parallel-sided. Phallic apparatus having large phallobase; horizontal shaft of the phallotheca narrower, the pair of the endothecal dorsal membrane anterad of the phallotremal sclerites armed with a single small spine; apical endothecal membranous eversible bag contains four medium-sized spines.

Etymology. vaza from "váza" flowerpot, flower vase in Hungarian, refers to ventral profile of the apical half of the phallotheca.

\section{Hydropsyche columnata species cluster}

\section{Hydropsyche columnata Martynov, 1931}

Material examined. China, Heibei, Xionglong, Dagoukum, 589 m, 11.VI.2014, leg. Li Xuankun (1 male, OPC).
Remarks. The pair of the endothecal dorsal membrane anterad of the phallotremal sclerites is rather slim, almost vestigial and the terminal spine is lacking. Moreover the lateral profile of the phallotheca is rather robust and differently bending. It may represent a diverged sibling of the $H$. columnata species. More specimens required to establish its real taxonomic position.

\section{Hydropsyche simulata species cluster}

\section{Hydropsyche camillus Malicky \& Chantaramongkol, 2000}

Material examined. China, Tibet, Muotuo, $80 \mathrm{~K} 1000 \mathrm{~m}$, 24.VII.2012, leg. Li Wenliang (1 males, DPP-HIST; 1 male, OPC).

Remarks. New species record for China! It was described from Thailand and recorded from Laos and Vietnam. It belongs to the Hydropsyche simulata species cluster of the Hydropsyche newae species group (Oláh \& Johanson 2008).

\section{Hydropsyche simulata Moselyi, 1942}

Material examined. China, Shaanxi Province, Yingpan, Niubeiliang, N33.7812 E108.8289, 1887 m, 29.VII.2014, leg. Tang Chufei (1 male, DPP-HIST). 
Remarks. The nominate species of the Hydropsyche simulata species cluster of the $H$. nevae species group (Oláh \& Johanson 2008).

\section{Hydropsyche spinata Kobayashi, 1987}

Material examined. China, Taiwan, Hualien, Pi-lu, Sacred tree, 6.VI.2013, leg. Li Wenliang (2 males, DPP-HIST).

Remarks. It belongs to the Hydropsyche simulata species cluster of the $H$. nevae species group (Oláh \& Johanson 2008).

\section{Hydropsyche penicillata new species complex}

Hydropsyche penicillata species complex is characterised by the following character combination: (1) The lateral profile of the phallic apparatus is dominated by an inverse U-shaped basal section of the phallotheca; (2) apicoventral setose lobe downward turning about middle; (3) the sclerotized apex of phallotheca, posterad of the phallotremal sclerite cylindrical with erectile apical membranous endothecal process with various spine pattern. Until a revision is realised we group the following species into this species complex: H. busiris, $H$. complicata, $H$. compressa, $H$. keska sp. nov., H. penicillata, H. tagra sp. nov., H. uvana.

\section{Hydropsyche penicillata Martynov, 1931}

Hydropsyche penicillata Martynov, 1931:8. "Basal joint of the inferior appendages long, somewhat thickened in its distal portion; second joint gradually tapering to its apex." The description of this character states that is the tapering shape of the harpago is clearly supported by the narrowing shape on the original drawings in all of the observational view: lateral, dorsal and ventral. The species was described on a single male from Sichuan.

Hydropsyche penicillata Schmid, 1965:137-138. "Je considère ces insects comme appurtenant à $H$. penicillata Mart. car les génitalia du $\sigma^{\widehat{T}}$ correspondent bien aux figures originales de Martynov. Il est vrai que ces dernières sont fort médiocres ce qui fait que cette opinion devra peut-être être revise plus tard." Misidentification!
Remarks. Schmid (1965) has examined a rather large series of specimens from Guangxi, Hunan, Shaanxi and Sichuan provinces. He has given complete drawings including phallic organ of the species, but unfortunately without indicating the locality of the drawn specimens. His drawings represent an unknown species: having parallel-sided not tapering harpago it is not $H$. penicillata, moreover the obtuse-angled phallotheca of the drawn species is a character state present in several member of the $H$. simulata species cluster, but the phallotheca is right-angled in the $H$. penicillata species complex.

\section{Hydropsyche keska sp. nov.}

(Figures 71-76)

Material examined. Holotype: China, Henan Province, Xinxiang, Hui County, Guangshan, 800 m, 15.VII.2008 (1 male, CAU). Paratypes: same as Holotype (3 males, DPP-HIST, 2 males, OPC).

Diagnosis. This new species belongs to the Hydropsyche penicillata species complex in the Hydropsyche simulata cluster of the $H$. newae species group. The profile of the phallic apparatus in this cluster is modified into an inverse Ushaped basal section of the phallotheca, forming double sinuate bends. The ring-shaped bend continues into the horizontal terminal section with a right angle, at least on the dorsum. The length of the bend is almost double of the horizontal terminal segment. This new species described from China (Henan, Hui County) is most close to $H$. tagra sp. nov described from China (Henan, Song County), but differs by having (1) gap present between the dorsal keel of segment IX and the dorsoapical setose lobe is very narrow (short); (2) dorsoapical setose lobe sloping anterad, not steep upward; (3) longer sclerotized cylindrical head of the phallotheca, (4) the pair of lateral membranous endothecal processes distad of the phallotremal sclerites without black spines, not tipped with three slender black spines.

Description. Redish brown species, forewing unicoloured, without pattern, forewing length 10 $\mathrm{mm}$. 


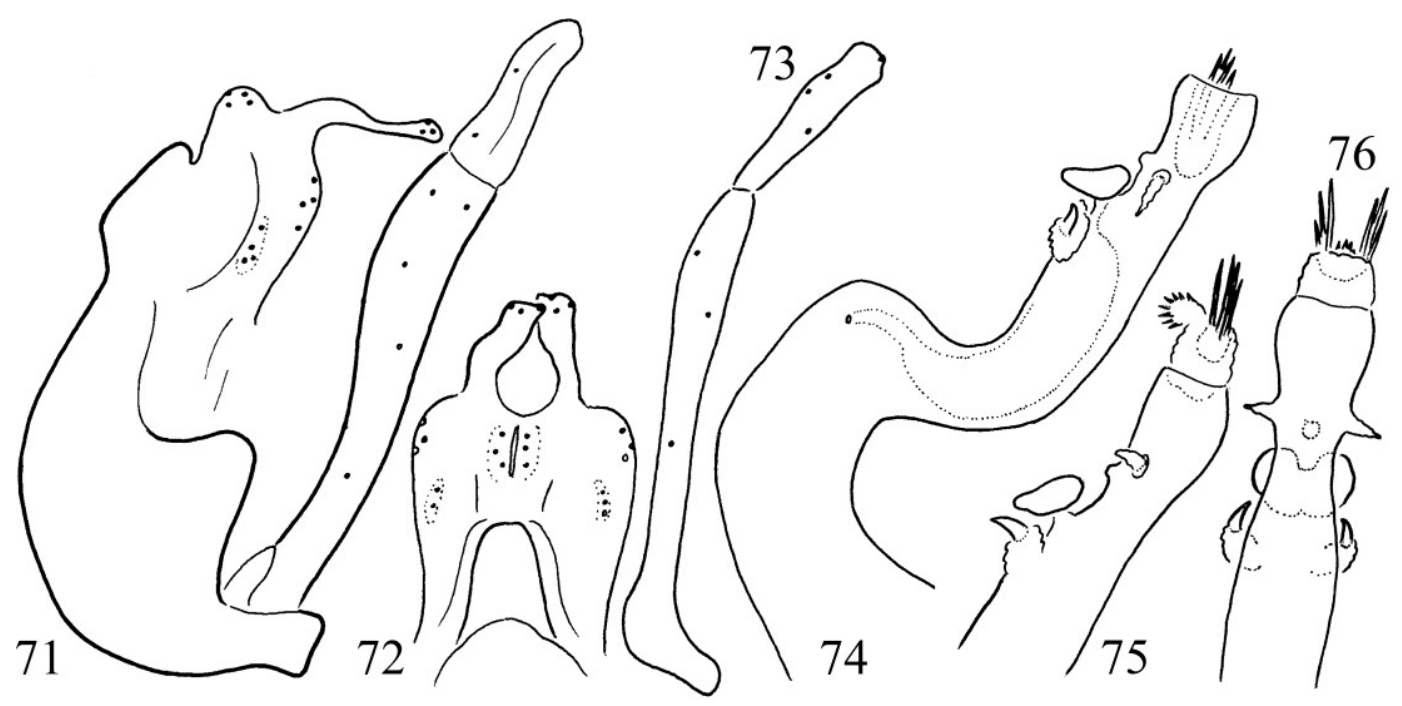

Figures 71-76. Hydropsyche keska sp. nov. Holotype. 71 = male genitalia in left lateral view, 72 = male genitalia in dorsal view, $73=$ left gonopod in ventral view, $74=$ phallic organ in left lateral view, $75=$ erected phallic organ in left lateral view, $76=$ erected phallic organ in ventral view.

Male genitalia. Abdominal segment IX fused annular, short; its median keel broad with granulose dorsal surface; anterior margin arciform, resulted in a very short ventrum and double longer dorsum; apical lobe on posterolateral margin robust rounded triangular, comprising the bulk of the segment; intersegmental depression between the ninth and tenth segments deep, narrow and bent anterad in lateral view. Body of segment $\mathrm{X}$ broad rounded slightly elongated; lateral setose area (cerci) in ventromesal position just below the setaless concavity; apicoventral setose lobe moved dorsad, longer than the body of segment $X$ narrow-based with downward directed apical half with broadening apex; dorsoapical setose lobe shifted back to basal region forming a fused pair of an upward produced large setose hump sloping anterad in lateral view; the unsetose cavity on the anterolateral area of the segment deep. The basal segment of the gonopods short robust and slightly sinuous dorsad, terminal segment, the harpago parallel-sided both in lateral and ventral view, with some broadening subapicad in ventral view; slightly S-forming in lateral view. Phallic apparatus double sinuate with right-angle, phallobase much higher than the apical horizontal shaft; phallotremal sclerites heavily pigmented pair of exposed reniform struc- ture; at these sclerites the tube narrowing, slightly constricted in the ventrum and followed by the cylindrical and truncate apex; the pair of dorsolateral endothecal processes just before the phallotremal sclerites short membranous tipped with a single curving small spine; the pair of lateral membranous endothecal processes distad of the phallotremal sclerites tipped with some tiny not sclerotized finger, single dorsal subapical pointed elevation present.

Etymology. keska from "keskeny" narrow in Hungarian, refers to the very narrow (short) gap present between the dorsal keel of segment IX and the dorsoapical setose lobe.

\section{Hydropsyche tagra sp. nov.}

(Figures 77-80)

Material examined. Holotype: China, Henan Province, Song County, Mt. Funiu, Muzhaling, 19.VIII.2012, leg. Weihai Li (1 male, CAU).

Diagnosis. This new species belongs to the Hydropsyche penicillata species complex in the Hydropsyche simulata cluster of the $H$. newae species group. The profile of the phallic apparatus in this cluster is modified into an inverse U- 


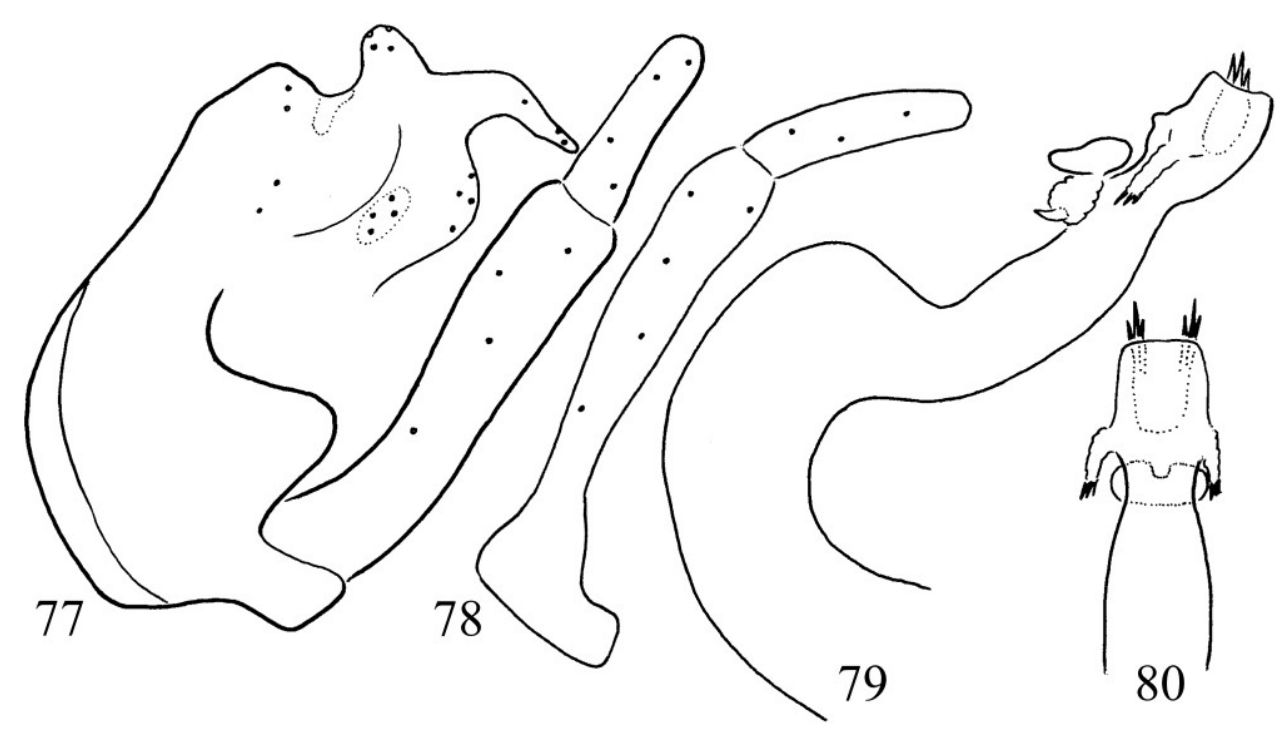

Figures 77-80. Hydropsyche tagra sp. nov. Holotype. 77 = male genitalia in left lateral view, $78=$ left gonopod in ventral view, $79=$ phallic organ in left lateral view, $80=$ phallic organ in ventral view.

shaped basal section of the phallotheca, forming double sinuate bends. The ring-shaped bend continues into the horizontal terminal section with a right angle, at least on the dorsum. The length of the bend is almost double of the horizontal terminal segment. This new species is most close to $H$. penicillata Martynov, 1931 described from China (Sichuan), but differs by having parallelsided harpago both in lateral, dorsal and ventral view, not tapering as drawn by Martynov in lateral, dorsal and ventral view. We have to emphasize that Martynov's drawings and shape explanations are proved to be extremely exact competing with many of our present day drawings and descriptions (Oláh et al. 2018). Remember that he was a contemporary of Navás and Banks whose drawings are incomparable because of their low resolution. Unfortunately Martynov has not cleared the genitalia therefore the lateral profile of the phallotheca is not drawn, not comparable to our new species. H. tagra has resemblance to $H$. busiris, but differs by the strongly upward directed dorsoapical setose lobe as well as in the fine structure of the phallic head: (1) the pair of dorsolateral endothecal processes just before the phallotremal sclerites short membranous and tipped with a single curving very short spine, not with long strong spine; (2) the pair of lateral membranous endothecal processes distad of the phallotremal sclerites tipped with three slender black spines, not without any black spines.

Schmid (1965) has identified Chinese specimens collected from Sichuan, Shaanxi, Guangxi and Hunan provinces under the name $H$. penicillata with declared uncertainty of their identity, emphasizing real need for a future revision. He has drawn the lateral shape of the complex of segment $X$ together with the ventroapical setose lobe from specimens collected in the four provinces; these drawings indicate significant shape divergences between the populations in the four provinces. It seems that Hydropsyche penicillata Martynov is a rather diverse species complex comprised of an unknown number of sibling incipient species differs by the speciation trait of the phallic organ. Schmid has recorded more shape stability in the structure of the phallic organ and drawn the lateral phallic profile only from a Sichuan population; his drawing of the lateral profile of the phallotheca from a population of Sichuan Province is markedly different from that of H. tagra sp. nov.

At our present knowledge the species identified by Schmid as H. penicillata from Sichuan, Shaanxi, Guangxi and Hunan provinces is not $H$. penicillata described from Sichuan by Martynov 
according at least to the parallel-sided harpago. Schmid complete drawings prepared from Sichuan population has an obtuse-angle between the basal and apical section of the phallotheca. $H$. tagra sp. nov. has clearly right-angled meeting and its harpago is not tapering like at $\mathrm{H}$. penicillata Martynov neither in lateral, dorsal or in ventral view.

Description. Light brown species, forewing unicoloured, without pattern, forewing length 10 $\mathrm{mm}$.

Male genitalia. Abdominal segment IX fused annular, short; its median keel broad with granulose dorsal surface; anterior margin arciform, resulted in a very short ventrum and double longer dorsum; apical lobe on posterolateral margin robust rounded triangular, comprising the bulk of the segment; intersegmental depression between the ninth and tenth segments deep obtuse angled in lateral view. Body of segment X broad rounded and short; lateral setose area (cerci) in mesal position below the setaless concavity; apicoventral setose lobe moved dorsad, shorter than the body of segment X, broad-based with downward directed apical half with tapering apex; dorsoapical setose lobe shifted back to basal region forming a fused pair of rounded upward produced large setose hump in lateral view; the unsetose cavity on the anterolateral area of the segment deep. The basal segment of the gonopods short robust and slightly sinuous dorsad, terminal segment, the harpago parallel-sided both in lateral and ventral view. Phallic apparatus double sinuate, phallobase much higher than the apical horizontal shaft; phallotremal sclerites heavily pigmented pair of exposed reniform structure; at these sclerites the tube narrowing, constricted in the ventrum and followed by the truncate apex; the pair of dorsolateral endothecal processes just before the phallotremal sclerites short membranous tipped with a single curving very short spine; the pair of lateral membranous endothecal processes distad of the phallotremal sclerites tipped with three slender spines.

Etymology. tagra from "tágra" widened in Hungarian, refers to the very wide gap present between the dorsal keel of segment IX and the dorsoapical setose lobe.

\section{Hydropsyche serpentina species cluster}

\section{Hydropsyche laposhat sp. nov.}

(Figures 81-83)

Material examined. Holotype: China, Shaanxi, Yang County, Huanyang Town, Wangjiagou, $\mathrm{N} 33^{\circ} 19 ' 33^{\prime}$ "68E107 $57^{\circ} 21$ "43, 453.2m, light trap, 11.V.2017, Liu Haoyu (1 male, CAU).

Diagnosis. This new species belongs to the Hydropsyche serpentina clade of the $H$. newae species group. The profile of the phallic apparatus in this clade is modified into a ring-shaped basal section of the phallotheca, forming double sinuate bends. The ring-shaped bend continues into the horizontal terminal section with a right angle, at least on the dorsum. The length of the bend is almost double of the horizontal terminal segment. This new species is a sibling of H. homunculus Schmid, 1965 described from China (Zhejiang), but differs by the lateral profile of the phallotheca, that is the speciation trait, having the dorsum of the basal ring flat, not produced upward like at $H$. homunculus. The pair of dorsolateral process before the phallotremal sclerites short, not long.

Description. Male genitalia. Abdominal segment IX fused annular, short; its median keel short and broad with granulose dorsal surface; anterior margin arciform, resulted in a very short ventrum and short but double longer dorsum; apical lobe on posterolateral margin robust semicircular, comprising the bulk of the segment; intersegmental depression between the ninth and tenth segments small triangular in lateral view. Body of segment $\mathrm{X}$ broad rounded and short; lateral setose area (cerci) in deep ventral position; apicoventral setose lobe moved dorsad, shorter than the body of segment X; dorsoapical setose lobe shifted back to basal region forming a fused pair of elongated setose area; the unsetose cavity on the anterolateral area of the segment very deep. The basal segment of the gonopods short robust and slightly sinuous, terminal long with slightly 


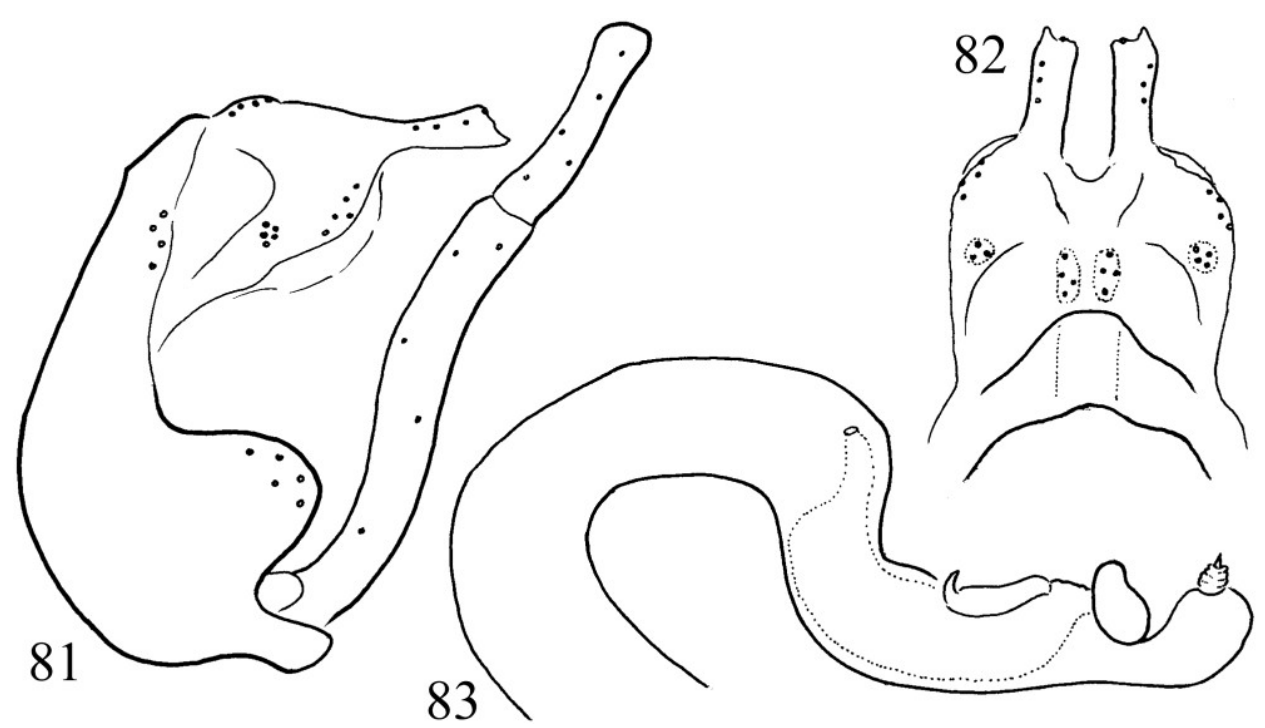

Figures 81-83. Hydropsyche laposhat sp. nov. Holotype. 81 = male genitalia in left lateral view, 82 = male genitalia in dorsal view, 83 = phallic organ in left lateral view.

dilated apex. Phallic apparatus double sinuate, forming a long tube of the same diameter along its whole length, up to the heavily pigmented pair of exposed reniform phallotremal sclerites; at these sclerites the tube narrowing, strongly constricted in ventral view and followed by the sclerotized ventral phallothecal lobe with two windows for membranous protuberances tipped with fine spine; the pair of dorsolateral processes just before the phallotremal sclerites is sclerotized, not membranous tipped with a single curving spine.

Etymology. laposhat from "lapos hát" flat dorsum in Hungarian, refers to the dorsal profile of the basal ring of the phallotheca compared to the upward produced hump-shaped profile of his sibling.

\section{Hydropsyche picibunk sp. nov.}

(Figures 84-88)

Material examined. Holotype: China, Shaanxi Province, Hanzhong city, Foping county, Qinling Mts. bank of Ziwu River in Foping old town, 890 m, N3331.366', E10759.012' 19.IV.2018(/1), leg. W. H. Li, R. R. Mo \& D. Murányi (1 male, OPC).
Diagnosis. This new species belongs to the Hydropsyche serpentina clade of the $H$. newae species group. The profile of the phallic apparatus in this clade is modified into a ring-shaped basal section of the phallotheca, forming double sinuate bends. The ring-shaped bend continues into the horizontal terminal section with a right angle, at least on the dorsum. The length of the bend is almost double of the horizontal terminal segment. This new species is most close to $H$. boreas described from Thailand, but differs by having capitate tip of harpago and the head of the phallotheca upward directed in lateral view and transversally widened in ventral view; pair of phallotremal sclerites differently shaped both in lateral and ventral view; moreover there is no any sclerotized structures developed below the phallotremal sclerites.

Description. Yellowish light brown species, forewing unicoloured, without pattern, forewing length $11 \mathrm{~mm}$.

Male genitalia. Abdominal segment IX fused annular, short; its median keel narrow elongated in dorsal view with granulose dorsal surface; anterior margin arciform, resulted in a very short ventrum and double longer dorsum; apical lobe on 


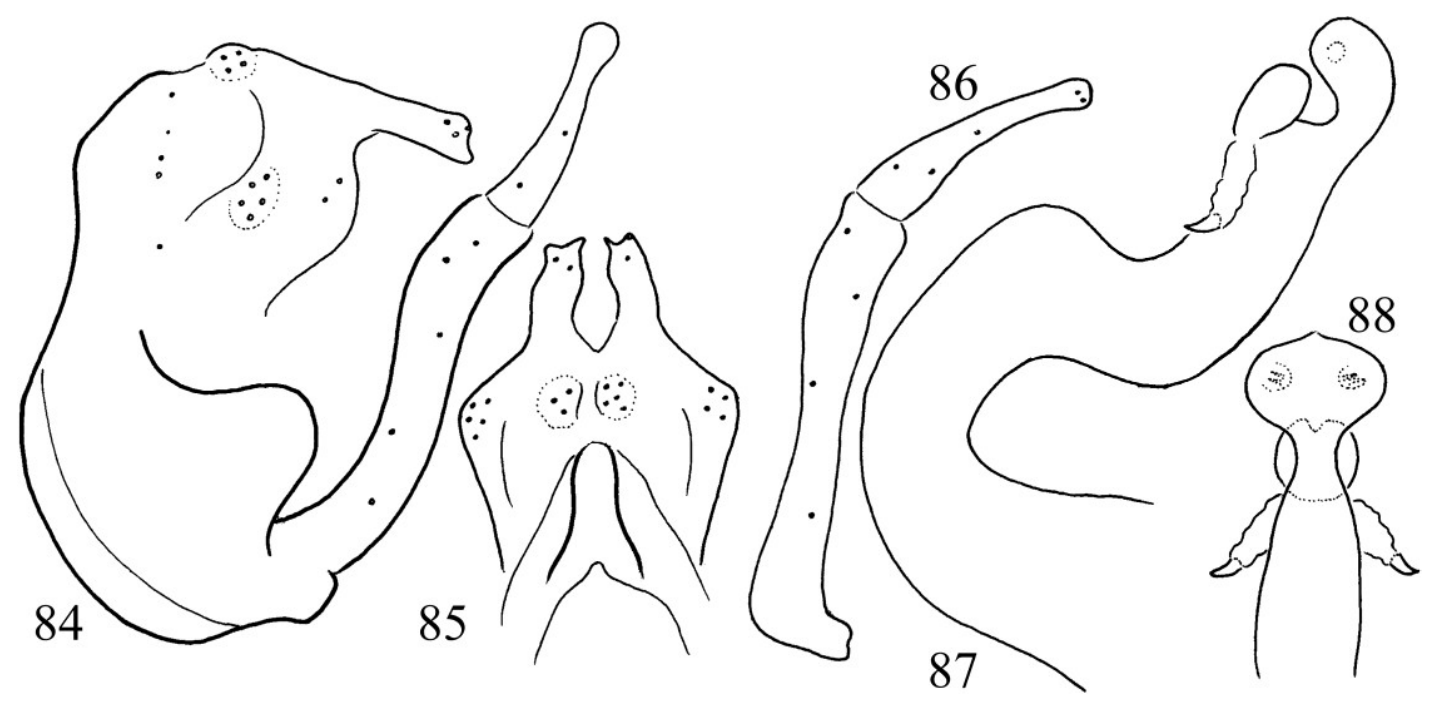

Figures 84-88. Hydropsyche picibunk sp. nov. Holotype. 84 = male genitalia in left lateral view, $85=$ male genitalia in dorsal view, 86 = left gonopod in ventral view, 87 = phallic organ in left lateral view, $88=$ phallic organ in ventral view.

posterolateral margin robust semicircular, comprising the bulk of the segment; intersegmental depression between the ninth and tenth segments disappeared in lateral view. Body of segment $\mathrm{X}$ broad rounded and short; lateral setose area (cerci) in mesal position; apicoventral setose lobe moved dorsad, shorter than the body of segment $\mathrm{X}$; dorsoapical setose lobe shifted back to basal region forming a fused pair of rounded setose area; the unsetose cavity on the anterolateral area of the segment very deep. The basal segment of the gonopods short robust and slightly sinuous, terminal segment, the harpago long with capitate apex. Phallic apparatus double sinuate, forming a long tube of the same diameter along its whole length, up to the heavily pigmented pair of exposed reniform phallotremal sclerites; at these sclerites the tube narrowing, strongly constricted in ventral view and followed by the upward turning short and robust apex of the phallotheca having flattened circular shape in ventral view; the pair of dorsolateral processes just before the phallotremal sclerites membranous tipped with a single curving spine.

Etymology. picibunk from "pici bunkós" small capitate in Hungarian, refers to very tip of the harpago with small, but distinct capitate apex.

\section{Hydropsyche formosana species group}

\section{Hydropsyche formosana Ulmer, 1911}

Material examined. China, Taiwan, Nantuo, Lienhauchih Research Centre, 5.VI.20132, leg. Li Wenliang (1 male, DPP-HIST).

Remarks. The nominate species of the $H$. formosana species group (Oláh \& Johanson 2008).

\section{Hydropsyche orectis Mey, 1999}

Material examined. China, Tibet, Muotuo, $1100 \mathrm{~m}, 26$. VII.2012, leg. Li Wenliang (12 males, DPP-HIST, 19 males, OPC).

Remarks. It belongs to the $H$. formosana species group (Oláh \& Johanson 2008)

\section{Hydropsyche pluvialis species group}

\section{Hydropsyche pluvialis species cluster}

\section{Hydropsyche lelapa sp. nov.}

(Figures 89-93)

Material examined. Holotype: China, Sichuan, Tangjia He Nature Reserve, 1700 m, leg. J. Oláh jr., 10-11.VI.2001 (1 male, OPC). 


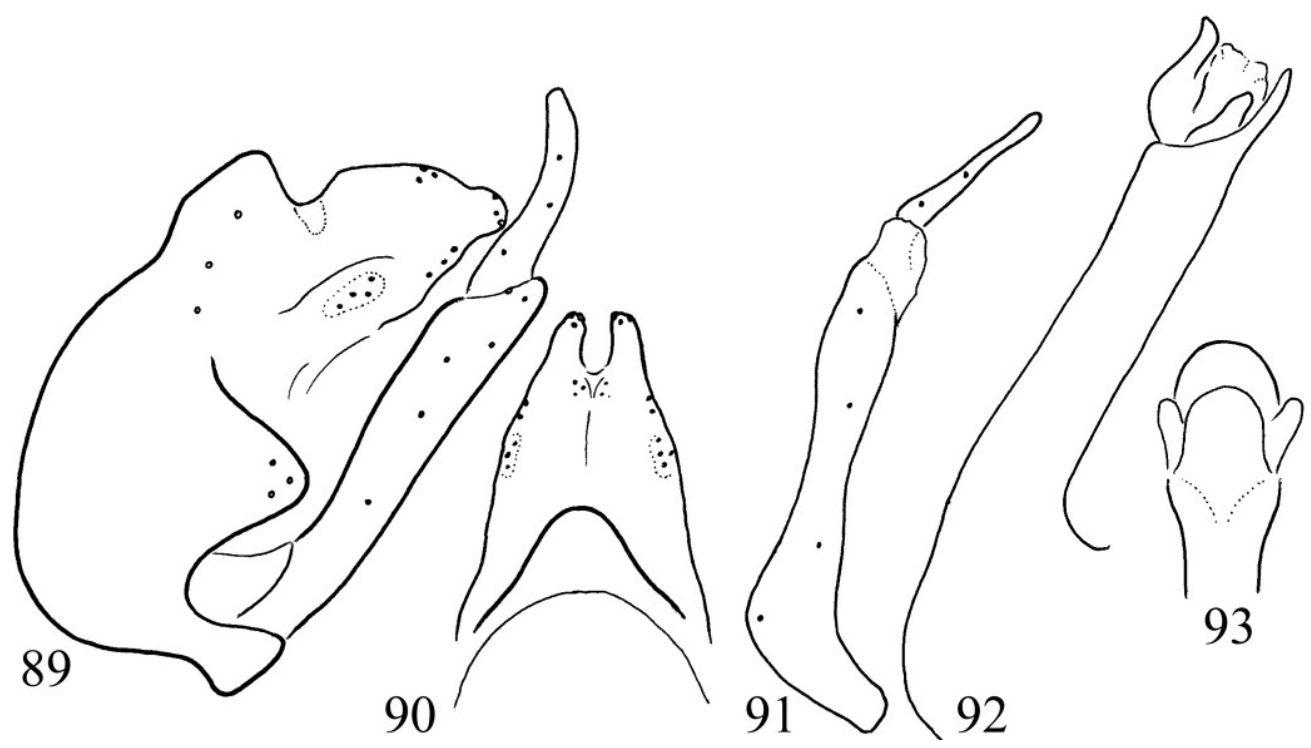

Figures 89-93. Hydropsyche lelapa sp. nov. Holotype. $89=$ male genitalia in left lateral view, $90=$ male genitalia in dorsal view, 91 = left gonopod in ventral view, 92 = phallic organ in left lateral view, 93 = phallic organ in ventral view.

Diagnosis. This new species belongs to the Hydropsyche pluvialis species cluster of the $H$. pluvialis species group. It is most close to $H$. camael described from China (Sichuan), but differs by having flat and fused elongated dorsoapical setose lobes setosed only on very posterad, not hump-like, bipartite and not setosed anterad; ventroapical setose lobes short and blunt, not pointed in dorsal view; harpago slender narrow, not broad in ventral view; endothecal sclerites longer and markedly produced laterad; the phallotremal sclerites fused rounded, not bipartite.

Description. A medium sized species with forewing length of $12 \mathrm{~mm}$. Body and wing colour brown, forewing uniform, without any pattern.

Male genitalia. Abdominal segment IX fused annular, short; its median keel short and broad with granulose dorsal surface; anterior margin arciform, resulted in a very short ventrum and little longer dorsum; apical lobe on posterolateral margin robust rounded subtriangular; intersegmental depression between the ninth and tenth segments deep, right-angled in lateral view. The complex body of segment $\mathrm{X}$ rounded and elongated; lateral setose area (cerci) in deep ventral position; apicoventral setose short with setose head; dorsoapical setose hump on segment $\mathrm{X}$ less produced, elongated, flat surface in lateral view; the unsetose cavity on the anterolateral area of the segment discernible. The basal segment of the gonopod straight; the terminal segments narrow slender especially in ventral view. Phallic apparatus having very low phallobase, the horizontal shaft of the phallotheca regular tube; pair of endothecal sclerite discernible laterad as short, blunt sclerotized structure, produced obliquely laterad; trough-like phallotremal sclerites with fused ventrum and rimmed laterally.

Etymology. lelapa euphemic coining from "lelapult, lelapított" flattened in Hungarian, refers to the rather flat and elongated dorsoapical setose lobes on segment $X$.

\section{Hydropsyche nulanka sp. nov.}

(Figures 94-98)

Material examined. Holotype: China, Henan Province, Song County, Mt. Funiu, Muzhaling, 19.VIII.2012 (1 male, CAU). Paratype: China, Gansu, Wen County, Bikou, Yaochangping, 845 m, 30.VII.2011 (1 male, DPP-HIST).

Diagnosis. This new species, having the apicodorsal setose process located far from the 


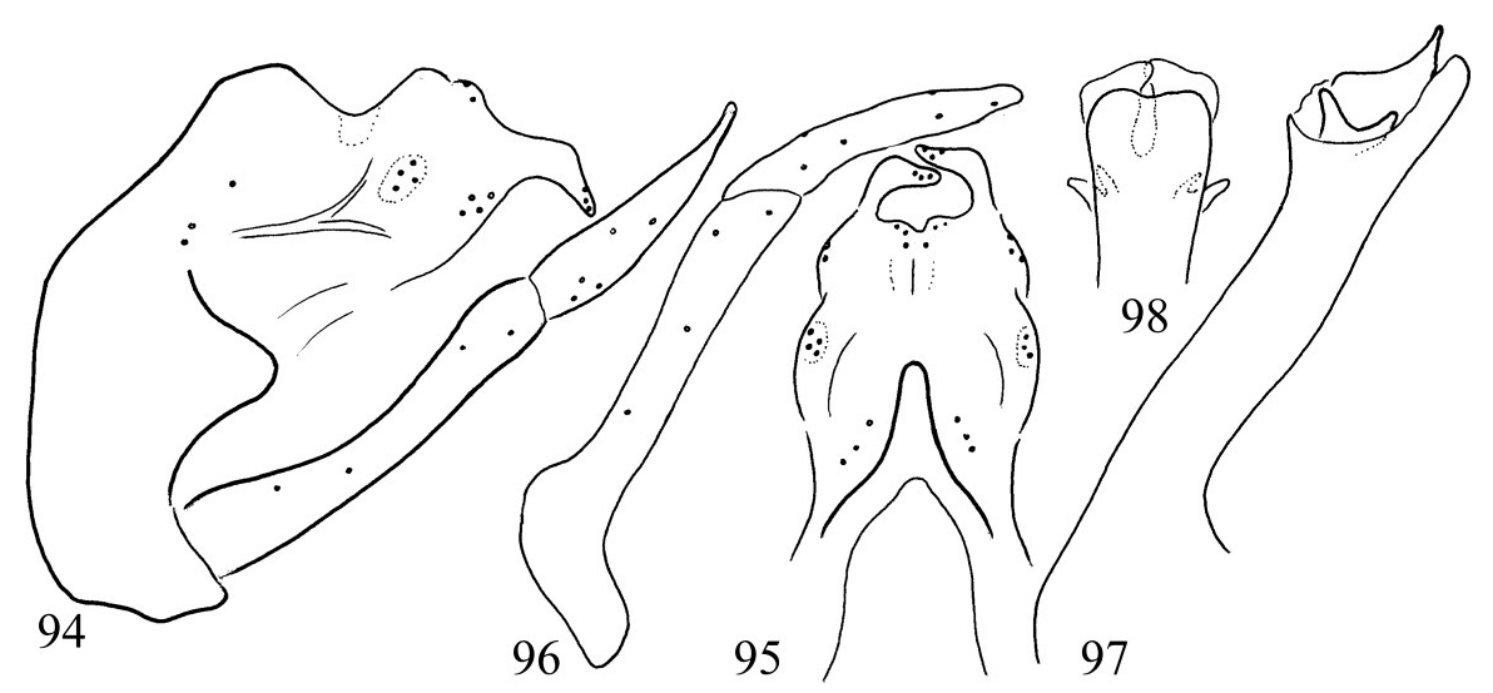

Figures 94-98. Hydropsyche nulanka sp. nov. Holotype. $94=$ male genitalia in left lateral view, $95=$ male genitalia in dorsal view, 96 = left gonopod in ventral view, 97 = phallic organ in left lateral view, $98=$ phallic organ in ventral view.

median keel of segment IX, belongs to the Hydropsyche pluvialis species clade of the $H$. pluvialis species group. It differs from all the described species by having harpago elongated as well as the pair of ventroapical setose lobe much elongated and its apical half downward directed. This structural development organised by modular genetic complex irregularly appears in other Hydropsyche species groups and clades as a result of holonic chimerism.

The new species resembles $H$. grahami Banks, 1940 but the shape of both of its dorsoapical and ventroapical setose lobes differs as well as the harpago is longer. Malicky and Chantaramongkol (2000) have drawn a specimen from Zhejiang Province under the name of $H$. grahami, but this drawn species has short and tapering harpago both in lateral and ventral view. $H$. grahami was characterized in the original species description with fairly long harpago that is not tapering, but the tip is forked in ventral view. Based upon their drawing of Zhejiang specimen they have extended the taxonomic status of $H$. grahami also to specimens from Sichuan and Henan provinces. The taxonomic status of $H$. grahami was extended with synonymy by Tian et al. (1996) to H. hoenei Schmid, 1959, a species with rather unique phallic organ described from China (Yunnan province). These taxonomic acts of lumpers are not based on comparative examination of type specimens, are not based on fine phenomics of speciation traits, and are not searching and concentrating on differences. Rather, lumpers are looking for similarities and highly underestimate biodiversity and neglect the most sensitive incipient species, the most efficient and effective local agents finely specialized to function as basic autonomous components in the energy flow and mineral cycling of local ecosystems (Oláh et al. 2019). It is very probable that Hydropsyche grahami is a rather large species complex characterized by the elongated ventroapical setose lobes of the complex of segment X. Hydropsyche nulanka sp. nov. belongs to this complex.

Description. A medium sized species with forewing length of $10 \mathrm{~mm}$. Body and wing colour yellowish light brown, forewing uniform, without any pattern.

Male genitalia. Abdominal segment IX fused annular, short; its median keel short and narrowing with granulose dorsal surface; anterior margin arciform, resulted in a very short ventrum and little longer dorsum; apical lobe on posterolateral margin rounded subtriangular; intersegmental depression between the ninth and tenth segments shallow, obtuse angled in lateral view. The complex body of segment $\mathrm{X}$ broad rounded and long; lateral setose area (cerci) in middle po- 
sition; apicoventral setose lobe elongated break down middle with narrowing head; dorsoapical setose hump on segment $\mathrm{X}$ produced elongated; the unsetose cavity on the anterolateral area of the segment discernible. The basal segment of the gonopod slightly sinuous dorsad, without dilated apex; the extremely elongated terminal segments tapering in lateral and broad in ventral view. Phallic apparatus having low phallobase, the horizontal shaft of the phallotheca almost parallelsided tube; pair of bilobed endothecal sclerite discernible laterad as strongly sclerotized structure; a pair of horizontally enlarged plate-like phallotremal sclerites discernible free, not fused and not forming a trough-like structure.

Etymology. nulanka from "nyúlánk" slender elongated in Hungarian, refers to the elongated ventroapical setose lobes, to the uniquely elongated harpago.

\section{Hydropsyche rhomboana species cluster}

\section{Hydropsyche kispupos sp. nov.}

(Figures 99-102)

Material examined. Holotype: China, Shaanxi, Qinling, Zhou Zhi, Houzhenzi, 1278 m, 16.VIII. 2014, leg. Lu Xiumei (1 male, CAU). Paratype: China, Shaanxi, Zhouzhi, Qinling, Laoxiancheng, 2057 m, 19.VIII.2014, leg. Li Xuankun (1 male, DPP-HIST).

Diagnosis. This new species belongs to the Hydropsyche rhomboana species cluster of the $H$. pluvialis species group. It is most close to $H$. rhomboana and $H$. nepalarawa, but differs by the following character combination: (1) dark brown forewing without any pattern; (2) broad, slightly bilobed dorsal keel on tergite IX; (3) deep intersegmental depression between segments IX and X; (4) high and long dorsoapical setose hump; (5) parallel-sided harpago in ventral view; (6) shape of the trough-like phallotremal sclerites with fused ventrum and rimmed laterally.

Description. A medium sized species with forewing length of $12 \mathrm{~mm}$. Body and wing colour dark brown, forewing uniform, without any pattern.

Male genitalia. Abdominal segment IX fused annular, short; its median keel short and broad with granulose dorsal surface, slightly bilobed; anterior margin arciform, resulted in a very short ventrum and little longer dorsum; apical lobe on posterolateral margin robust rounded subtriangular; intersegmental depression between the ninth and tenth segments shallow, right-angled in lateral view. The complex body of segment $\mathrm{X}$ broad rounded and long; lateral setose area (cerci) in deep ventroapical position; apicoventral setose lobe break down middle with patterned head; dorsoapical setose hump on segment $\mathrm{X}$ less produced accompanied with a less distinct pair of hump basolaterad; the unsetose cavity on the anterolateral area of the segment discernible. The basal segment of the gonopod slightly sinuous dorsad, with dilated apical half; the terminal segments narrow in lateral, broad in ventral view. Phallic apparatus having very high phallobase, the horizontal shaft of the phallotheca broad bellied tube; pair of endothecal sclerite discernible laterad as short, blunt sclerotized structure; trough-like phallotremal sclerites with fused ventrum and rimmed laterally.

Etymology. kispupos from "kis púpos" small hump in Hungarian, refers to the high and long rounded dorsoapical setose area, lobe or crest on segment X, distad of transversal suture absent on Cheumatopsyche, but present frequently on Hydropsyche as a setose winglet, paired or fused setose dorsal crest. This may represent the doubled epiproct of segment XI.

\section{Hydropsyche rhomboana Martynov, 1909}

Material examined. China, Tibet, Muotuo, $80 \mathrm{~K} 1000 \mathrm{~m}$, 24.VII.2012, leg. Li Wenliang (1 male, DPP-HIST; 1 male, OPC). China, Yunnan Province, Gongshan, Dulongjiangi, $1542 \mathrm{~m}$, 1.VII.2013, leg. Zhang Wei (1 male, DPP-HIST; 1 male, OPC).

Remarks. It belongs to and the nominate species of the Hydropsyche rhomboana species cluster of the Hydropsyche pluvialis species group (Oláh \& Johanson 2008). 


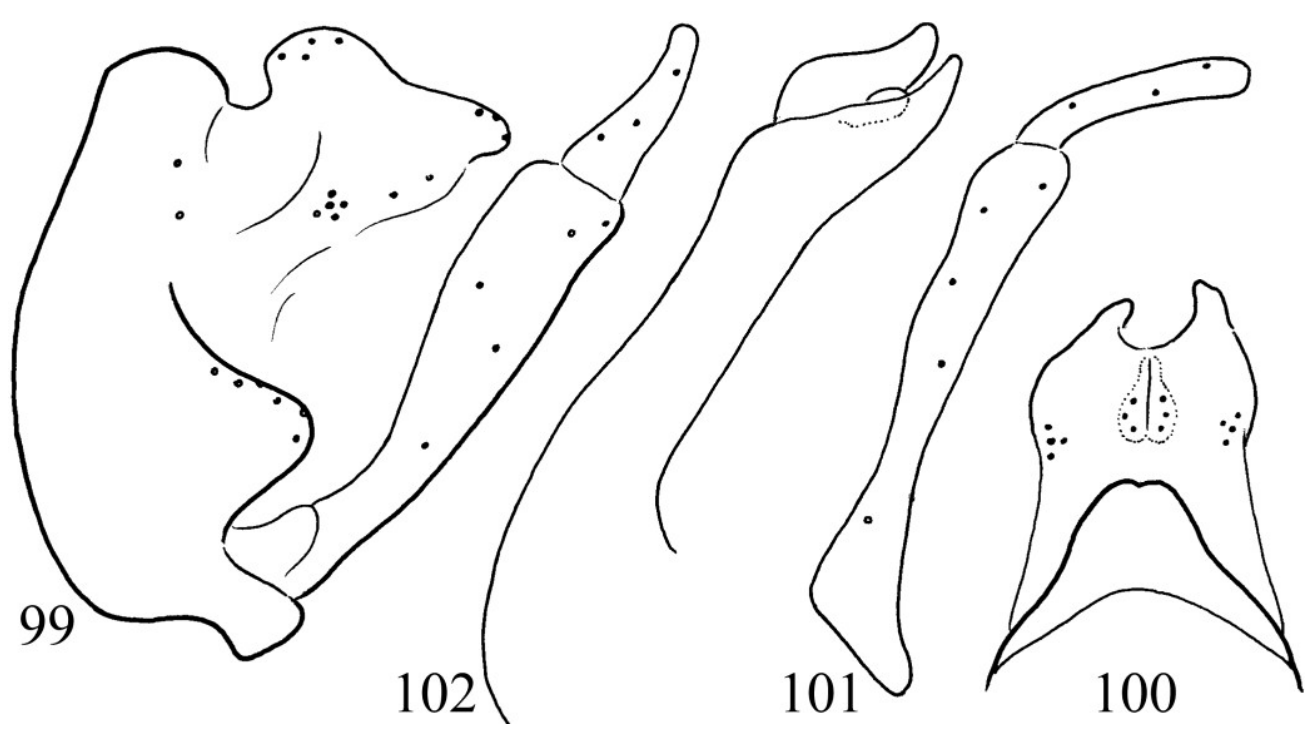

Figures 99-102. Hydropsyche kispupos sp. nov. Holotype. 99 = male genitalia in left lateral view, $100=$ male genitalia in dorsal view, 101 = left gonopod in ventral view, 102 = phallic organ in left lateral view.

\section{Hydropsyche asiatica species group}

\section{Hydropsyche aiakos Malicky, 1997}

Material examined. China, Tibet, Beibengxiang, $700 \mathrm{~m}, 30$. VII.2012, leg. Li Wenliang (1 male, DPP-HIST, 2 males, OPC).

Remarks. New species record for China! A member of Hydropsyche asiatica specie group described from Nepal and recorded from India (Oláh \& Johanson 2008).

\section{Hydropsyche angustipennis species group \\ Hydropsyche pellucidula species cluster}

\section{Hydropsyche lehajla sp. nov.}

(Figures 103-107)

Material examined. Holotype: China, Inner Mongolia, Bayin, Mt Helan, Halawu, 2260 m, 12.VIII.2011 (1 male, CAU). Paratypes: China, Inner Mongolia, Bayin, Mt Helan, Shuimogou, $2260 \mathrm{~m}, 9$.VIII.2011 (8 males, 6 probably associated females, DPP-HIST; 15 males, 3 probably associated females, OPC). China, Neimeng- gu, Helanshan, Halawugou, 2370 m, 4.VII.2014, leg. Shili (16 males, DPP-HIST; 2 males, OPC).

Diagnosis. Belongs to the Holarctic Hydropsyche angustipennis species group and to the Hydropsyche pellucidula species clade of Oláh \& Johanson (2008). Close to Hydropsyche pellucidula but differs by the lateral profile of the phallic apex, more rounded, less narrowed as well as more downward directed. Moreover, there is divergence in some neutral traits that is in the development of the pair of the setaless distal winglet attached to the dorsoapical setose lobe as visible both in lateral and dorsal view; it is very much produced at the new species.

Description. Male (in alcohol). Body yellowish light brown, dorsal thoracic sclerites darker. Wings ochraceous with lighter pubescence, without pronounced pattern. Forewing length $12 \mathrm{~mm}$.

Male genitalia. Segment IX fused annular and short; its median keel narrowing apicad with granulose dorsal surface, this narrow keel representing the entire dorsum of segment IX shifted posterad; apical lobe on posterolateral margin rounded triangular. Intersegmental profile be- 


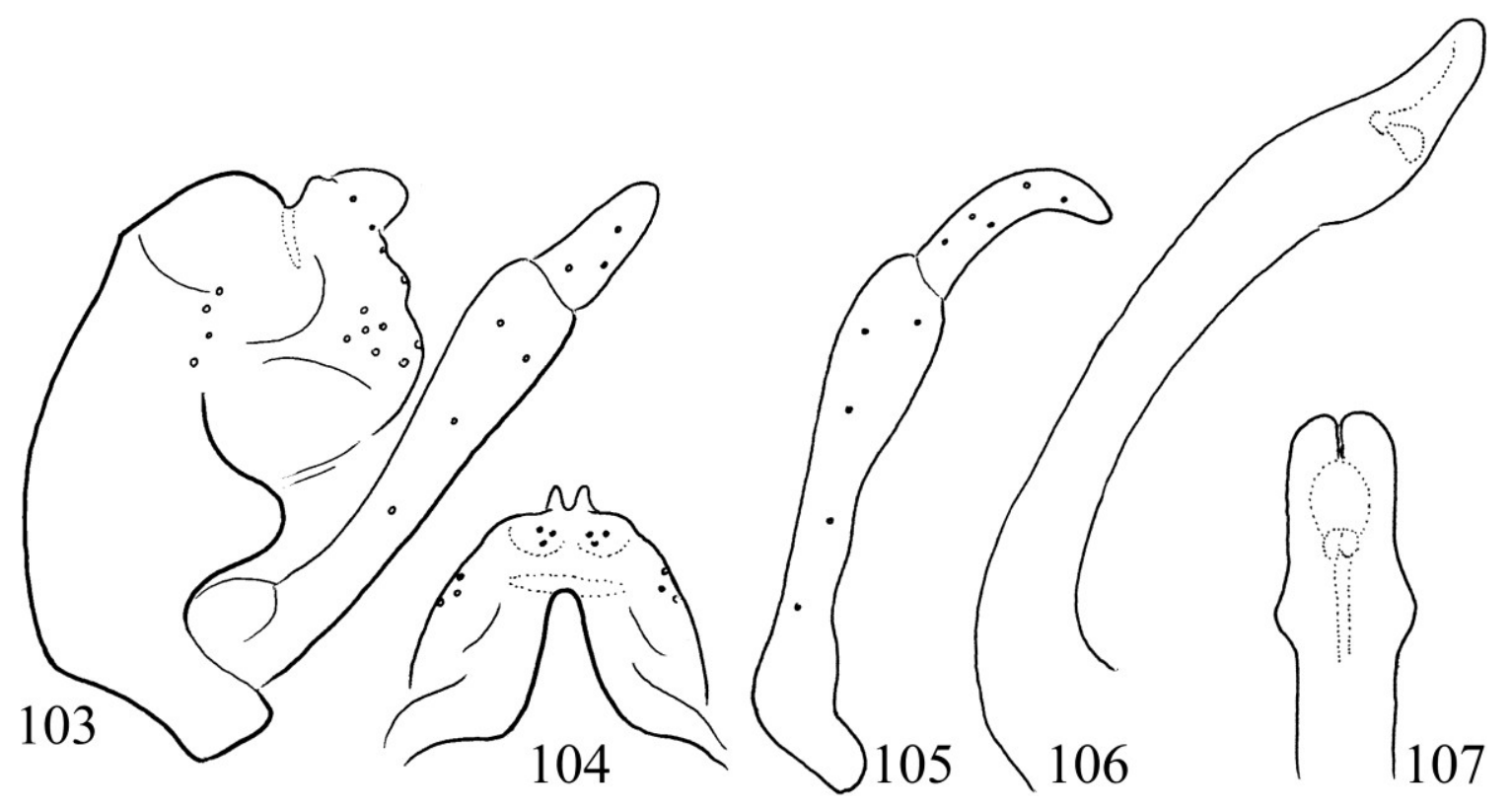

Figures 103-107. Hydropsyche lehajla sp. nov. Holotype. $103=$ male genitalia in left lateral view, $104=$ male genitalia in dorsal view, $105=$ left gonopod in ventral view, $106=$ phallic organ in left lateral view, $107=$ phallic organ in ventral view.

tween the ninth and tenth segments deep, acutely angled. Segment X short, with produced setaless winglets in lateral view and semicircular in dorsal view; lateral setose area, the cerci circular and located in apical position; very short and rounded ventroapical and dorsoapical setose lobes forming the apicomarginal profile of segment $\mathrm{X}$ in lateral view. The coxopodit of the gonopod as long as the apex of segment $X$, harpago parallel-sided and mesad curving in ventral view. Phallic organ with downward bending apex and rounded tip in lateral view; the phallic head parallel-sided in ventral view apicad of the subapical lateral projection.

Etymology. lehajla, from "lahajló", bent downward in Hungarian, refers to the phallic head with a pronounced downward bending shape in lateral view.

\section{Cheumatopsyche genus}

\section{Cheumatopsyche lepida species group}

\section{Cheumatopsyche acantha Sun, Yang \& Morse, 2011}

Material examined. China, Guangxi Zhuang Autonomous Region, Shangsi County, Shiwand- ashan Natural Forest Park, light trap above the confluence of Pinglong River and Minan River, $\mathrm{N} 21^{\circ} 51.929^{\prime} \mathrm{E} 107^{\circ} 50.675^{\prime}, 315 \mathrm{~m}, 28 . \mathrm{III} .2015$ (/21), leg. J. Kontschán, J. N. Li, S. Li, W. H. Li, D. Murányi \& G. Q. Wang (37 males, DPP-HIST; 53 male, OPC).

\section{Cheumatopsyche chihonana Kobayashi, 1987}

Material examined. China, Taiwan, Taoyuan, Fuxing, 10.VI.2013, leg. Li Wenliand (1 male, DPP-HIST; 1 male, OPC).

\section{Cheumatopsyche infascia species complex}

This species complex in the Cheumatopsyche lepida species group is characterized by the straight dorsal profile of the apicoventral setose lobes and by the small dorsoapical interlobular gap on the complex of segment X. The common, abundant and "widely distributed and highly varying" nominal species of Cheumatopsyche infascia exhibits real difficulties to delineate exactly form its incipient sibling species. In alcohol the faintly spotted forewing is not discernible. The pair of setose apicoventral lobes, this sensitive structure in the reproductive isola- 
tion of copulatory processes, is particularly liable to significant shape modification either by artefact produced during preparatory treatments or by deformations created during biological functioning of reproductive mechanisms. The dorsal interlobular gap is flexible and reduced easily by the movable setose lobes and the lobes themselves change their shape by transversal and sagittal movements. Here we have described nine new species distinguished mostly by the fine structure of the bilobed apex of segment $\mathrm{X}$ that is by the shape divergences in the formation of the apicoventral setose lobes: $C$. bujkala sp. nov. C. domborula sp. nov., C. forrta sp. nov., C. kiugra sp. n., C. lepa sp. nov., C. magaska sp. nov., $C$. perem sp. nov., C. rovides sp. nov., $C$. sikoska $\mathrm{sp}$. nov. We have redrawn the nominate species $C$. infascia Martynov, 1934 recorded from China for the first time.

Based upon this limited survey it seems that this is an extremely diverse species complex of recent divergences and probably represented by large number of unknown incipient sibling species. In the present depressed state of taxonomy there is no real potential to discover and to describe its biodiversity. Widespread population sampling and studies on the fine phenomics of the most important speciation traits on segment $\mathrm{X}$ combined with the latero-perpendicular and ventro-perpendicular profile of the harpago would be required to understand the contemporary divergences of this environmentally sensitive taxa.

\section{Cheumatopsyche bujkala sp. nov.}

(Figures 108-111)

Material examined. Holotype: China, Fujian Province, Wuyishan, Sangang, 740 m, 9.V.2004, leg. Liu Xingyue (1 male, CAU).

Diagnosis. This new species having setose bilobed segment $\mathrm{X}$ that is the ventroapical pair of setose lobes and elongated setaless apicomesal lobe belongs to the Cheumatopsyche infacia species complex in the C. lepida species group (Oláh et al. 2008). It has resemblance to $C$. magaska sp. nov. but differs by differently shaped phallotheca, larger sclerotized endothecal process and by having the ventroapical setose lobes with rounded apical margin, not truncated as well as the harpago clearly broad based both in lateral and ventral view and narrowing abruptly from the middle.

Description. A uniformly brown coloured species without any discernible spotting; forewing length $6 \mathrm{~mm}$.

Male ganitalia. Abdominal segment IX fused annular, short; anterior margin arciform, resulted in a very short dorsum and short but double longer ventrum; apical margin is straight vertical marked with a row of strong spines; intersegmental depression between the ninth and tenth segments deep and step-wise in lateral view. Body of segment $X$ low in lateral view, somehow elongated; lateral setose area (cerci) in subapical middle position; apicoventral setose lobes mesad turned, adhering each other and to the apicomesal setaless lobe; smooth apicomesal lobe less produced small semicircular in dorsal view. The basal segment of the gonopods straight dilated slightly apicad; harpago, the terminals segment broad based and tapering abruptly from middle both in lateral and ventral view. Phallic apparatus with broad phallobase, phallothecal shaft narrowing, endothecal processes large ovoid, almost double higher than the constricted phallothecal tube.

Etymology. bujkala from "bújkáló" in Hungarian, refers to the ventroapical setose lobes on segment $\mathrm{X}$ having attached tightly to each other and to the setaless smooth mesocaudal lobe.

\section{Cheumatopsyche domborula sp. nov.}

(Figures 112-115)

Material examined. Holotype: China, Yunnan Province, Zhaotong, Erxicun, 25.IV.2014, leg. Lu Xiumei (1 male, CAU).

Diagnosis. This new species having setose bilobed segment $\mathrm{X}$ that is the ventroapical pair of setose lobes and elongated setaless apicomesal lobe belongs to the Cheumatopsyche infacia species complex in the C. lepida species group 


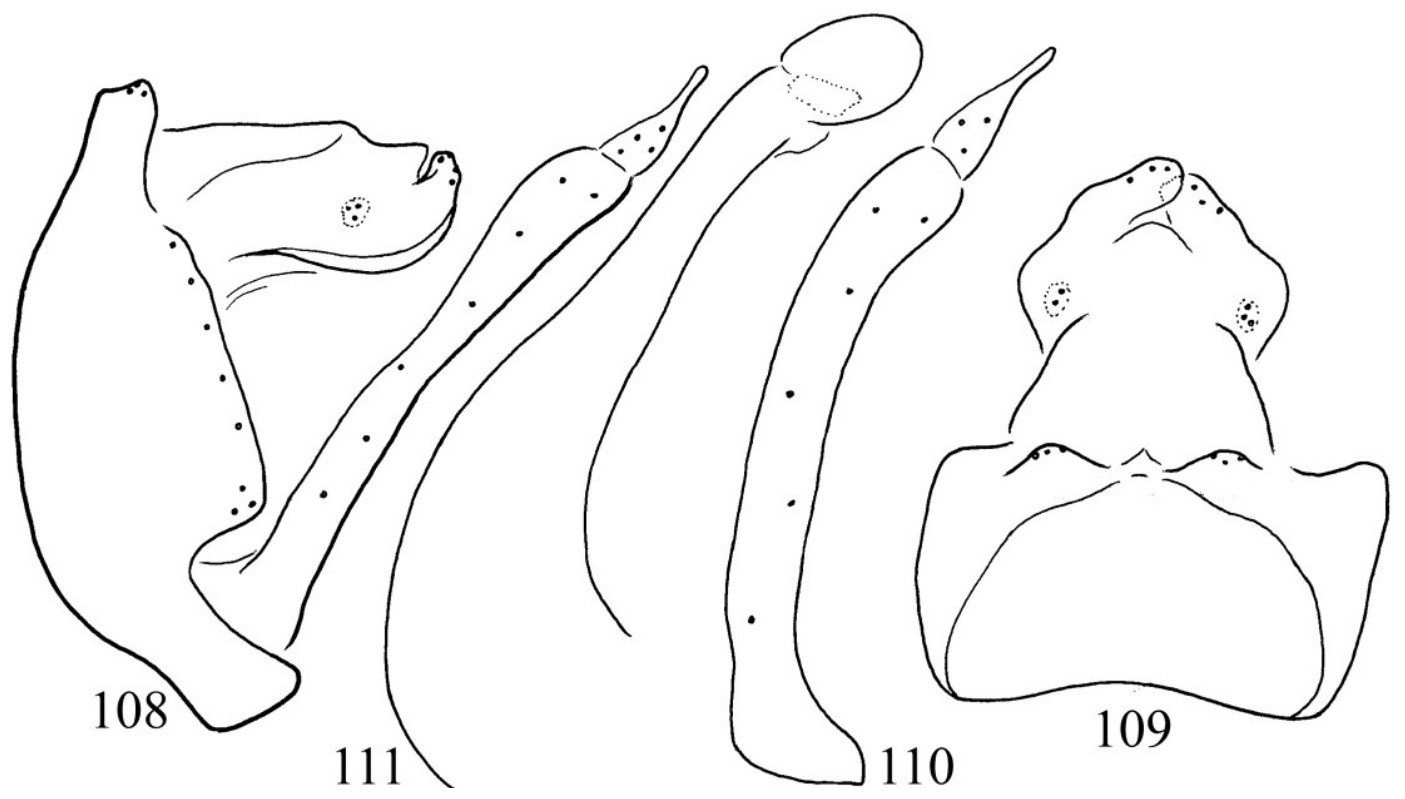

Figures 108-111. Cheumatopsyche bujkala sp. nov. Holotype. $108=$ male genitalia in left lateral view, $109=$ male genitalia in dorsal view, 110 = left gonopod in ventral view, 111 = phallic organ in left lateral view.

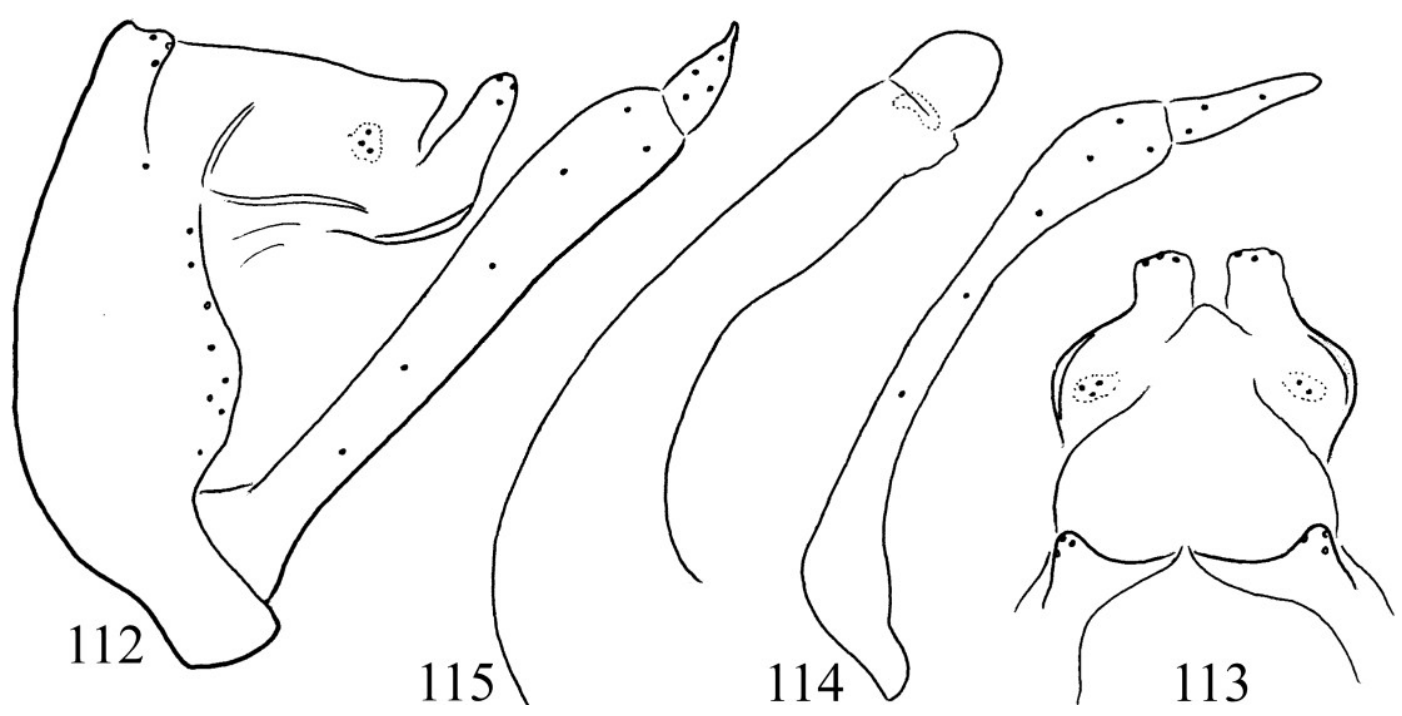

Figures 112-115. Cheumatopsyche domborula sp. nov. Holotype. $112=$ male genitalia in left lateral view, $113=$ male genitalia in dorsal view, $114=$ left gonopod in ventral view, $115=$ phallic organ in left lateral view.

(Oláh et al. 2008). According to the enforced horizontal suture present on the lateral edges of segment $\mathrm{X}$ this uniform brown species is most close to C. kiugra sp. nov. and C. perem sp. nov., but differ by having the heavily sclerotized enforcement of different pattern; moreover the apical ending, the head of the ventroapical setose lobes differs, as well as the latero-perpendicular profile of cerci broad slandering digitiform at the very tip; papering apruptly from the middle at $C$. perem sp. nov. and tapering gradually from the base at $C$. kiugra sp. nov.

Description. A uniformly brown coloured small species (in alcohol) without any discernible light spots on forewing, forewing length $6 \mathrm{~mm}$. 
Male ganitalia. Abdominal segment IX fused annular, short; anterior margin arciform, resulted in a very short dorsum and little longer ventrum; apical margin is almost straight vertical, marked with a row of strong spines; intersegmental depression between the ninth and tenth segments very shallow in lateral view. Body of segment $X$ longer than high; lateral setose area (cerci) in subapical middle position; apicoventral setose lobe straight with truncate apex; smooth apicomesal lobe small and triangular in dorsal view. The basal segment of the gonopods with regular straight ventrum and dorsum, slightly dilated apicad; harpago, the terminals segment broad up to subapicad with slender digitiform tip. Phallic apparatus arching horizontal, endothecal processes rounded.

Etymology. domborula from "domboruló" bulging in Hungarian, refers to the heavily sclerotized laterad protruded and rounded ending of the heavily sclerotized horizontal suture on the lateral edges of the ventrum of segment X.

\section{Cheumatopsyche forrta sp. nov.}

(Figures 116-119)

Material examined. Holotype: China, Yunnan Province, Gongshan, Dulongjiang, $1542 \mathrm{~m}, 1$.VII. 2013, leg. Zhang Wei (1 male, CAU). Paratype: same as Holotype (1 male, OPC).

Diagnosis. This new species having setose bilobed segment $X$ that is the ventroapical pair of setose lobes and elongated setaless apicomesal lobe belongs to the Cheumatopsyche infacia species complex in the $C$. lepida species group (Oláh et al. 2008). A unique species in the complex having the pair of dorsocaudal spiny lobes fused forming together a single mesal dorsocaudal spiny pointed triangular structure. This fused structure occurs in several species of the $C$. concava species group indicating the chimeric nature of taxa.

Description. A uniformly brown coloured small species (in alcohol) without any discernible light spots on forewing, forewing length $6 \mathrm{~mm}$.

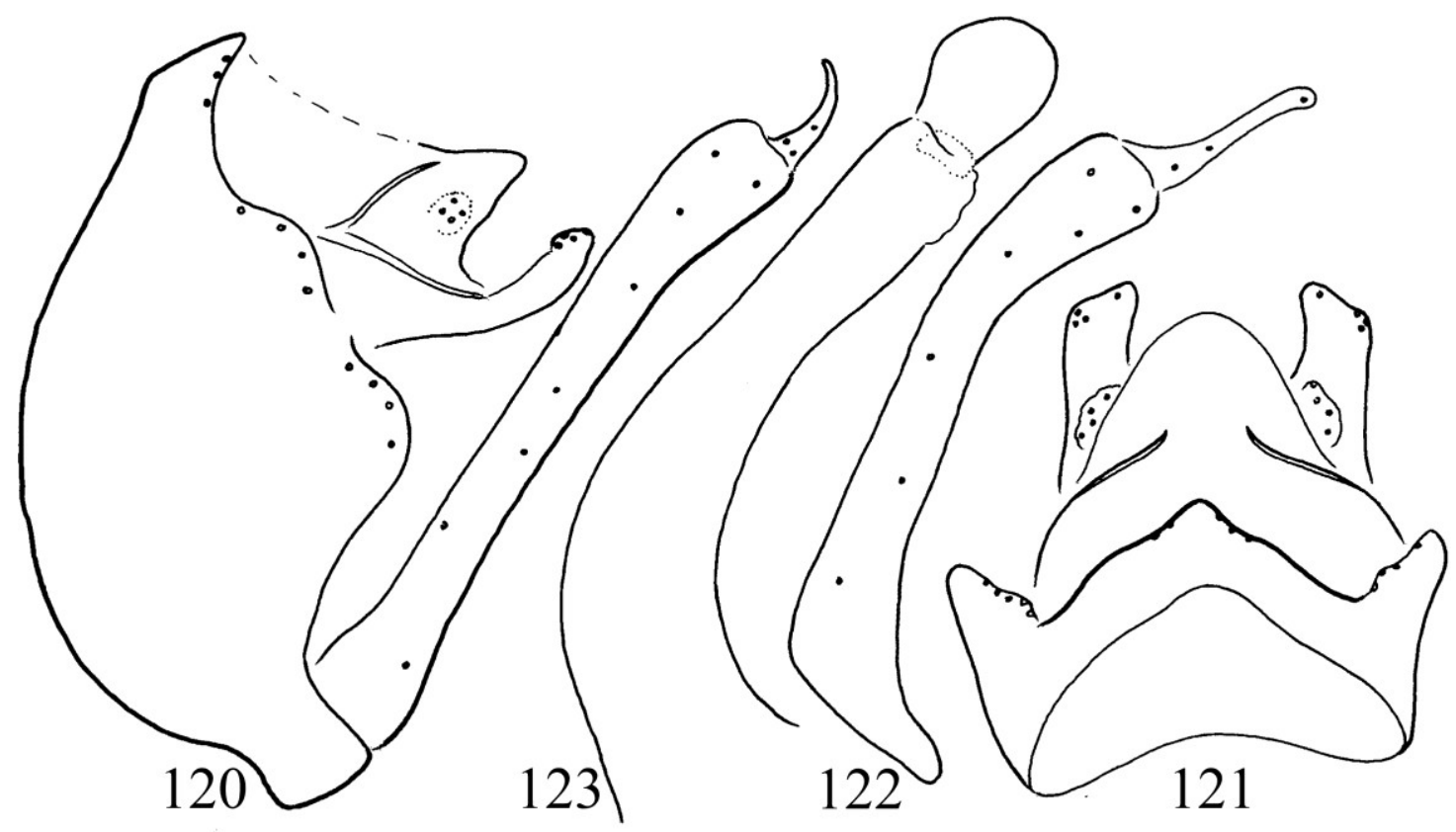

Figures 116-119. Cheumatopsyche forrta sp. nov. Holotype. $116=$ male genitalia in left lateral view, $117=$ male genitalia in dorsal view, $118=$ left gonopod in ventral view, $119=$ phallic organ in left lateral view. 
Male ganitalia. Abdominal segment IX fused annular, short; anterior margin arciform, resulted in a very short dorsum and little longer ventrum; apical margin double convex, marked with a row of strong spines; the pair of dorsocaudal spiny lobes fused and moved mesad; intersegmental depression between the ninth and tenth segments very shallow in lateral view. Body of segment $X$ longer than high; its basal half is less pigmented; lateral setose area (cerci) in subapical middle position; apicoventral setose lobe straight with truncate and mesad turning apex; smooth apicomesal lobe highly produced and rounded in dorsal view. The basal segment of the gonopods with regular straight ventrum and dorsum, slightly dilated apicad; harpago, the terminals segment slender digitiform. Phallic apparatus arching horizontal, endothecal processes large and rounded.

Etymology. forrta from "forrt, összeforrorott, összeforrt" fused, coalescent in Hungarian, refers to the fused dorsocaudal spiny lobes located generally on the apicolateral corners of tergum IX..

\section{Cheumatopsyche infascia Martynov, 1934}

(Figures 120-123)

Material examined. China, Shaanxi Province, Hanzhong city, Foping county, Qinling Mts. bank of Ziwu River in Foping old town, $890 \mathrm{~m}$, N33 ${ }^{\circ} 31.366^{\prime} \mathrm{E}^{2} 07^{\circ} 59.012^{\prime} 19 . \mathrm{IV} .2018(/ 1)$, leg. W. H. Li, R. R. Mo \& D. Murányi (3 males, DPPHIST, 2 males, OPC). China, Heibei, Xionglong, Dagoukum, 589 m, 11.VI.2014, leg. Tang Chifei (10 males, DPP-HIST, 10 males, OPC). China, Heibei, Xionglong, Dagoukum, 589m, 11.VI. 2014, leg. Ding Shuangmei (6 males, DPP-HIST, 4 males, OPC). China, Heibei, Xionglong, Dagoukum, 589 m, 11.VI.2014, leg. Li Xuankun (18 males, DPP-HIST, 10 males, OPC). China, Henan Province, Song County, Mt. Funiu, Muzhaling, 19.VIII.2012 (7 males, OPC). China, Henan Province, Xinxiang, Hui County, Guangshan, 800 m, 16.VII.2008 (1 male, DPP-HIST).

Remarks. New species record for China! Cheumatopsyche infascia was described from Russia (Ussuriland) with slightly spotted fore- wings. According to the present limited sampling it seems that this species is one of the most abundant Cheumatopsyche species in Shaanxi, Heibei and Henan provinces of China. The pair of apicoventral setose lobes on segment $\mathrm{X}$ is rounded, capitate in dorsal view, not truncate like at $C$. sikoska sp. nov. or not with a stepwise stair laterad like at C. lepa sp. nov. In the original description Martynov's drawings represent the dry condition of the apicoventral setose lobes, slightly deformed, especially their lateral profiles in dorsal view.

\section{Cheumatopsyche kiugra sp. nov.}

(Figures 124-127)

Material examined. Holotype: China, Guangxi Zhuang Autonomous Region, Shangsi County, Shiwandashan Natural Forest Park, light trap on Yunwu Hotel balcony above Pearl River, N2154.316', E10754.203', $295 \mathrm{~m}$, 26-29.III. 2015(/14), leg. J. Kontschán, J. N. Li, S. Li, W. H. Li, D. Murányi \& G. Q. Wang (1 male, OPC).

Diagnosis. This new species having setose bilobed segment $\mathrm{X}$ that is the ventroapical pair of setose lobes and elongated setaless apicomesal lobe belongs to the Cheumatopsyche infacia species complex in the $C$. lepida species group (Oláh et al. 2008). According to the structure of segment $\mathrm{X}$ and the phallic organ this uniform brown species is most close to Cheumatopsyche perem, but differ by having tapering, not blunt apex of the ventroapical setose lobes in dorsal view; by the heavily sclerotized laterad protruded ending of the sclerotized horizontal suture on the lateral edges of the ventrum of segment X; by the differently shaped harpago, more slender and gradually tapering in lateral view; by the longer endothecal sclerite.

Description. A uniformly brown coloured small species (in alcohol) without any discernible light spots on forewing, forewing length $6 \mathrm{~mm}$.

Male ganitalia. Abdominal segment IX fused annular, short; anterior margin arciform, resulted in a very short dorsum and little longer ventrum; apical margin is straight vertical, marked with a 


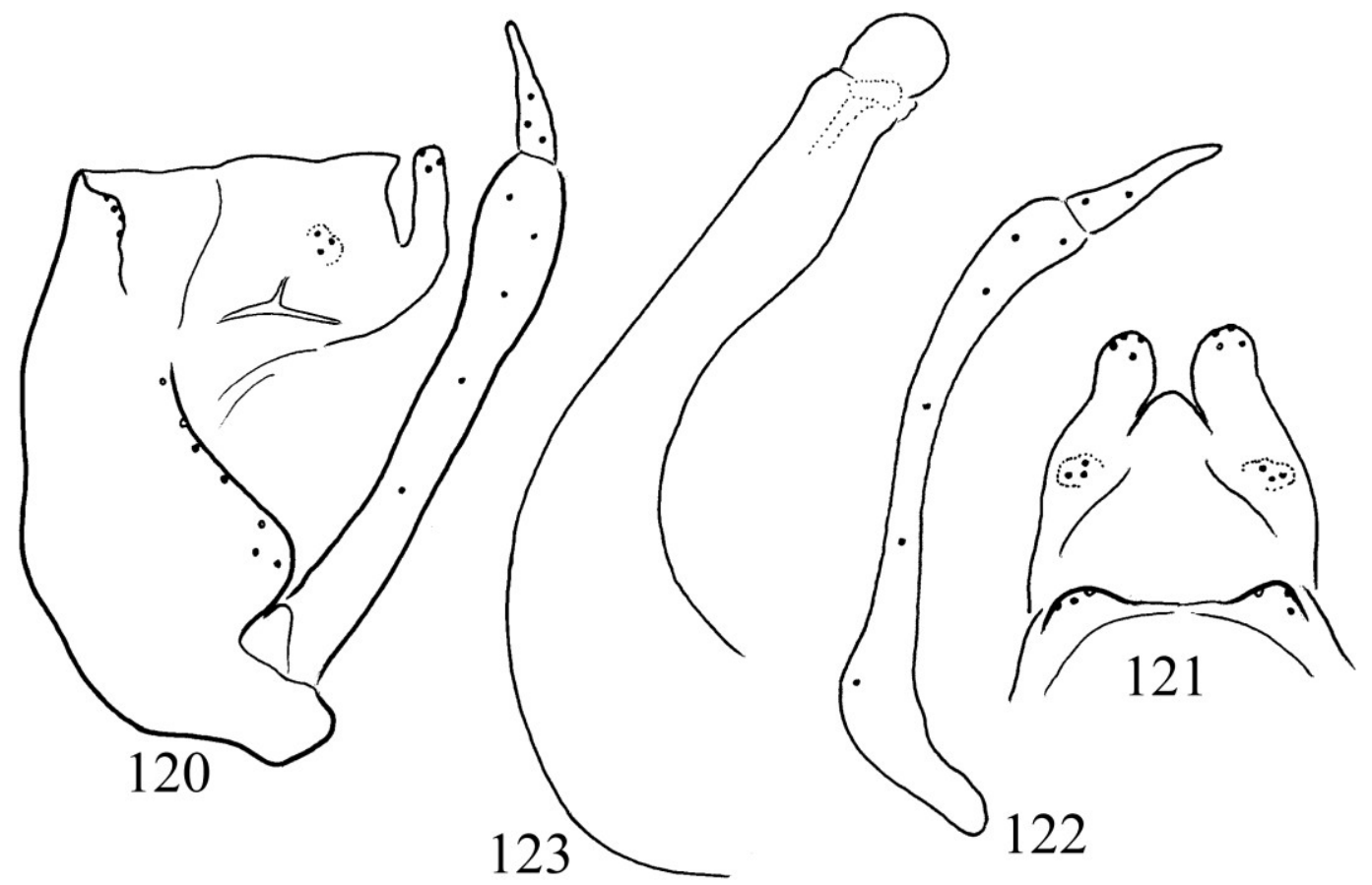

Figures 120-123. Cheumatopsyche infascia Martynov, 1934. $120=$ male genitalia in left lateral view, $121=$ male genitalia in dorsal view, 122 = left gonopod in ventral view, 123 = phallic organ in left lateral view.

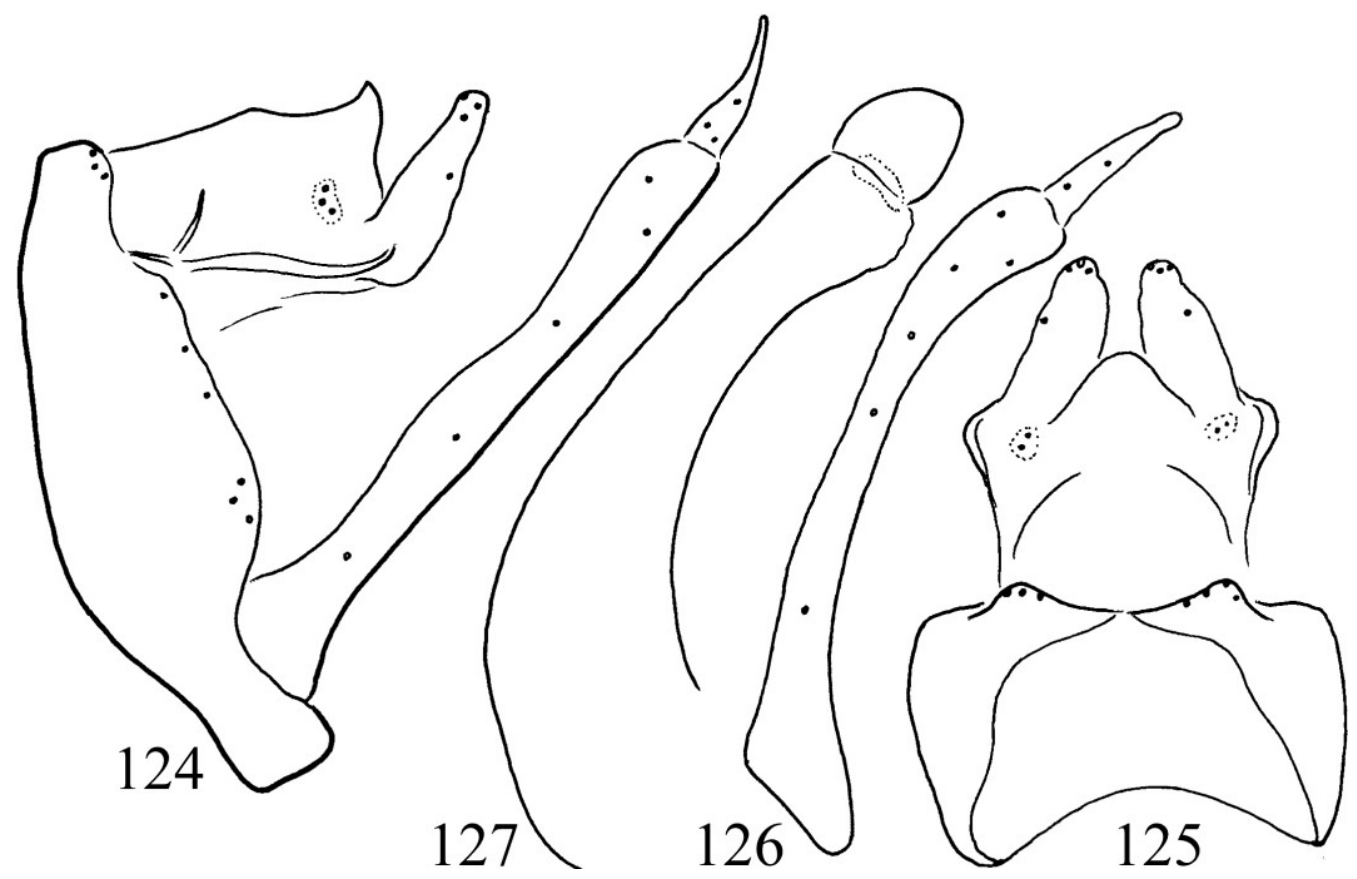

Figures 124-127. Cheumatopsyche kiugra sp. nov. Holotype. $124=$ male genitalia in left lateral view, $125=$ male genitalia in dorsal view, 126 = left gonopod in ventral view, 127 = phallic organ in left lateral view. 
row of strong spines; intersegmental depression between the ninth and tenth segments shallow in lateral view. Body of segment X longer than high; lateral setose area (cerci) in subapical middle position; apicoventral setose lobe straight with tapering apex; smooth apicomesal lobe produced triangular in dorsal view, slightly upward turning in lateral view. The basal segment of the gonopods with regular straight ventrum and with waving dorsum, dilated middle and apicad; harpago, the terminals segment broad-based with gradually narrowing in lateral and straight gradually, but less narrowing in ventral view. Phallic apparatus arching horizontal, endothecal processes rounded.

Etymology. kiugra from "kiugró" protrusive in Hungarian, refers to the heavily sclerotized laterad protruded ending of the heavily sclerotized horizontal suture on the lateral edges of the ventrum of segment $\mathrm{X}$.

\section{Cheumatopsyche lepa sp. nov.}

(Figures 128-131)

Material examined. Holotype: China, Henan, Luanchuan County, Longyuwan, 18.VIII.2012, leg. Weihai Li (1 male, CAU).

Diagnosis. This new species having setose bilobed segment $X$ that is the ventroapical pair of setose lobes and elongated setaless apicomesal lobe belongs to the Cheumatopsyche infacia species complex in the C. lepida species group (Oláh et al. 2008). According to the structure of segment $\mathrm{X}$ and the phallic organ this uniform brown species is most close to Cheumatopsyche sikoska sp. nov., but differs by having the apicoventral setose pair of lobes with rounded apex, not truncate, as well as a basolateral stepwise shaped small stairlike structure present and well discernible in dorsal view.

Description. A uniformly brown coloured small species with forewing length of $7 \mathrm{~mm}$.
Male ganitalia. Abdominal segment IX fused annular, short; anterior margin arciform, resulted in a very short dorsum and short but double longer ventrum; apical margin is straight vertical marked with a row of strong spines; intersegmental depression between the ninth and tenth segments low step-wise in lateral view. Body of segment $\mathrm{X}$ longer than high; lateral setose area (cerci) in subapical middle position; apicoventral setose lobe straight with rounded apex, a basolateral stepwise structure present; smooth apicomesal lobe slightly produced, small triangular in dorsal view. The basal segment of the gonopods straight dilated slightly apicad; harpago, the terminals segment broad-based in lateral and long slender in ventral view. Phallic apparatus straight horizontal, endothecal processes rounded, not higher than the phallothecal tube.

Etymology. lepa from "lép", "lépcső" a step, stair in Hungarian, refers to the small stepwise structure diverged basolaterad on the ventroapical setose lobes discernible in dorsal view.

\section{Cheumatopsyche magaska sp. nov.}

(Figures 132-135)

Material examined. Holotype: China, Guangxi Zhuang Autonomous Region, Shangsi County, Shiwandashan Natural Forest Park, Pearl River above tourist route bridge, N21 ${ }^{\circ} 53.913^{\prime}$ E107 54.283', 375 m, 27.III.2015(/15), leg. J. Kontschán, J. N. Li, S. Li, W. H. Li, D. Murányi \& G. Q. Wang (1 male, OPC).

Diagnosis. This new species having setose bilobed segment $\mathrm{X}$ that is the ventroapical pair of setose lobes and elongated setaless apicomesal lobe belongs to the Cheumatopsyche infacia species complex in the $C$. lepida species group (Oláh et al. 2008). According to the structure of segment $\mathrm{X}$ and the phallic organ this uniform brown species with fade light spotting is most close to Cheumatopsyche lepa sp. nov., but differs by having (1) higher segment X; (2) the apico- 


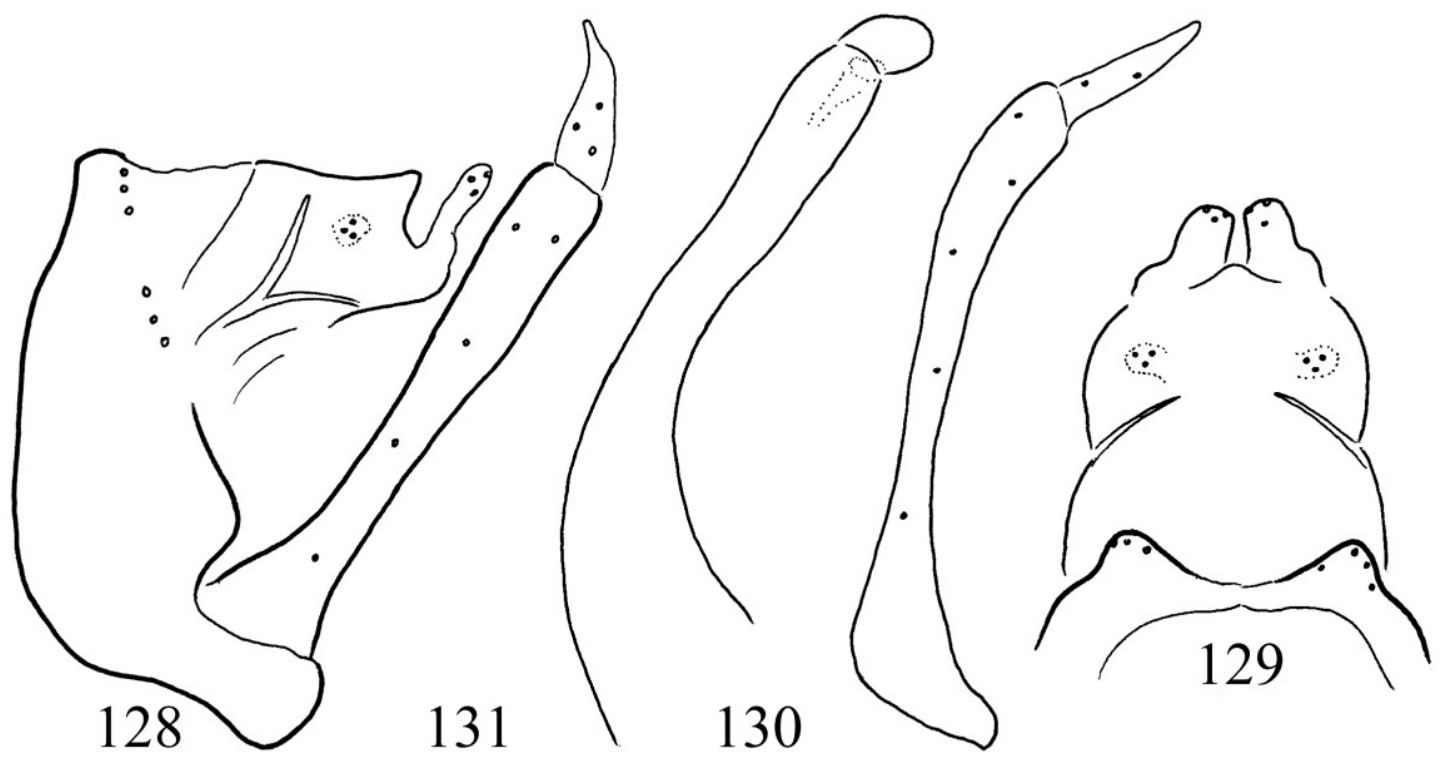

Figures 128-131. Cheumatopsyche lepa sp. nov. Holotype. $128=$ male genitalia in left lateral view, $129=$ male genitalia in dorsal view, 130 = left gonopod in ventral view, 131 = phallic organ in left lateral view.

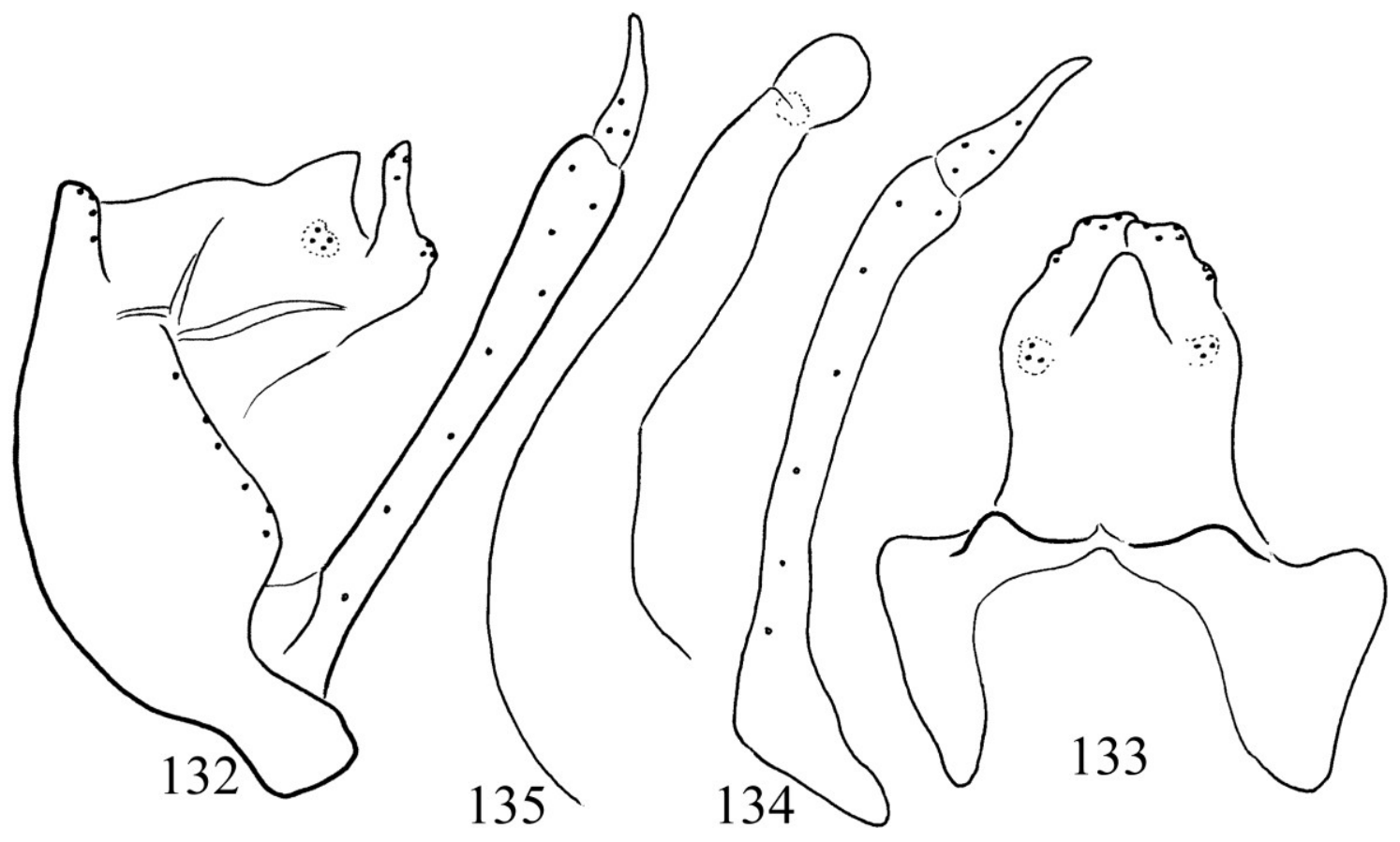

Figures 132-135. Cheumatopsyche magaska sp. nov. Holotype. $132=$ male genitalia in left lateral view, $133=$ male genitalia in dorsal view, 134 = left gonopod in ventral view, 135 = phallic organ in left lateral view. 
ventral setose pair of lobes with truncate or even concave, not rounded apex, not truncate.

Description. A uniformly brown coloured species with some fade light forewing spotting; forewing length $7 \mathrm{~mm}$.

Male ganitalia. Abdominal segment IX fused annular, short; anterior margin arciform, resulted in a very short dorsum and short but triple longer ventrum; apical margin is straight vertical marked with a row of strong spines; intersegmental depression between the ninth and tenth segments low step-wise in lateral view. Body of segment X high; lateral setose area (cerci) in subapical middle position; apicoventral setose lobe straight with truncate or concave apex, a basolateral small lobe-like structure present; smooth apicomesal lobe produced triangular in dorsal view. The basal segment of the gonopods straight dilated slightly apicad; harpago, the terminals segment broad based gradually tapering both in lateral and ventral view; slightly S-forming in ventral view. Phallic apparatus straight horizontal with some Sshape, endothecal processes rounded, slightly higher than the tip of the phallothecal tube.
Etymology. magaska from "magaska" diminutive of magas in Hungarian, refers to the high segmet $\mathrm{X}$ compared to the segment $\mathrm{X}$ of his sibling C. lepa sp.nov.

\section{Cheumatopsyche perem sp. nov.}

(Figures 136-139)

Material examined. Holotype: China, Guangxi Zhuang Autonomous Region, Shangsi County, Shiwandashan Natural Forest Park, Pearl River above tourist route bridge, N21 ${ }^{\circ} 53.913^{\prime}$ E107 ${ }^{\circ}$ 54.283', 375 m, 27.III.2015(/15), leg. J. Kontschán, J. N. Li, S. Li, W. H. Li, D. Murányi \& G. Q. Wang (1 male, OPC).

Diagnosis. This new species having setose bilobed segment $X$ that is the ventroapical pair of setose lobes and elongated setaless apicomesal lobe belongs to the Cheumatopsyche infacia species complex in the $C$. lepida species group (Oláh et al. 2008). According to the structure of segment $\mathrm{X}$ and the phallic organ this uniform brown species is most close to Cheumatopsyche infascia. It has no truncate ventroapical setose

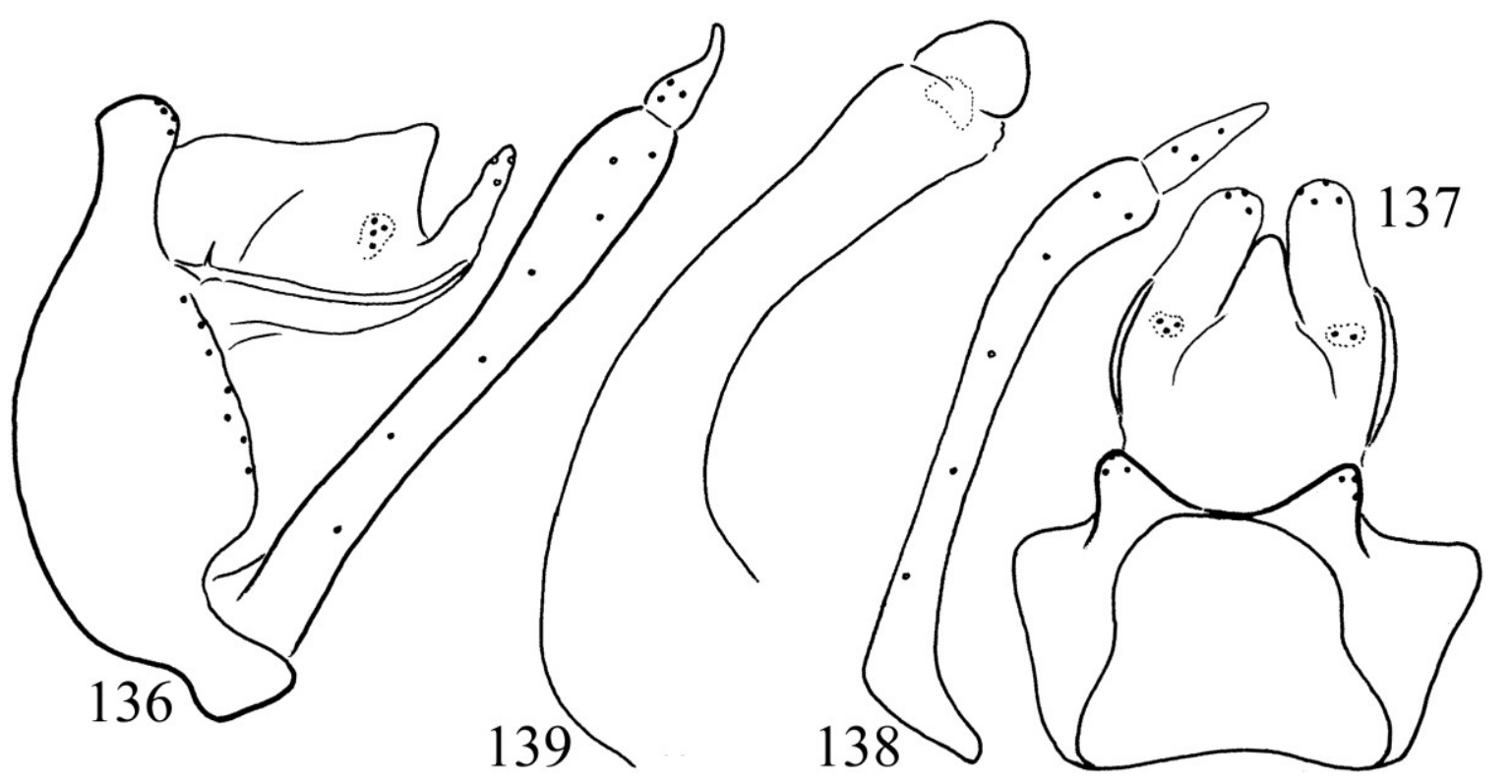

Figures 136-139. Cheumatopsyche perem sp. nov. Holotype. $136=$ male genitalia in left lateral view, $137=$ male genitalia in dorsal view, 138 = left gonopod in ventral view, 139 = phallic organ in left lateral view. 
lobes of C. sikoska sp. nov. and has no angled step of C. lepa sp. nov. on the lateral margin of the ventroapical lobes. It differs from $C$. infascia by having setaless mesocaudal lobe more produced in dorsal view; uniquely sclerotized and enforced horizontal suture developed on the ventrolateral margin of segment $X$. There are subtle divergences in the lateral and ventral shape of harpago: (1) broad-based and abruptly not gradually narrowing apicad in lateral view, and (2) straight and gradually narrowing apicad in ventral view, not slightly S-forming.

Description. A uniformly brown coloured small species (in alcohol) with some just discernible light spots on forewing, forewing length $6 \mathrm{~mm}$.

Male ganitalia. Abdominal segment IX fused annular, short; anterior margin arciform, resulted in a very short dorsum and little longer ventrum; apical margin is straight vertical, marked with a row of strong spines; intersegmental depression between the ninth and tenth segments deep stepwise in lateral view. Body of segment $\mathrm{X}$ longer than high; lateral setose area (cerci) in subapical middle position; apicoventral setose lobe straight with rounded apex; smooth apicomesal lobe produced triangular in dorsal view. The basal segment of the gonopods straight dilated slightly apicad; harpago, the terminals segment broadbased with abrupt narrowing in lateral and straight gradually narrowing in ventral view. Phallic apparatus arching horizontal, endothecal processes rounded subtriangular, slightly lower than the phallothecal tube.

Etymology. perem from "perem" edge in Hungarian, refers to the heavily sclerotized horizontal suture on the lateral edges of the ventrum of segment X.

\section{Cheumatopsyche rovides sp. nov.}

(Figures 140-144)

Material examined. Holotype: China, Shaanxi, Yang County, Huayang Town, Zhoujiayu

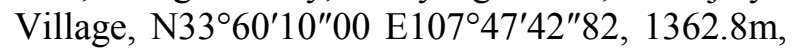
12.V.2017 (1 male, CAU).
Diagnosis. This new species having setose bilobed segment $\mathrm{X}$ that is the ventroapical pair of setose lobes and elongated setaless apicomesal lobe belongs to the Cheumatopsyche infacia species complex in the $C$. lepida species group (Oláh et al. 2008). According to the structure of segment $\mathrm{X}$ and harpago most close to Cheumatopsyche trifascia Li 1988 but differs by having abbreviated harpago with thin apical half, different lateral profile of segment $\mathrm{X}$ and the endothecal process on the end of the phallic organ not higher than the endothecal tube.

Description. Male genitalia. Abdominal segment IX fused annular, short; anterior margin arciform, resulted in a very short dorsum and short but double longer ventrum; apical margin is straight vertical marked with a row of strong 5-6 spines; intersegmental depression between the ninth and tenth segments step-wise deep in lateral view. Body of segment X longer than high; lateral setose area (cerci) in middle position; apicoventral setose lobe straight in lateral and mesad turning in dorsal view; smooth mesocaudal lobe not produced, slightly bilobed. The basal segment of the gonopods straight; harpago, the terminal segment short with needle-like apical half. Phallic apparatus straight horizontal, phallotremal sclerite pronounced large, endothecal processes not higher than the phallothecal tube.

Etymology. rovides from "rövid", "rövides" short, shortened in Hungarian, refers to the abbreviated and pointed-from-middle harpago compared to his siblings.

\section{Cheumatopsyche sikoska sp. nov.}

(Figures 145-148)

Material examined. Holotype: China, Heibei, Xionglong, Caojialu, $561 \mathrm{~m}, 12 . \mathrm{VI} .2014$, leg. Ding Shuangmei (1 male, CAU). Paratype: same as Holotype (1 male, DPP-HIST).

Diagnosis. This new species having setose bilobed segment $\mathrm{X}$ that is the ventroapical pair of setose lobes and elongated setaless apicomesal lobe belongs to the Cheumatopsyche infacia 


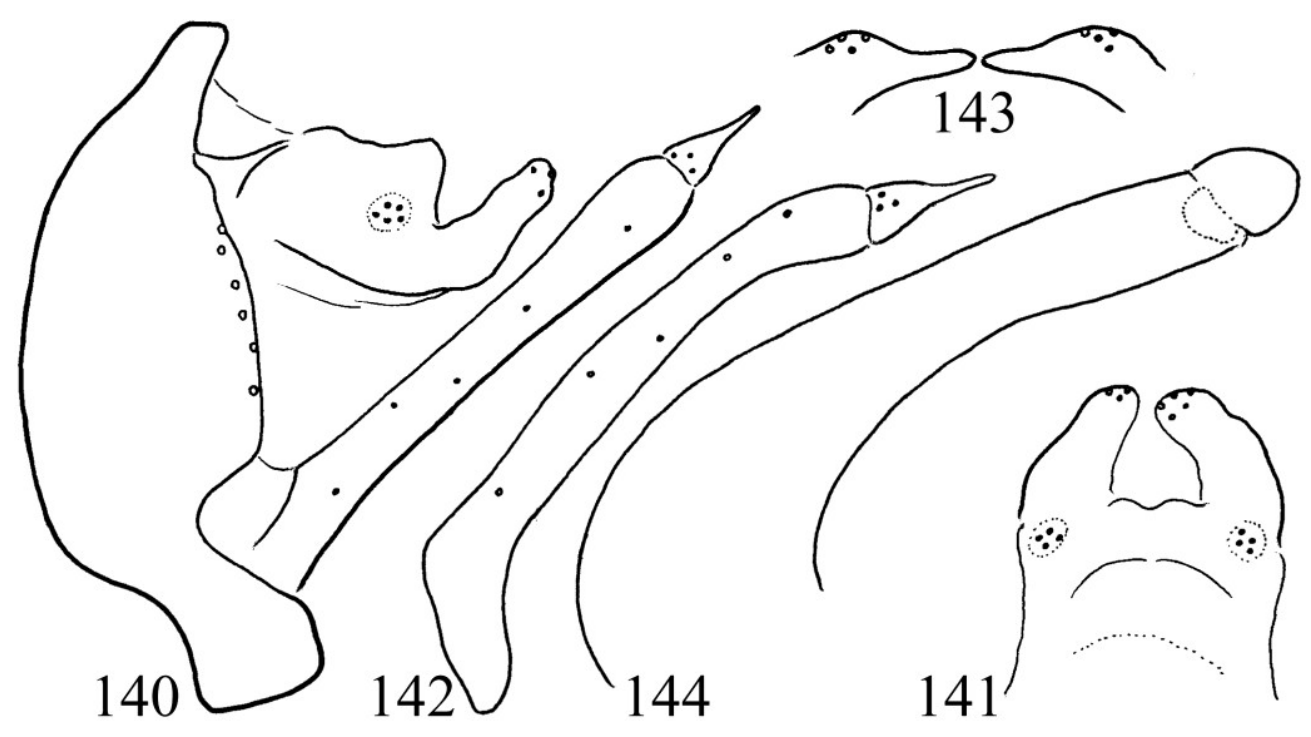

Figures 140-144. Cheumatopsyche rovides sp. nov. Holotype. $140=$ male genitalia in left lateral view, $141=$ male genitalia in dorsal view, 142 = left gonopod in ventral view, 143 = left and right harpago in dorsal view, 144 = phallic organ in left lateral view.

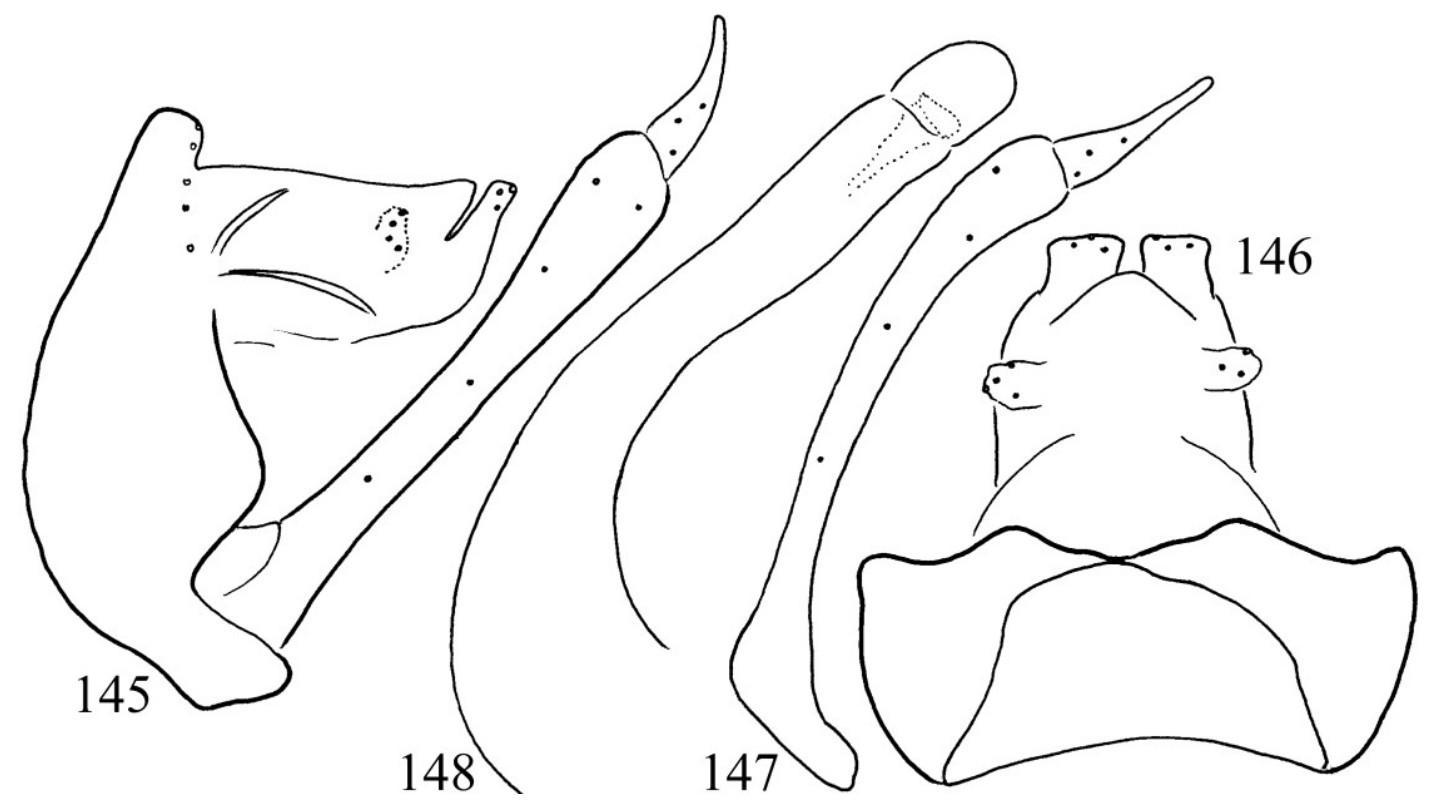

Figures 145-148. Cheumatopsyche sikoska sp. nov. Holotype. $145=$ male genitalia in left lateral view, $146=$ male genitalia in dorsal view, $147=$ left gonopod in ventral view, $148=$ phallic organ in left lateral view.

species complex in the C. lepida species group (Oláh et al. 2008). According to the structure of segment $\mathrm{X}$ and the phallic organ this uniform brown species is most close to Cheumatopsyche infascia Martynov 1934 but differs by having the apicoventral setose pair of lobes clearly truncate, straight-cut in dorsal view, not rounded and having long harpago with slender narrowing apical two thirds.

Description. A uniformly brown coloured small species with forewing length of $7 \mathrm{~mm}$. 
Male ganitalia. Abdominal segment IX fused annular, short; anterior margin arciform, resulted in a very short dorsum and short but double longer ventrum; apical margin is straight vertical marked with a row of strong 5-6 spines; intersegmental depression between the ninth and tenth segments deep step-wise in lateral view. Body of segment $\mathrm{X}$ longer than high; lateral setose area (cerci) in subapical middle position; apicoventral setose lobe straight and truncate, straight-cut well discernible both in in lateral in dorsal view; smooth apicomesal lobe slightly produced, triangular in dorsal view. The basal segment of the gonopods straight dilated apicad; harpago, the terminals segment long slender with narrowing apical two-thirds. Phallic apparatus straight horizontal, phallotremal sclerite pronounced large, endothecal processes equal, not higher than the phallothecal tube.

Etymology. sikoska from "síkoska", a diminutive form of level, aclinic in Hungarian, refers to the levelled, straight horizontal lateral profile of the dorsum of segment $\mathrm{X}$, to the straight-cut, truncate apical margin of the ventroapical setose lobes in dorsal view as well as to the rather straight tube-like shape of the horizontal shaft of the phallic organ that is without any pronounced dorsal and ventral concavity or convexity or apical dilatation.

\section{Cheumatopsyche dubitans species group}

\section{Cheumatopsyche bunkos sp. nov.}

(Figures 149-152)

Material examined. Holotype: China, Guangxi Zhuang Autonomous Region, Jinxiu County, Dayaoshan, Yinshan Wild Station, light traps (1 male, CAU). Paratypes: same as Holotype (1 male, OPC, 1 male, DPP-HIST; 7 males CAU). China, Fujian Province, Wuyishan, Sangang, 740 m, 9.V.2004, leg. Liu Xingyue (1 male, OPC).

Diagnosis. This new species having setose bilobed segment $X$ that is the ventroapical pair of setose lobes and reduced setaless apicomesal lobe belongs to the Cheumatopsyche dubitans species group (Oláh et al. 2008). According to the struc- ture of segment X, especially of the apicoventral lobes most close to Cheumatopsyche mariannae Oláh \& Johanson 2008 described from India (Karnataka) but differs by having dorsal interlobular gap narrow and rounded, not wide and flat-based as well as the harpagones clavate in ventral view, not broad-based.

Description. A small dark brown animal with some faded small spots on forewing Sc and R, forewing length of $6 \mathrm{~mm}$.

Male genitalia. Abdominal segment IX fused annular, short; anterior margin bow-shaped, resulted in a very short dorsum and short but triple longer ventrum; apical margin is straight vertical marked with a row of strong spines; intersegmental depression between the ninth and tenth segments sloping deep in lateral view. Body of segment $\mathrm{X}$ as high as long; lateral setose area (cerci) in middle position forming a short setose process packed with alveoli; apicoventral setose lobe capitate in lateral and slightly mesad turning in dorsal view; apicomesal lobe indiscernible. The basal segment of the gonopods with dilated and down-ward turning apex; harpago, the terminals segment short with clavate apex in ventral view. Phallic apparatus straight horizontal with middle constriction, phallotremal sclerite pronounce large, endothecal processes slightly shorter than the the head of the phallothecal tube.

Etymology. bunkos from "bunkós" clavate in Hungarian, refers to the shape of harpago characterized by terminal broadening with slight middle constriction.

\section{Cheumatopsyche davisi Oláh \& Johanson, 2008}

Material examined. China, Taiwan, Pingtung, Kenting National Park, 16.VI.2013, leg. Li Wenliang (11 males, DPP-HIST, 10 males, OPC).

\section{Cheumatopsyche kurtula sp. nov.}

(Figures 153-156)

Material examined. Holotype: China, Fujian Province, Wuyishan, Sangang, 740 m, 9.V.2004, leg. Liu Xingyue (1 male, CAU). 


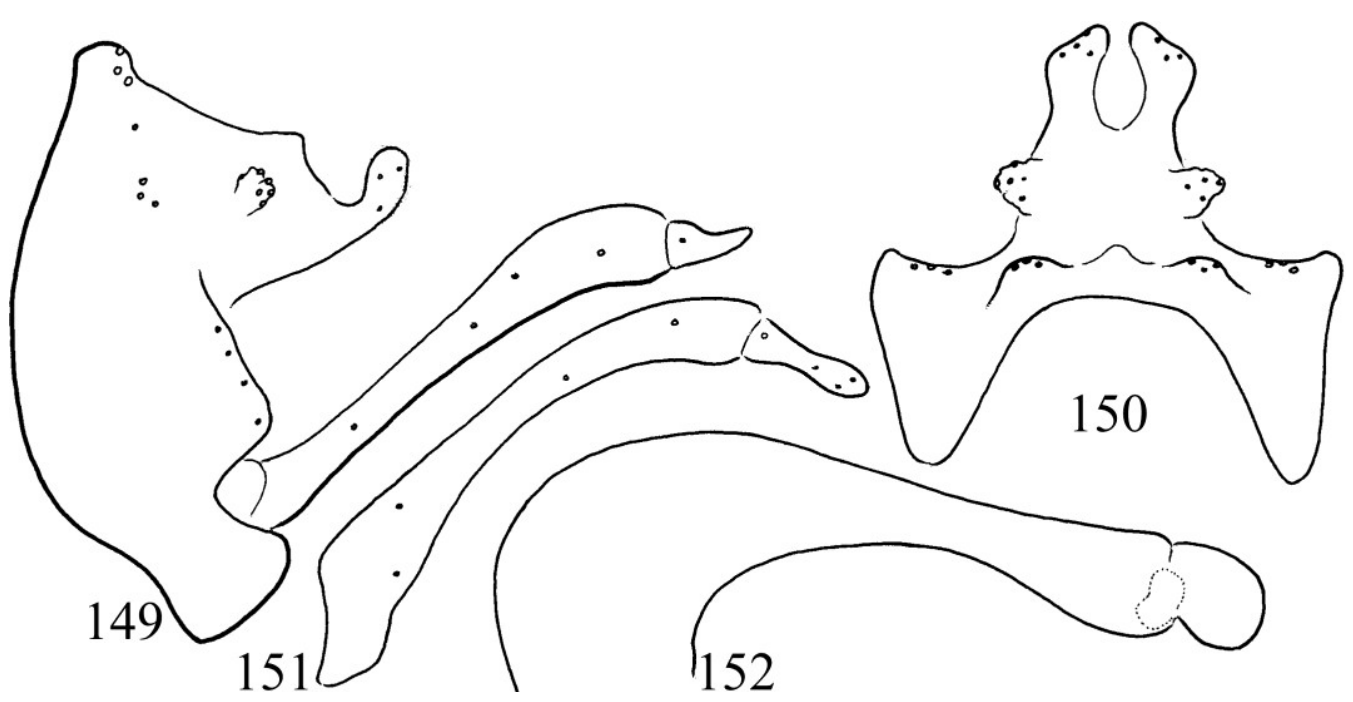

Figures 149-152. Cheumatopsyche bunkos sp. nov. Holotype. $149=$ male genitalia in left lateral view, $150=$ male genitalia in dorsal view, 151 = left gonopod in ventral view, 152 = phallic organ in left lateral view.

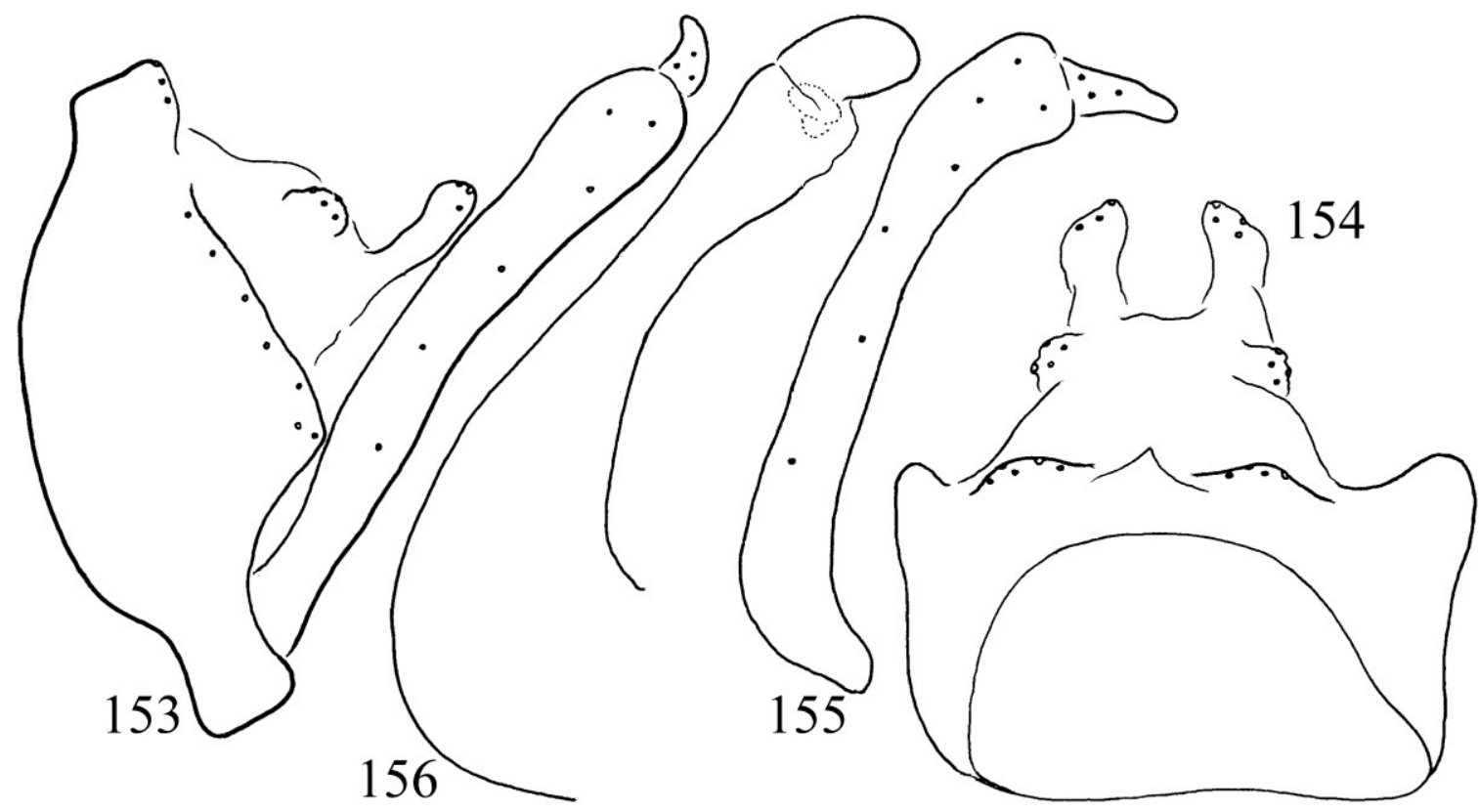

Figures 153-156. Cheumatopsyche kurtula sp. nov. Holotype. $153=$ male genitalia in left lateral view, $154=$ male genitalia in dorsal view, $155=$ left gonopod in ventral view, $156=$ phallic organ in left lateral view.

Diagnosis. This new species having setose bilobed segment $\mathrm{X}$ that is the ventroapical pair of setose lobes and reduced setaless apicomesal lobe belongs to the Cheumatopsyche dubitans species group (Oláh et al. 2008). According to the structure of the apicoventral lobes most close to Cheu- matopsyche bunkos sp. nov. but differs by having larger size, lighter body colour, spotless forewing; short basal part of segment X; robust coxopodite; gradually narrowing harpago, not constricted mesad and not clavate; more elongated endothecal sclerites on the phallic head. 
Description. A medium-sized brown animal without any spots on forewing; forewing length of $9 \mathrm{~mm}$.

Male genitalia. Abdominal segment IX fused annular, short; anterior margin bow-shaped, resulted in a short dorsum and ventrum; apical margin is straight vertical marked with a row of strong spines; intersegmental depression between the ninth and tenth segments sloping deep in lateral view. Basal body of segment X short; lateral setose area (cerci) shifted apicad, forming a short setose process packed with alveoli; apicoventral setose lobe slightly capitate in lateral and slightly mesad turning in dorsal view; apicomesal lobe reduced, indiscernible. The basal segment of the gonopods robust with dilated apex, especially visible in ventral view; the terminals segment short gradually tapering. Phallic apparatus straight horizontal with middle constriction, phallotremal sclerite pronounce large, endothecal sclerites long, slightly downward directed.

Etymology. kurtula coined from "kurta, kurtul" abbreviating in Hungarian, refers to the short harpagones and to the abbreviated basal part of segment X.

\section{Cheumatopsyche sara sp. nov.}

(Figures 157-160)

Material examined. Holotype: China, Heibei, Xionglong, Dagoukum, 589 m, 11.VI.2014, leg. Li Xuankun (1 male, CAU).

Diagnosis. This new species having setose bilobed segment $\mathrm{X}$ that is the ventroapical pair of setose lobes and elongated setaless apicomesal lobe belongs to the Cheumatopsyche dubitans species group (Oláh et al. 2008). The bilobed harpago relates this new species to six Oriental species: C. abhugna, C. carna, C. ceres, C. faniel, $C$. guadunica, $C$. rienga. It differs from all by having ventroapical setose lobes with pronounced pedicel discernible both from dorsal and lateral view. The lateral profile of the phallotheca also diverged by the produced dorsum on its basal half.

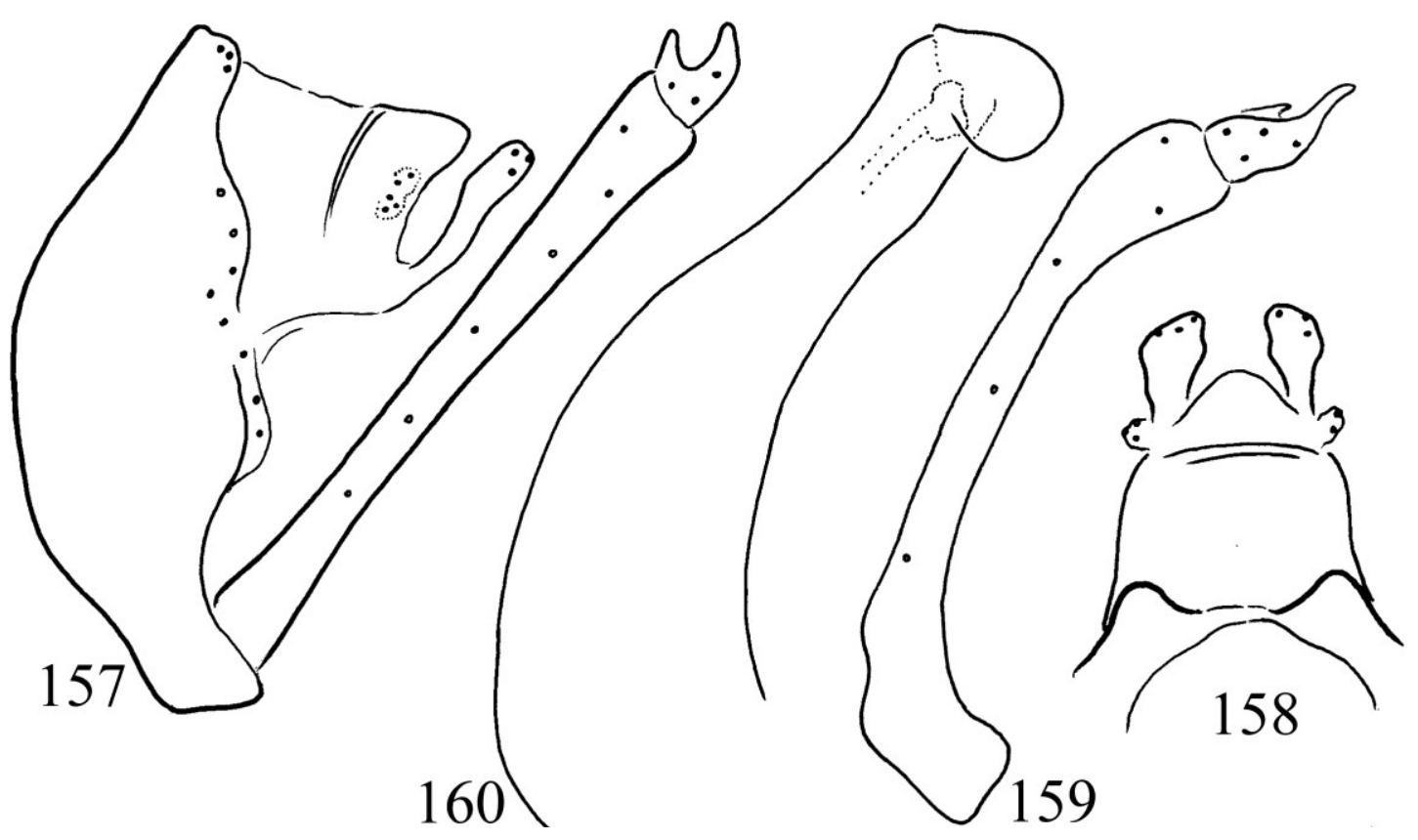

Figures 157-160. Cheumatopsyche sara sp. nov. Holotype. $157=$ male genitalia in left lateral view, $158=$ male genitalia in dorsal view, $159=$ left gonopod in ventral view, $160=$ phallic organ in left lateral view. 
Description. A uniformly brown coloured small species with forewing length of $7 \mathrm{~mm}$.

Male ganitalia. Abdominal segment IX fused annular, short; anterior margin arciform, resulted in a very short dorsum and short but longer ventrum; apical margin is straight vertical marked with a row of strong spines; intersegmental depression between the ninth and tenth segments small step-wise in lateral view. Body of segment $\mathrm{X}$ as long as high; lateral setose area (cerci) in middle on the apical margin; apicoventral setose lobe stalked with capitate head in dorsal view; stalk especially discernible as a long pedicel in lateral view; smooth apicomesal lobe slightly produced, rounded triangular in dorsal view. The basal segment of the gonopods very straight only slightly dilating apicad; harpago, the terminals segment bilobed; the ventral lobe tapering and Sforming. Phallic apparatus with produced dorsum on its two thirds basal region.

Etymology. sara from "szár", pedicle, stalk in Hungarian, refers to stalked shape of the apicoventral setose lobe on segment $X$.

\section{Cheumatopsyche yangmorseorum Oláh \& Johanson, 2008}

Material examined. China, Inner Mongolia, Dayinggou, 23.VII.2014, leg. Wang Ning \& Yang Ding (1 male, OPC).

Remarks. This species was described from Hubei Province based on the single Holotype deposited in NMNH.

\section{Cheumatopsyche costalis species group}

\section{Cheumatopsyche ningmapa Schmid, 1975}

Material examined. China, Yunnan Province, Tongbiguanu, Jinzhuzhai, 3.V.2012, leg. Liu Yuanye (50 males, DPP-HIST; 50 males, OPC).

Remarks. New species record for China!

\section{Cheumatopsyche concava species group}

\section{Cheumatopsyche kirimaduwa species complex}

This new species complex belongs to the Cheumatopsyche concava species group by having monolobed segment $\mathrm{X}$ with fused ventroapical pair of setose lateral lobes. The monolobed apical margin of segment $X$ is accompanied by an innovation structure that is by the ventrocaudal spiny lobe on the apical margin of sternite IX. This character combination delineates this species complex recorded from the Andaman Islands to Henan Province of China: C. dhanikari Malicky, 1978 (Andaman I.); C. kirimaduwa Schmid, 1958 (Sri Lanka); C. kysonia Oláh \& Johanson, 2008, C. songbua Oláh \& Johanson, 2008, C. songda Oláh \& Johanson, 2008, C. zao Oláh \& Johanson, 2008, (Vietnam); C. suswanad Oláh \& Barnard, 2008 (India); C. harma sp. nov. China (Henan), C. lekera sp. nov. China (Hainan I.).

\section{Cheumatopsyche harma sp. nov.}

(Figures 161-164)

Material examined. Holotype: China, Henan Province, Song County, Mt. Funiu, Muzhaling, 19.VIII.2012 leg. Weihai Li (1 male, CAU).

Diagnosis. This new species having unilobed segment $X$ that is the ventroapical pair of setose lobes fused to the body of segment $\mathrm{X}$ belongs to the Cheumatopsyche concava species group (Oláh et al. 2008). According to the structure of segment $\mathrm{X}$ and the phallic organ this uniform brown species is most close to Cheumatopsyche dhanikari Malicky, 1979 described from the Andaman Islands but differs by having the apicoventral setose pair of lobes really lobe-like, clearly posterad produced in dorsal view and strongly developed into upward direction as an independent lobes discernible in oblique lateral view. Malicky (1997) has determined specimens from Thailand and Vietnam as well as we have determined specimens from India (Karnataka State) under the name of $C$. dhanikari. These determinations are doubtful and the exact taxonomic status of specimens from India, Thailand and Vietnam need a comparative trait matrix study on population samples. The new species, C. harma sp. nov. from China (Henan Province) is markedly diverged from the specimens of Karnataka at least by the lobe-like setose lateral structures.

Description. A uniformly brown coloured small species with forewing length of $7 \mathrm{~mm}$. 


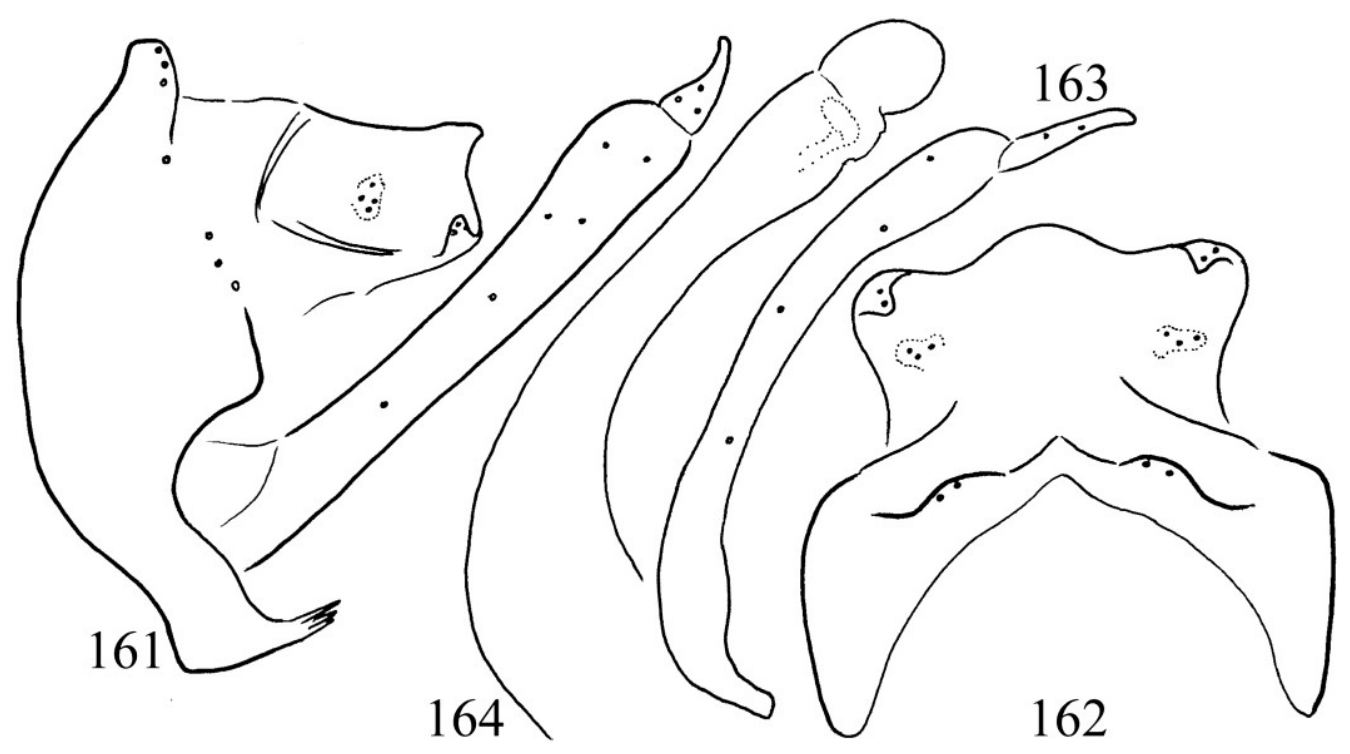

Figures 161-164. Cheumatopsyche harma sp. nov. Holotype. $161=$ male genitalia in left lateral view, $162=$ male genitalia in dorsal view, 163 = left gonopod in ventral view, 164 = phallic organ in left lateral view.

Male genitalia. Abdominal segment IX fused annular, short; anterior margin arciform, resulted in a very short dorsum and short but longer ventrum; the ventrum is elongated by the spiny ventrocaudal mesal lobe; apical margin is straight vertical marked with a row of strong spines and ventrad terminated in a triangular lobe above the gonopods; intersegmental depression between the ninth and tenth segments present, deep and stepwise in lateral view. Body of segment $\mathrm{X}$ little longer than high; lateral setose area (cerci) in middle position; apicoventral setose lobe discernible as incompletely fused to the apicoventrum of the segment and discernible as a small setose lobe visible both in dorsal and lateral view. The basal segment of the gonopods straight only slightly dilating apicad; harpago, the terminals segment broad-based in lateral and digitate in ventral view. Phallic apparatus with slender curving tube from the phallobase to the phallic head; the pair of endothecal sclerites rounded.

Etymology. harma from "hármas", triple in Hungarian, refers to the tripartite dorsal profile of the apical margin on segment X composed of the smooth setaless mesocaudal lobe and the apicoventral pair of setose lobes, mostly fused to the segment body, but anyhow posterad produced in dorsal and upward produced in lateral view.

\section{Cheumatopsyche lekera sp. nov.}

(Figures 165-168)

Material examined. Holotype: China, Hainan, Baisha County, Yinggeling, Hongmao, 28.XI. 2011, leg. Weihai Li (1 male, CAU).

Diagnosis. This new species having unilobed segment $\mathrm{X}$ with apicoventral setose lobe almost completely fused with segment $\mathrm{X}$ belongs to the Cheumatopsyche concava species group (Oláh et al. 2008). A special innovation of the ventrocaudal spiny lobe on segment IX developed in integrative organisation in this complex of species recorded from Sri Lanka to Vietnam and Malaysia. Species in this complex differ by wing pattern, by the shape of harpago and the complex of segment X. The new species is most close to $C$. songda described from Vietnam, but differs by having no any spot pattern on forewing; the complex of segment $\mathrm{X}$ is rounded in dorsal view, not deltoid; as well as the phallobase is slender, not broad based. 


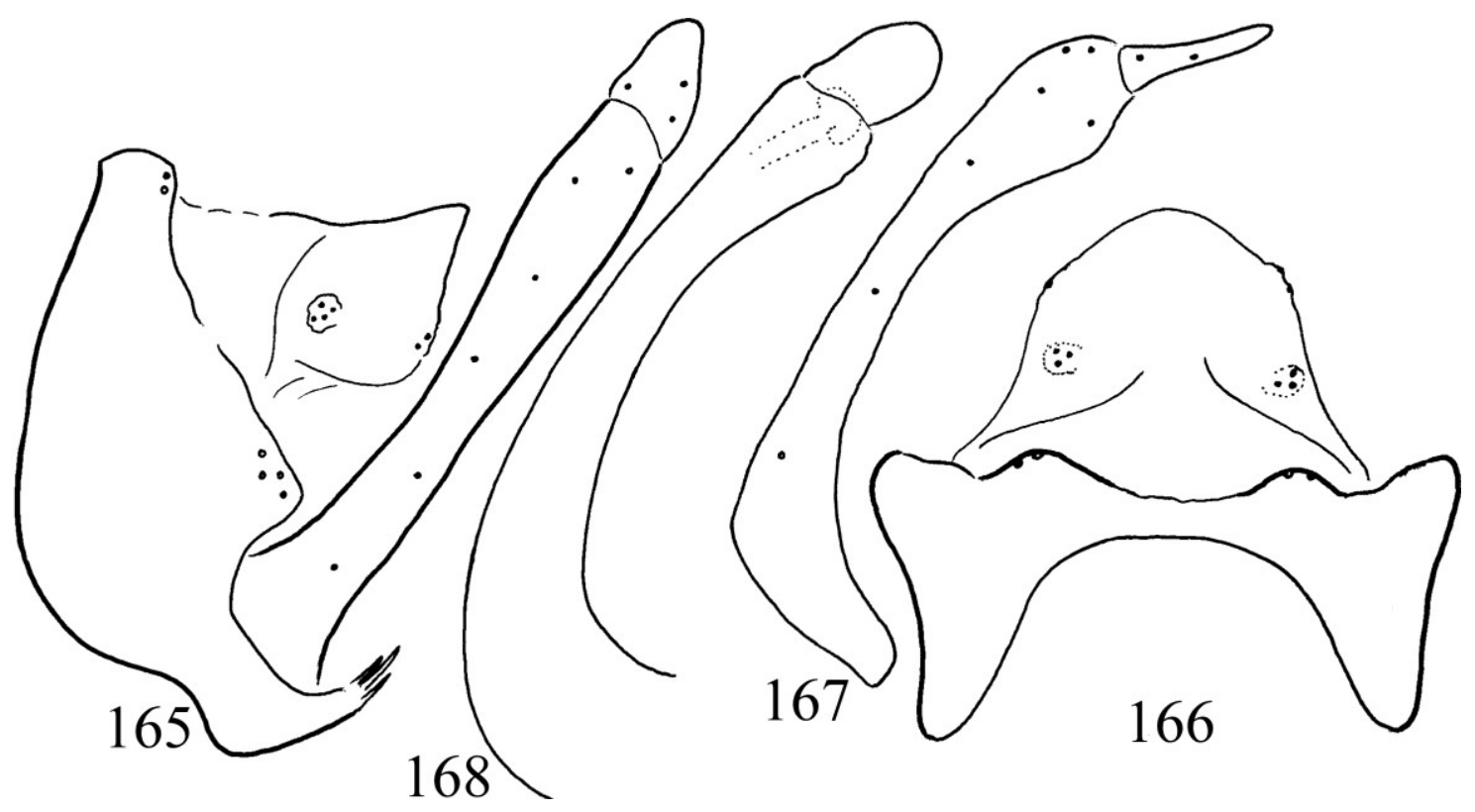

Figures 165-168. Cheumatopsyche lekera sp. nov. Holotype. $165=$ male genitalia in left lateral view, $166=$ male genitalia in dorsal view, 167 = left gonopod in ventral view, 168 = phallic organ in left lateral view.

Description. A uniformly brown coloured small species with forewing length of $7 \mathrm{~mm}$.

Male ganitalia. Abdominal segment IX fused annular, short; anterior margin arciform, resulted in a very short dorsum and short but longer ventrum; the ventrum is elongated by the spiny ventrocaudal mesal lobe; apical margin is straight vertical marked with a row of strong spines and terminated in a triangular lobe ventrad above the gonopods; intersegmental depression between the ninth and tenth segments present and step-wise in lateral view. Body of segment $X$ little longer than high high; lateral setose area (cerci) in middle position; apicoventral setose lobe vestigial fused to the apicoventrum of the segment and discernible as a small setose area visible both in dorsal and ventral view. The basal segment of the gonopods straight only slightly dilating apicad; harpago, the terminals segment rounded triangular in lateral and digitate in ventral view as a result of vertically flattened shape. Phallic apparatus with slender curving tube from the phallobase to the phallic head; the pair of endothecal sclerites rounded and elongated.

Etymology. lekera from "lekerekített", rounded in Hungarian, refers to the dorsal shape of segment $X$.

\section{Potamyia genus}

\section{Potamyia chinensis (Ulmer, 1915)}

Material examined. China, Yunnan Province, Xishuangbanna, $661 \mathrm{~m}, 9$. Vii.2016, leg. W. Li (1 male, DPP-HIST). China, Yunnan Province, Zhaotong, Erxicum, 25.IV.2014, leg. Lu Niumei (1 male, DPP-HIST). China, Shaanxi Province, Hanzhong city, Foping county, Qinling Mts. bank of Ziwu River in Foping old town, $890 \mathrm{~m}$, N33³1.366' E10759.012', 19.IV.2018(/1), leg. W. H. Li, R. R. Mo \& D. Murányi (1 male, OPC). China, Shaanxi, Yang Country, Huanyang Town, Wangiiagou, N3319'33"68, E10757'21"43 453 m, light traps, 11.V.2017, leg. Liu Haoyu (4 male, DPP-HIST). 


\section{Spicipalpia}

\section{Glossosomatidae}

\section{Glossosoma altaicum (Martynov, 1914)}

Material examined. China, Xinjiang, Buerjin, Kanas Beishan river, N48.687120 ${ }^{\circ}$ E87.013350 ${ }^{\circ}$, 1368, 17-15-1 (sample number), 19.VII.2017. leg. Ren Jinlong (1 male, DPP-HIST).

\section{Glossosoma subaequale Schmid, 1971}

Material examined. China, Tibet, Linzhi, N29 19'53" E94²0'38”, 2926 m, 20.IV-20.V. 2017 leg. W. Li, (2 males, DPP-HIST; 2 males, OPC).

\section{Rhyacophilidae}

\section{Rhyacophila simpla sp. nov.}

(Figures 169-171)

Material examined. Holotype: China, Tibet, Yigong, VI.2016, M. traps for the first time, (1male, CAU). Paratypes: same as Holotype (2 males, DPP-HIST). China, Tibet, Sejila Mount, Zhongshan Station, 5.V.-5.VI. 2017. (2 males, $\mathrm{OPC})$

Diagnosis. This new species belongs to the Rhyacophila naviculata species group of the Rhyacophila naviculata branch. Based on the shape of harpagones and the apicodorsal lobe of segment IX $R$. simpla sp. nov. is most close to $R$. poba Schmid, 1970 described from Sikkim as well as to R. macrorrhiza Sun \& Yang, 1995 and R. vasariah Malicky, 2016 both described from Sichuan. Rhyacophila simpla sp. nov. differs from these species by having the apicodorsal lobe on segment IX very simple abbreviated monolobed, tapering mesad not bilobed and not excised apicomesad. The neutral trait of the apicodorsal lobe has a range of variation. The aedeagus has no any dorsal process, the basal sleeve of penis at Kimmins. It is lost. The dorsal process of the aedeagus is present in most members of this species group. However, both the dorsal process of the aedeagus as well as the parameres may be completely lacking in some species having otherwise the same genital architecture.

Description. Male (in alcohol). Body, appendages and wings brown, forewing length $14 \mathrm{~mm}$ with marble spotted pattern.

Male genitalia. Segment IX forms an almost regular ring, its anterior and posterior margins are almost parallel-sided in lateral view. Segment X less produced horizontal. Cerci lacking. Pair of epiproct (anal sclerite) small rounded ventrally elongated, without discernible root. Paraproct (Ushaped or wishbone-shaped apical band and tergal strap or band) present connected to the tergal strap. Gonopod bisegmented, coxopodite high, long and slightly constricted midway; harpago Lshaped. Phallic organ composed of phallobase (just discernible phallotheca and most developed endotheca), aedeagus and parameres; aedeagus long digitiform; parameres filiform.

Etymology. simpla from "szimpla" simple in Hungarian, refers to the abbreviated with abruptly narrowing, almost pointed apex of the apicodorsal lobe of segment IX in dorsal view.

\section{Rhyacophila stenostyla Martynov, 1930}

Material examined. China, Tibet, Sejila Mount, Zhongshan Station, 5.V.-5.VI. 2017. (1 male, OPC)

\section{Rhyacophila taraja sp. nov.}

(Figures 172-175)

Material examined. Holotype: China, Tibet, Sejila Mount, Zhongshan Station, 5.V.-5.VI. 2017, (1 male, CAU).

Diagnosis. Having large dorsoapical lobe on segment IX, segment X horizontal, paired anal sclerite small, cerci absent, phallic organ simple and slender, this new species belongs to the Rhyacophila naviculata branch. According to Schmid (1970)'s simplified grouping of the Rhyacophila genus it is contradicting to find the natural 


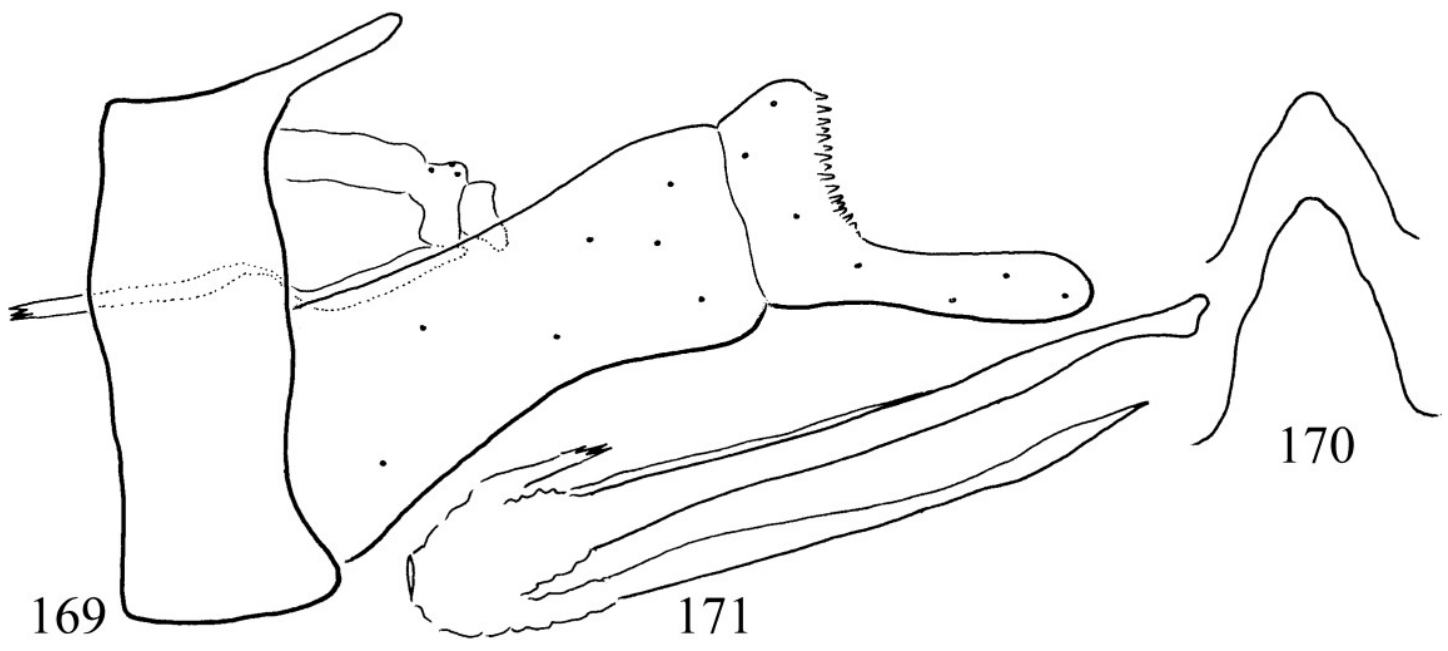

Figures 169-171. Rhyacophila simpla sp. nov. Holotype. $169=$ male genitalia in left lateral view, $170=$ variation of the dorsal process of segment IX between populations, $171=$ phallic organ in left lateral view.

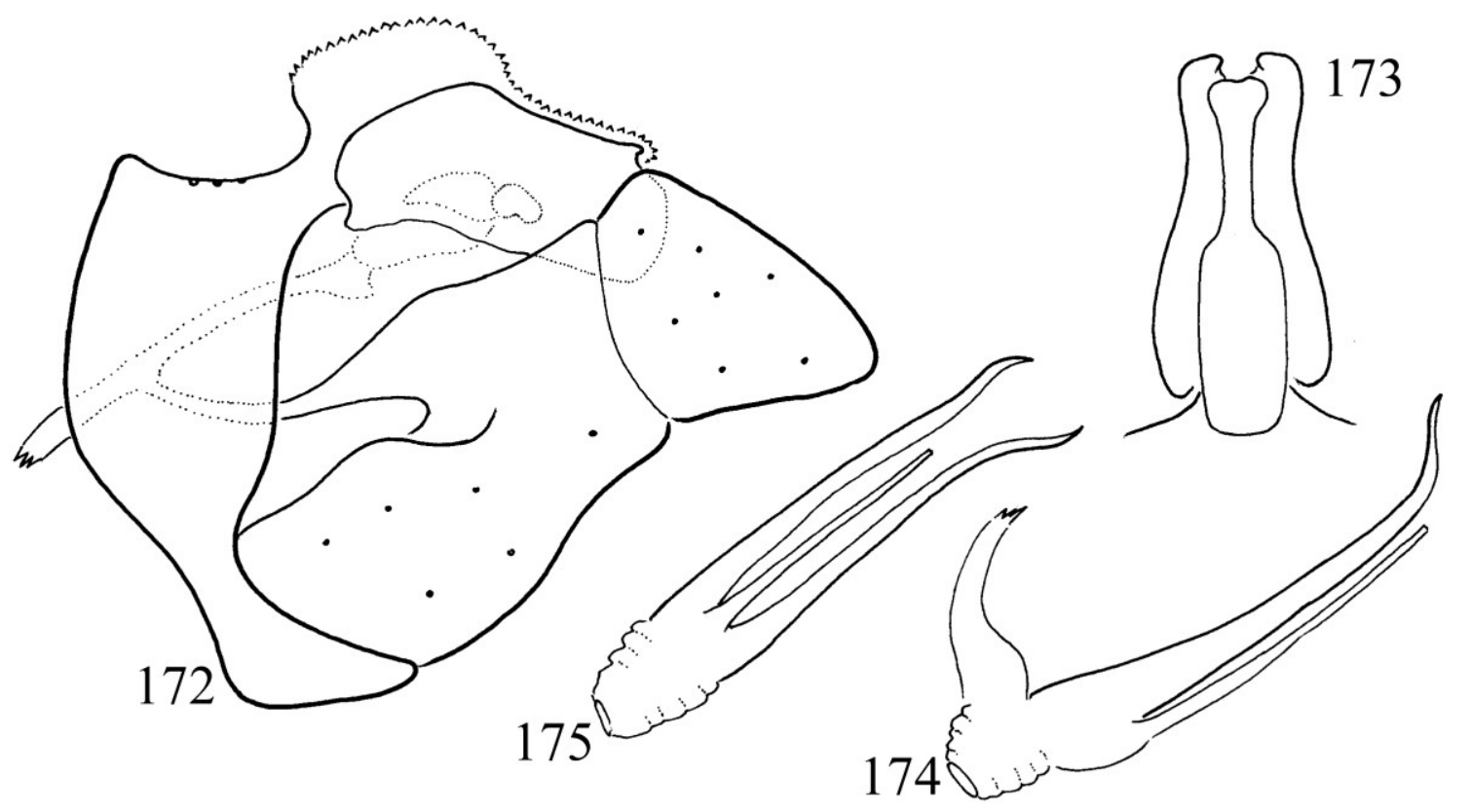

Figures 172-175. Rhyacophila taraja sp. nov. Holotype. $172=$ male genitalia in left lateral view, $173=$ segment $\mathrm{X}$ in dorsan view, $174=$ phallic organ in left lateral view, 175 = phallic organ in ventral view.

taxonomic status of this new species. But it is not surprising, it is natural. The generality of the taxonomical incongruences due to both stochastic ontology and probabilistic epistemology makes classification of any entities highly artificial. Beside the overall character states of the $R$. naviculata branch, $R$. taraja sp. nov. has abbrevi- ated ventrum of segment IX, horizontal segment $\mathrm{X}$, dorsal process of the phallic organ lost, segment $X$ large, segment $X$ slightly oblique, phallotheca and endotheca reduced in size. Based on this character combination it is most close to the small $R$. lieftincki species group, but the U-shaped apical band and tergal strap less sclerotized 
almost fully membranous, anal sclerite with root. Gonopods tendons long connected to the tergal strap. The basement of the tendon is heavily produced, unique in the genus dominating the mesal region of the apical half of the coxopodite. All members of the $R$. lieftincki species group has segment X clearly detached from the apicodorsal lobe of segment IX, but segment $\mathrm{X}$ of the new species is tightly adhered or even fused to the apicodorsal lobe.

Description. Male (in alcohol). Male genitalia. Segment IX forms an abbreviated ventrum, its anterior and posterior margins constricted in lateral view; apicodorsal process very specially formed, very unique; upward produced and cockcrest shaped; it apical half narrow with clavate apex in dorsal view; fully packed with short peglike noncellular cuticular processes; dentate in lateral view like the crests of the cocks. Segment $\mathrm{X}$ large-sized almost horizontal, slightly oblique adhered to the dorsal lobe, fully covering the paired small anal sclerites and the membranous apical band, the vestigial structures of segment XI. Cerci lacking. Pair of epiproct (anal sclerite) small reniform with discernible root. Paraproct (U-shaped or wishbone-shaped apical band and tergal strap or band) present, membranous, almost indiscernible connected to the tergal strap. Gonopod bisegmented, coxopodite high, mesal region of the apical half modified to basement for the gonopod tendon. Phallic organ composed of less developed phallobase (phallotheca and endotheca) aedeagus and parameres; aedeagus filiform, parameres spine like.

Etymology. taraja from "taraj”, "taréj”, crest in Hungarian, refers to the highly upward produced with cock crest-like shaped apicodorsal process of segment IX.

\section{Integripalpia}

\section{Brevitentoria}

Leptoceroidea

Molannidae

\section{Molanna moesta Banks, 1906}

Material examined. China, Hubei,Yingshan, Taohuachong 600m, 15.VI.2018, leg. Jiang Yunlan (1 male, DPP-HIST), China, Da qingkou 2016.VI.13 Light traps. (1male, DPP-HIST).

\section{Leptoceridae}

\section{Oecetis clavata Yang \& Morse, 2000}

Material examined. China, Guangxi, Jinxiu County, Dayaoshan, Yinshan wild Station, light traps, 17.VIII.2016, leg. Weihai Li, Raorao Mo \& Guoquan Wang (1 female, OPC).

\section{Oecetis girba sp. nov.}

(Figures 176-181)

Material examined. Holotype: China, Guangxi, Jinxiu County, Dayaoshan, Yinshan wild Station, light traps, 17.VIII.2016, leg. Weihai Li, Raorao Mo \& Guoquan Wang (1 male, CAU). Allotype: same as Holotype (1 female, DPPHIST). Paratypes: same as Holotype (1 male, DPP-HIST; 1 male, OPC).

Diagnosis. Phallus asymmetrical with more paramere spines; cerci not fused to segment X; tergum IX short and sternum IX long. This character combination relates $O$. girba to the Pleurograpta subgenus of genus Oecetis (Chen, 1993). The second flagellar segment elongated, hindwing median vein divided after $m$ cross-vein, lower part of segment X not fused with segment IX laterally, pregenital tergums without honeycomb structure. This character combination characterizes the $O$. hamata species group. The second flagellar segment has no tuft of long setae. Has similarity to $O$. cornuata, but differs having rather straight vertical anterior margin of segment IX, not abruptly excised posteriorly in dorsal half; rounded cercal apex, not bifid apex; gonopod more complex (girbe-gurba); three parameres present, not a single sclerotized stout structure. Differs by the shape of female lamella, cerci and spermathecal sclerite. 

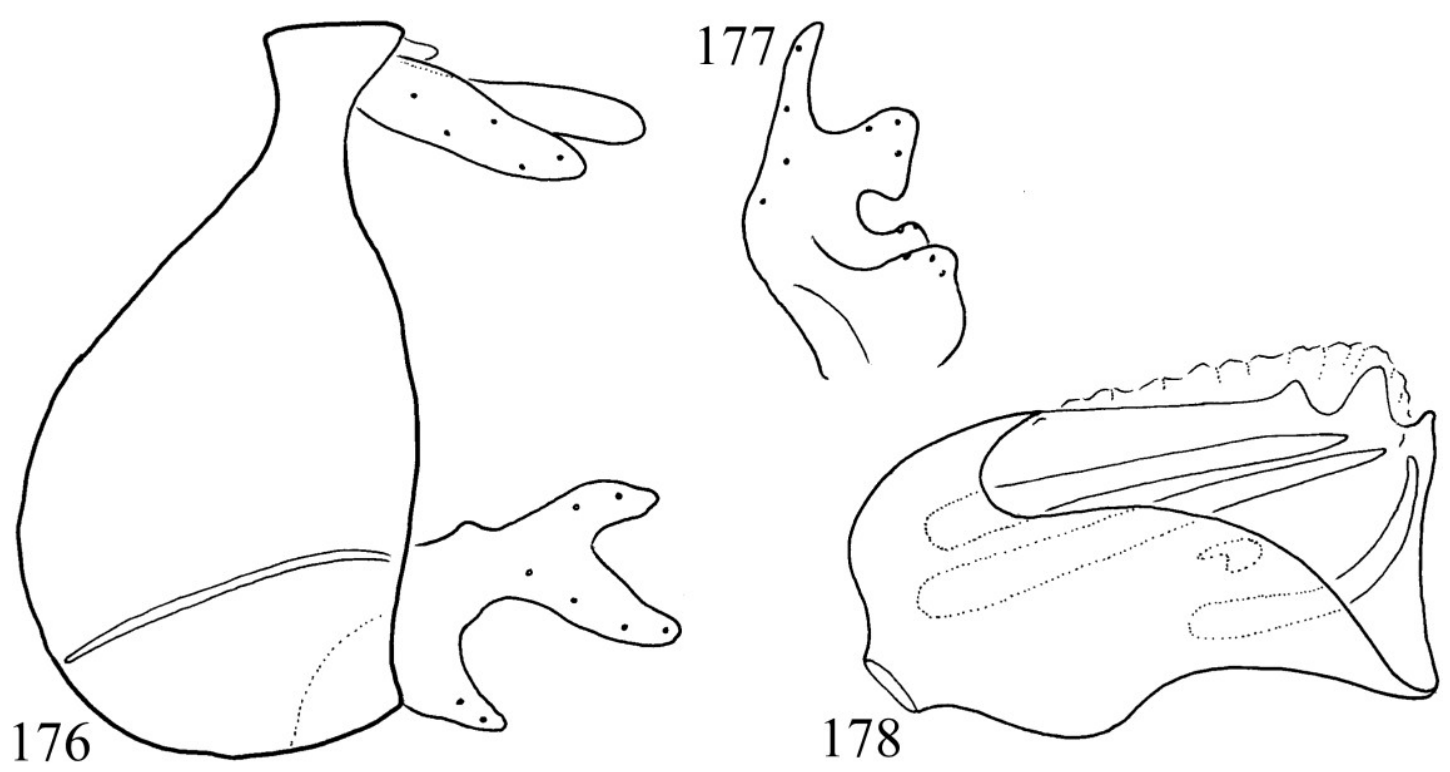

Figures 176-178. Oecetis girba sp. nov. Holotype. male: $176=$ male genitalia in left lateral view, $177=$ left gonopod in ventral view, $178=$ phallic organ in left lateral view.

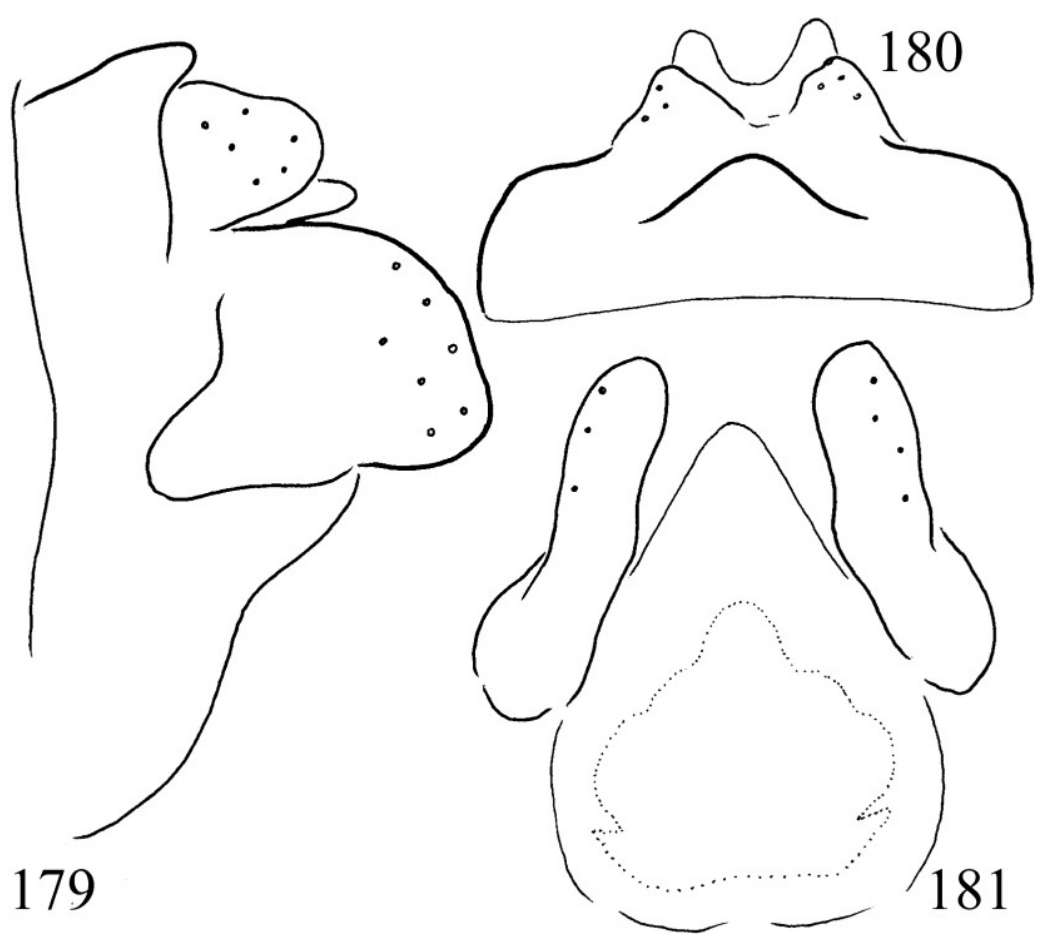

Figures 179-181. Oecetis girba sp. nov. Allotype female: $179=$ female genitalia in left lateral view, $180=$ female genitalia in dorsal view, 181 = female genitalia in ventral view. 
Description. Male (in alcohol). Body pale yellow, thorax light brown. Antennae with second flagellar segment elongated and without long setae, similarly to $O$. cornuata. Tibial spur 1-2-2. Forewing length $6 \mathrm{~mm}$; forks, cross-veins, anastomosis and apices of the longitudinal veins shaded with brown on the light background.

Male genitalia. Segment IX bottle-like in lateral view, short dorsum, long ventrum; an oblique horizontal suture may delineate ventrum and pleuron. Segment X (upper part of segment X) digitate, slightly longer than cerci. Cerci (preanal or superior appendages) setose digitate or foliform. Paraproct (lower part of segment X) indiscernible, probably vestigial. Gonopod complex composing of almost five variously produced lobes. Phallic organ composed of phallotheca, indistinct endotheca, three spine-like parameres and heavily sclerotized phallotremal sclerite. Phallotheca about twice as long as high; globular closed tube basally with open dorsum distally right distal margin with three heavily sclerotized robust lobes; two parameres straight, one paramere curving.

Female genitalia. Segment IX longest dorsad, tergum IX slightly produced mesad, cerci setose as long as high, lamella slightly downward directed, spermathecal sclerite short and wide.

Etymology. girba from "girbe-gurba" overly curved in Hungarian, refers to the phallotheca with overly patterned dorsal edge as well as to the complex structure of the gonopods.

\section{Plenitentoria}

\section{Limnephiloidea superfamily}

Apataniidae

\section{Apatania trifurca Tian \& Sun, 1992}

Material examined. China, Tibet, Linzhi, N29 19'53" E94²0'38", 2926 m, 20.IV-20.V. 2017 leg. W. Li, (1 male, DPP-HIST).

\section{Goeridae}

\section{Goera martynowi Ulmer, 1932}

Material examined. China, Shaanxi, Han zhong, Yang County, Huayang Town, Banqiao Village, N33.6155 ${ }^{\circ} \mathrm{E} 107.5079^{\circ}, 1154 \mathrm{~m}$, light traps, 4.V.2017, (4 males, DPP-HIST).

\section{Limnephilidae}

\section{Asynarchus delies sp. nov.}

(Figures 182-184)

Material examined. Holotype: China, Xinjiang, Qinghe, 2625 m, 14.VII.2016, leg. W. H. Li, (1 male, CAU). Paratypes: same as Holotype (1 male, DPP-HIST; 1 male, OPC).

Diagnosis. The new species belongs to the Asynarchus lapponicus species group of Schmid. The lateral profile of the cerci resembles $A$. lapponicus and $A$. mongolicus, but differs by having more pointed apex and the ventral process is blunt, not pointed in lateral view. The caudal profile of the paraproct with produced lateral wings. The paramere tips are supplied with two almost equal sized spines, not with a single terminal spine accompanied by several small subapical spines.

Description. This is a medium-sized animal with dark brown, almost black body sclerites. The forewing length is $16 \mathrm{~mm}$.

Male (in alcohol). Segment IX very short dorsad, longer ventrad. The cerci are large, subtriangular, apex is pointed, ventral lobe broad blunt. The paraproct is truncate apicad and abbreviated in size in lateral view; in caudal view the lateral wings are more developed. Gonopod lateral profile is characterized with larger dorsal and shorter ventral apical lobe. Phallic organ composed of phallotheca (phallobase), endotheca, aedeagus, endophallus and parameres. The parameres are characterized by the anterad curving shaft with two almost equal sized terminal spines; the small lobes armed with long setae are short.

Etymology. delies from "délies" southern in Hungarian, refers to the most south representative of the Asynarchus lapponicus species group. 


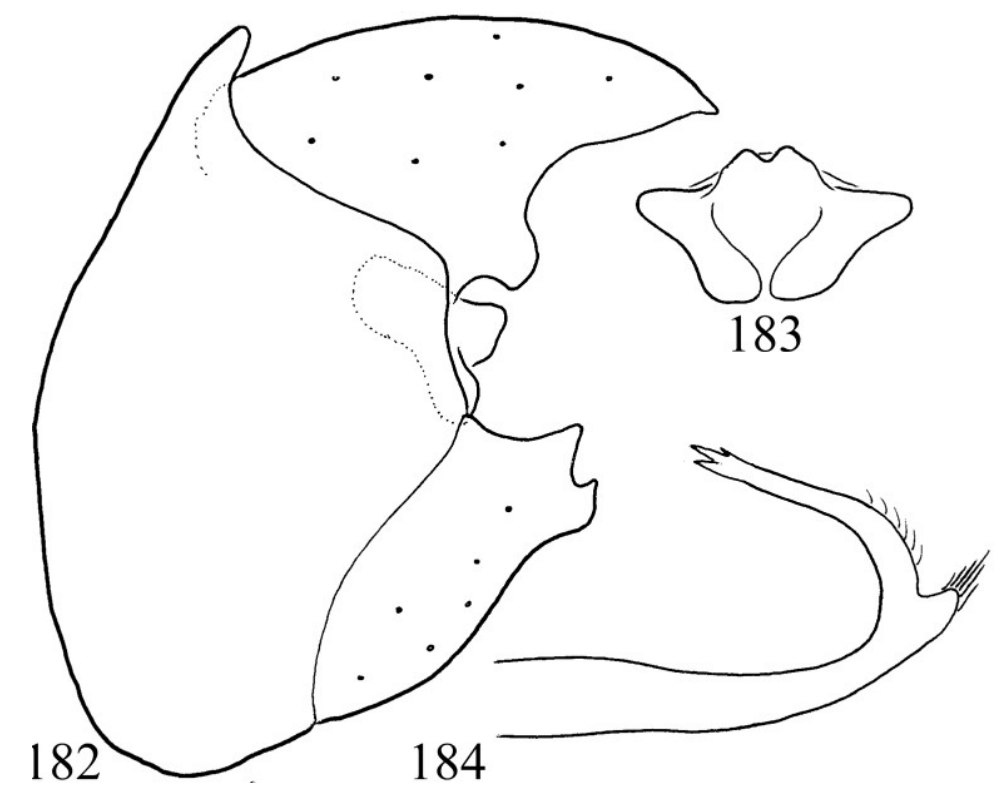

Figures 182-184. Asynarchus delies sp. nov. Holotype. 182 = male genitalia in left lateral view, $183=$ paraproct in caudal view, $184=$ left paramere in left lateral view.
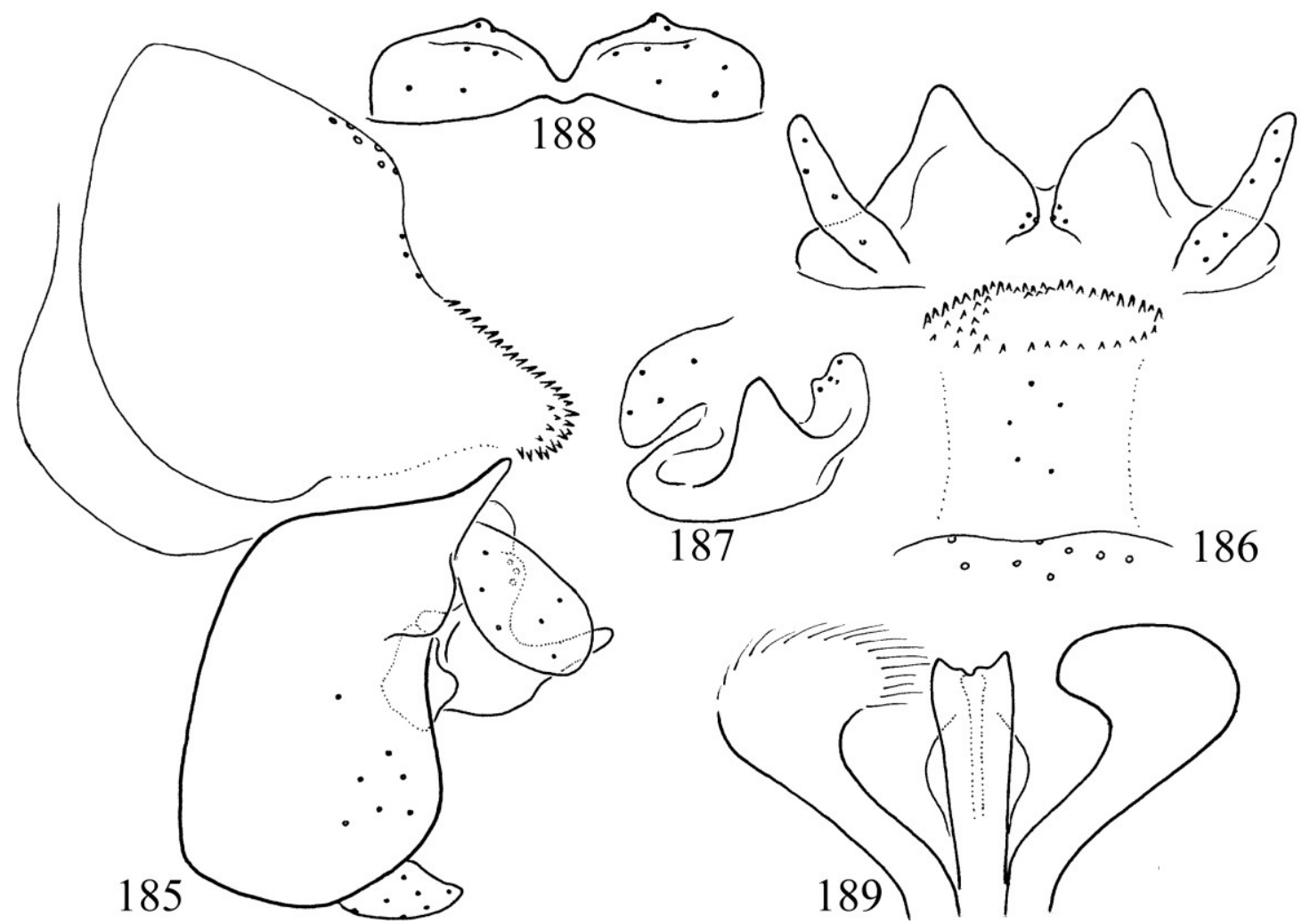

Figures 185-189. Pseudostenophylax haromsog sp. nov. Holotype. $185=$ male genitalia with tergite VIII in left lateral view, $186=$ male genitalia with tergite VIII in dorsal view, 187 = left paraproct and cercus in caudal view, $188=$ gonopods in ventral view, $189=$ phallic organ in dorsal view. 
Pseudopotamorites rufescens (Martynov, 1930)

Material examined. China, Tibet, Sejila Mount, Zhongshan Station, light trap 5.V.5.VI.2017 (2 males, OPC).

\section{Pseudostenophylax haromsog sp. ov.}

(Figures 185-189)

Diagnosis. The new species belongs to the Pseudostenophylax ichtar species group of Schmid. Most close to $P$. sophar Schmid and $P$. yangae Malicky but differs from both by having the apical arm of the dorsal branch of paraproct regular triangular in dorsal view, not rounded or laterad hooked.

Description. Male (in alcohol). Dorsum of tergite VIII clearly bipartite as visible both in lateral and dorsal view; basal half elevated, its distal part supplied with strong and long setae; apical half sloping with a few scattered smaller setae on the slope followed by the spinulose apical area, the sloping zone is clearly darker pigmented in a broad band. Segment IX very short dorsad, longer ventrad, almost parallel-sided between. The cerci are as long as the paraproct, elongated ovoid. The paraproct is bilobed, apical lobe/arm strongly sclerotized, long digitate in lateral and regular triangular in dorsal view; basomesal lobe/arm less sclerotized setose. Gonopod lateral profile is characterized by slightly upward directed triangular shape; elongated halfcircualr in ventral view with small process middle and with a submarginal ridge. Phallic organ composed of phallotheca (phallobase), endotheca, aedeagus, and parameres. The parameres are characterized by falciform, but very rounded inflated apex.

Material examined. Holotype: China, Shaanxi, Yang County, Huanyang Town, Luojiaping, N $33.6029^{\circ}$, E107.4699 $, 131 \mathrm{~m}, 6 . V .2017$, light traps, leg. Liu Haoyu (1 male, CAU)

Etymology. haromsog from "háromszög" tri angle in Hungarian, refers to the almost regular triangular shape of the apical arm on the dorsal branch of paraproct.

\section{Phryganeoidea superfamily}

\section{Lepidostomatidae family}

\section{Lepidostoma hirtum (Fabricius, 1775)}

Material examined. China, Xinjiang,Buerjin, Kanas, Beishan river, 17-15-1 (sample number), $\mathrm{N} 48.687120^{\circ} \mathrm{E} 87.013350^{\circ}, 1368 \mathrm{~m}, 19 . \mathrm{VII} .2017$, leg. Ren Jinlong. (1 male, DPP-HIST). ( 2 male, DPP-HIST).

\section{Lepidostoma orientale (Tsuda, 1942)}

Material examined. China, Shaanxi, Yang Country, Huayang Town, Hanbeicun, N33.5219 , E107.5967 , 893.3m, 6.V. 2017, light traps, leg. Liu Haoyu (1 male, DPP-HIST).

\section{Phryganeidae}

\section{Eubasilissa mandarina Schmid, 1959}

Material examined. China, Shaanxi Province, Zhouzhi, Laoxiancheng, 2057m, 19.VIII.2014, leg. Li Nuankun (1 male, 1 female; OPC).

\section{Eubasilissa mclachlani (White, 1862)}

Material examined. China, without any more information about this widely distributed species (1 female, DPP-HIST).

\section{Eubasilissa morsei Yang \& Yang, 2006}

Material examined. China, Henan Province, Luanchuan County, Longyuwan, 18.VIII.2012, (1 male, DPP-HIST). China, Shaanxi Province, Zhouzhi, Houzhenzi, 1278m, 16.VIII.2014, leg. Lu Xiumei (1 female, OPC). China, Shaanxi Province, Zhouzhi, Houzhenzi, 1278m, 17.VIII. 2014, leg. Lu Xiumei (1 female, DPP-HIST). 


\section{REFERENCES}

BANKS, N. (1939): Notes and description of Oriental Oestropsychinae (Tricoptera). Psyche, 46: 52-61.

BANKS, N. (1940): Report on certain groups of neuropteroid insects from Szechwan, China. Proceedings of the United States National Museum, 88(3079): 178-220. doi: 10.5479/si.00963801.88-3079.173

BARNARD, P.C. (1980): A revision of the Old World Polymorphanisini (Trichoptera: Hydropsychidae). Bulletin of the British Museum (Natural History), Entomology series, 41(2): 59-106.

CHEN, E.Y. (1993): Revision of the Oecetis (Trichoptera: Leptoceridae) of the world. Dissertation Presented to the Graduate School of Clemson University. UMA Dissertation Services, 704 pp.

HWANG, C.-L. (1957): Descriptions of Chinese caddis flies (Trichoptera). Acta Entomologica Sinica, 12(4): 373-404.

MaLICKY, H. (1979): Neue Köcherfliegen (Trichoptera) von den Andaman-Inseln. Zeitschrift der Arbeitsgemeinschaft Österreichischer Entomologen, 30: 97-109.

MALICKY, H. (1997): Ein Beitrag zur Kenntnis asiatischer Arten der Gattungen Cheumatopsyche Wallengren, 1891 und Potamyia Banks 1900 (Trichoptera, Hydropsychidae). Linzer biologische Beiträge, 29(2): 1015-1055.

MALICKY, H. (1998): Ein Beitrag zur Kenntnis asiatischer Amphipsyche und Polymorphanisini (Trichoptera, Hydropsychidae). (Gleichzeitig 23. Arbeit über thailändische Köcherfliegen). Stapfia, 55: 399-408.

Malicky, H. \& ChantaramongKol, P. (2000): Ein Beitrag zur Kenntnis asiatischer HydropsycheArten (Trichoptera, Hydropsychidae). Linzer biologische Beiträge, 32(2): 791-860.

MALICKY, H. (2002): Ein Beitrag zur Kenntnis asiatischer Arten der Gattung Diplectrona Westwood 1840 (Trichoptera, Hydropsychidae). Linzer biologische Beiträge, 34(2): 1201-1236.

MARTYNOV, A.B. (1931): Report on a collection of insects of the order Trichoptera from Siam and China. Proceedings of the United States National Museum, 79(25): 1-20. doi: 10.5479/si.00963801.79$\underline{2891.1}$
OlÁH, J. (2018a): Species delineation and description in Aethaloptera Brauer genus by phallic head (Trichoptera, Hydropsychidae, Macronematinae). Opuscula Zoologica, Budapest, 49(1): 3-16. doi: $\underline{10.18348 / \text { opzool.2018.1.3 }}$

OLÁH J. (2018b): Revisiting the genus Aethaloptera Brauer (Trichoptera, Hydropsychidae, Macronematinae): new species and records. Opuscula Zoologica, Budapest, 49(2): 181-190. doi: 10.18348/opzool.2018.2.181

OLÁH, J. \& JOHANSON, K.A. (2008) Generic review of Hydropsychinae, with description of Schmidopsyche, new genus, 3 new genus clusters, 8 new species groups, 4 new species clades, 12 new species clusters and 62 new species from Oriental and Afrotropical regions (Trichoptera: Hydropsychidae). Zootaxa, 1802: 1-248. doi: $10.11646 /$ zootaxa.1802.1.1

OlÁH J., JOHANSON, K.A. \& BARNARD, P.C. (2008): Revision of the Oriental and Afrotropical species of Cheumatopsyche Wallengren (Trichoptera: Hydropsychidae). Zootaxa, 1738: 1-171. doi: $\underline{10.11646 / \text { zootaxa.1738.1.1 }}$

Oláh, J., BeshKov, S., ChVojKa, T.P., Ciubuc, C., COPPA, G., IBRAHIMI, H., KovÁCs, T., MEY, W. \& OLÁH, J. JR. (2017): Revision of Drusinae subfamily (Trichoptera, Limnephilidae): divergence by paraproct and paramere, speciation in isolation by integration. Opuscula Zoologica, Budapest, 48(1): 3-228. doi: 10.18348/opzool.2017.S1.3

Oláh, J., Andersen, T., BeshKov, S., Ciubuc, C., COPPA, G., IBRAHIMI, H., KovÁCS, T., OlÁH, J. JR. \& SZCZESNY, B. (2018): Unified phylogenetic species concept: taking subspecies and race mout of science: postmodern theory applied to the Potamophylax cingulatus group (Trichoptera, Limnephilidae). Opuscula Zoologica, Budapest, 49(1): 33-70. doi: 10.18348/opzool.2018.1.33

Oláh, J. Andersen, T., BeshKov, S., Chvojka, P., COPPA, G., JOHANSON, K.A., MALM, T., RUIZ GARCIA, A. \& ZAMORA-MUÑOZ, C. (2019): Revision of European Wormaldia species (Trichoptera, Philopotamidae): Incongruent chimeric taxa of integrative organization. Opuscula Zoologica, Budapest, 50(1): 31-85. doi: 10.18348/opzool.2019.1.31

OLÁH, J. \& DE VRIES, P.J. (2019): New Baliomorpha species (Trichoptera, Hydropsychidae) from Papua, Indonesia, with plesiomorphic state of phallic or- 
gan. Suara Serangga Papua (SUGAPA digital), 11(2): 87-93. doi: 10.19269/sugapa2019.11(2).05

SCHMID, F. (1958): Trichoptères de Ceylan. Archive für Hydrobiologie, 54: 1-173.

SCHMID, F. (959): Quelques Trichoptères de Chine. Mitteilungen aus dem Zoologischen Museum in Berlin, 35(2): 317-345. doi: 10.1002/mmnz.19590350207

SCHMID, F. (1965): Quelques Trichoptères de Chine II. Bonner zoologische Beiträge, 16: 127-154.

TIAN, L., YANG, L. \& LI, Y. (1996): Trichoptera (1): Hydroptilidae, Stenopsychidae, Hydropsychidae,
Leptoceridae. Economic Insect Fauna of China, 49: 1-195.

YANG, L.F., Sun, C.H., WANG, B.X. \& MorSE, J.C. (2005): Present status of Chinese Trichoptera, with an annotated scecklist. In. TANIDA, K \& ROSSITER, A. (Eds.) Proceedings of the $11^{\text {th }}$ International Symposium on Trichoptera (2003, Osaka), p. 441465.

YANG, L.F., Sun, C.H. \& MorSE, J.C. (2016): An amended checklist of the caddisflies of China (Insecta, Trichoptera). Zoosymposia, 10: 451-479. doi: $\underline{10.11646 / \text { zoosymposia.10.1.42 }}$ 